\title{
REPORT ON THE EVALUATION \\ OF THE TRITIUM PRODUCING \\ BURNABLE ABSORBER ROD \\ LEAD TEST ASSEMBLY
}

RECEIVED

Revision 1

March 1997

Prepared for the U. S. Department of Energy under Contract DE-AC06-76RLO 1830

Pacific Northwest National Laboratory Operated for the U.S. Department of Energy by Battelle
APR 041997

OSTI

9.

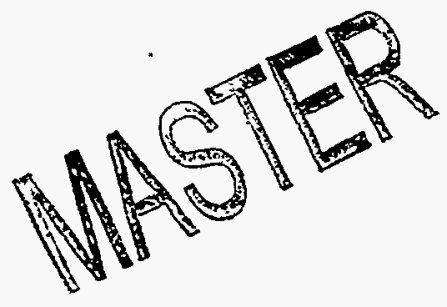

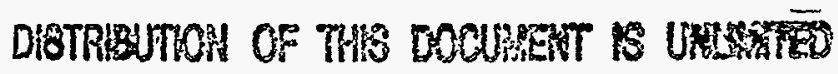

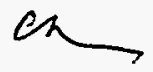




\title{
DISCLAIMER
}

This report was prepared as an account of work sponsored by United States Department of Energy. Reference herein to any specific commercial product, process, or service by trade name, trademark, manufacturer, or otherwise does not necessarily constitute or imply its endorsement, recommendation, or favoring by the United States Government or any agency thereof, or Battelle Memorial Institute. The views and opinions of authors expressed herein do not necessarily state or reflect those of the United States Government or any agency thereof.

\author{
PACIFIC NORTHWEST NATIONAL LABORATORY \\ operated by \\ BATTELLE \\ for the \\ UNITED STATES DEPARTMENT OF ENERGY \\ under Contract DE-AC06-76RLO 1830
}




\section{DISCLAIMER}

This report was prepared as an account of work sponsored by an agency of the United States Government. Neither the United States Government nor any agency thereof, nor any of their employees, make any warranty, express or implied, or assumes any legal liability or responsibility for the accuracy, completeness, or usefulness of any information, apparatus, product, or process disclosed, or represents that its use would not infringe privately owned rights. Reference herein to any specific commercial product, process, or service by trade name, trademark, manufacturer, or otherwise does not necessarily constitute or imply its endorsement, recommendation, or favoring by the United States Government or any agency thereof. The views and opinions of authors expressed herein do not necessarily state or reflect those of the United States Government or any agency thereof. 


\section{DISCLAMIER}

Portions of this document may be illegible in electronic image products. Images are produced from the best available original document. 


\begin{abstract}
This report describes the design and fabrication requirements for a tritium-producing burnable absorber rod lead test assembly and evaluates the safety issues associated with tritium-producing burnable absorber rod irradiation on the operation of a commercial light water reactor. The report provides an evaluation of the tritium-producing burnable absorber rod design and concludes that irradiation can be performed within U.S. Nuclear Regulatory Commission. regulations applicable to a commercial pressurized light water reactor.
\end{abstract}


PNNL-11419, Rev. 1

March 12, 1997

(This page intentionally blank)

iv 


\section{SUMMARY}

The U.S. Department of Energy has tasked Pacific Northwest National Laboratory (PNNL) with developing and qualifying the tritium-producing burnable absorber rod (TPBAR) lead test assembly (LTA). The qualification process will involve demonstration of fabricability and safe irradiation under fully prototypic conditions. Target design and fabrication are being done at PNNL to support irradiation at a host reactor beginning in 1997 or 1998. A host plant has been identified and contracts initiated to support the design, fabrication, irradiation, and regulatory evaluation. The host plant is a Westinghouse-designed, four-loop pressurized water reactor (PWR).

The TPBAR LTA (see the appendix for list of acronyms) will be used to demonstrate the feasibility of safely generating and containing tritium for DOE in a commercial light water reactor (CLWR) licensed by the Nuclear Regulatory Commission (NRC). Because this demonstration program brings the DOE-developed technologies of the TPBAR into an NRC-licensed facility, the NRC has requested that this technical report be provided for their review prior to LTA irradiation.

The TPBAR design has been developed to demonstrate production of desired levels of tritium (up to $1.2 \mathrm{~g}$ pdr rod) and tritium leakage consistent with a TPBAR design goal of $<6.7 \mathrm{Ci}$ per rod per year for a full production core. The TPBAR shares many characteristics with a standard Westinghouse burnable poison rod assembly (BPRA) rod and a wet annular burnable absorber (WABA) rod. Like the BPRA and WABA rods, the TPBARs will be attached to hold-down assemblies and inserted in fuel assembly guide thimbles. After a single operating cycle of irradiation, the TPBAR LTAs will be removed from the reactor and stored in the spent fuel pool. After cooldown, the TPBARs will be placed in shipping casks and transported off-site.

The design and analysis presented in this report are representative of the LTAs and the host reactor, with the exception of the nuclear design analysis. The nuclear design scoping calculations establish a high degree of confidence that plant-specific reload safety analysis will demonstrate that the LTA host reactor core will meet existing licensing basis fuel design limits. The specific host plant design and operational practices were considered in the LTA evaluations. 
The LTAs will not impact the safe operation of the host reactor. With the LTAs installed, the host reactor core will continue to meet specified acceptable fuel design limits during normal operations and transients described as Condition I and II events in the host plant final safety analysis report (FSAR). Tritium releases from the LTAs to the reactor coolant will be sufficiently low to meet the full production core design goals which limit off-site tritium releases, off-site exposures, and on-site occupational doses to a small fraction of regulatory limits. The impacts of LTAs on the radiological consequences of the design basis LOCA are within 10 CFR 100 regulatory guidelines and the LTAs will not cause a difference in the analyzed behavior of the reactor during a LOCA.

This assessment of LTA irradiation at the host plant supports the conclusion that this activity does not constitute a risk to public health and safety. Final confirmation of this determination will be accomplished as part of the reload safety analysis performed for the host plant in accordance with the safety evaluation process prescribed in 10 CFR 50.59 . 


\section{CONTENTS}

1 INTRODUCTION

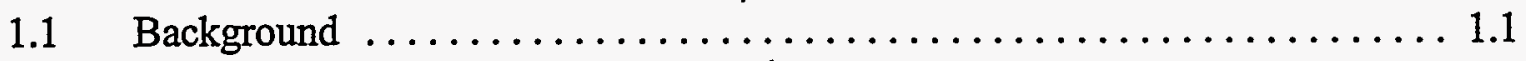

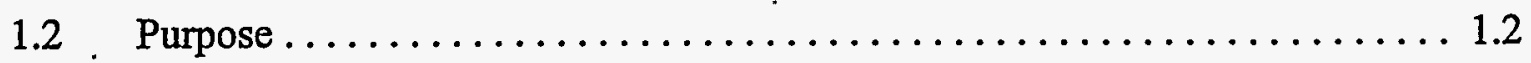

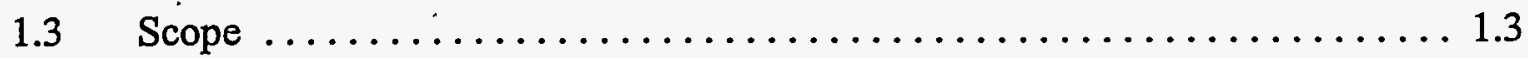

1.4 Organization of This Report $\ldots \ldots \ldots \ldots \ldots \ldots \ldots \ldots \ldots \ldots \ldots \ldots \ldots \ldots \ldots \ldots \ldots .3$

2 TRITIUM-PRODUCING BURNABLE ABSORBER ROD

LEAD TEST ASSEMBLY DESIGN

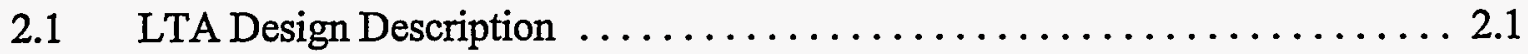

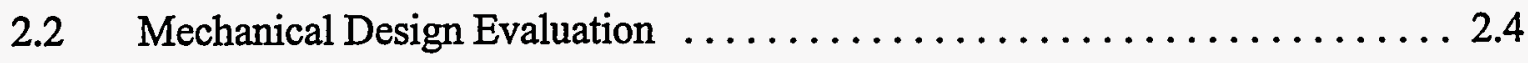

2.2.1 Cladding and Top and Bottom End Plugs $\ldots \ldots \ldots \ldots \ldots \ldots \ldots \ldots$

2.2.2 Absorber Pellets .............................. 2.10

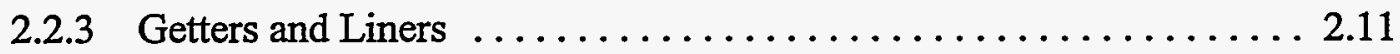



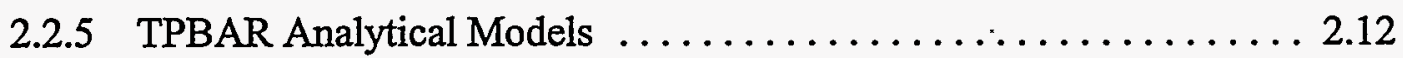

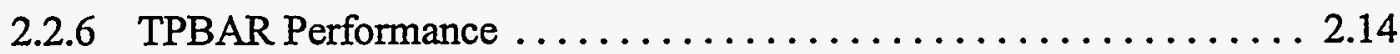

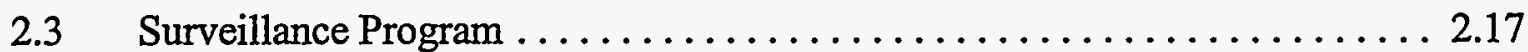

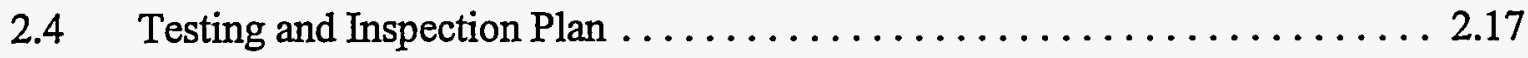

2.4.1 Inspection of Critical Characteristics During Fabrication ....... 2.17

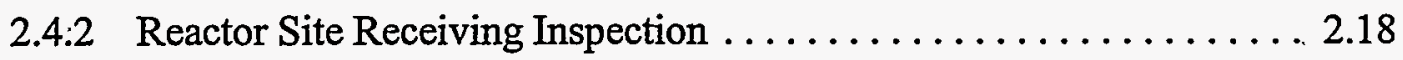

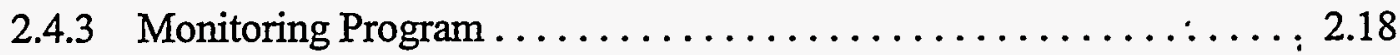

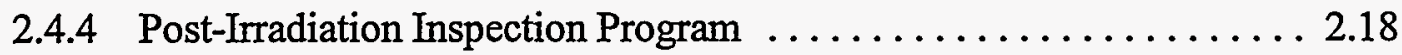



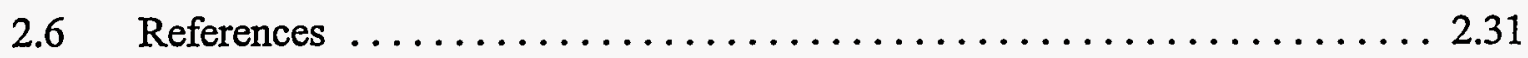

3 NUCLEAR DESIGN DESCRIPTION

3.1 Effects on Reactor Nuclear Design $\ldots \ldots \ldots \ldots \ldots \ldots \ldots \ldots \ldots \ldots \ldots \ldots \ldots \ldots \ldots \ldots$

3.1.1 Methodology Used for Scoping Calculations $\ldots \ldots \ldots \ldots \ldots \ldots . .2$ 


\section{CONTENTS (cont'd.)}

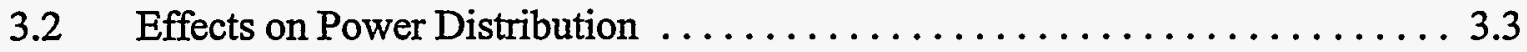

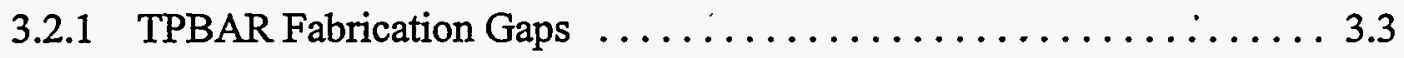

3.2.2 Sensitivity to Pellet Fabrication Tolerances $\ldots \ldots \ldots \ldots \ldots \ldots \ldots .4$

3.2.3 Summary of TPBAR Effects on Local Power Distribution ......... 3.5

3.3 Effects on Control Requirements ........................ 3.5

3.4 Changes in Reload Safety Analysis . . . . . . . . . . . . . . . . 3.5

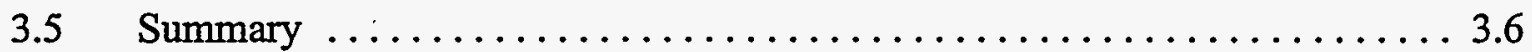

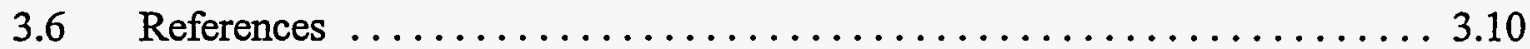

4 THERMAL AND HYDRAULIC DESIGN

$4.1 \quad$ TPBAR Thermal Hydraulic Design $\ldots \ldots \ldots \ldots \ldots \ldots \ldots \ldots \ldots \ldots .1$

4.1.1 TPBAR Thermal Hydraulic Design Bases $\ldots \ldots \ldots \ldots \ldots \ldots \ldots . . \ldots .1$

4.1.2 Description of TPBAR Thermal and Hydraulic Design . . . . . . . 4.3

4.1.3 Thermal Effects of Operational Transients ............... 4.4

4.2 Impact on Reactor Core Thermal Hydraulic Design $\ldots \ldots \ldots \ldots \ldots \ldots .4 .4$

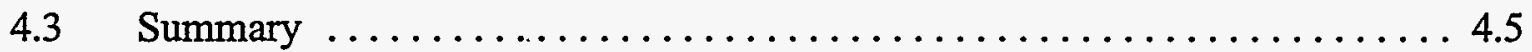

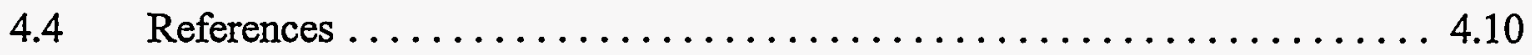

5 MATERIALS

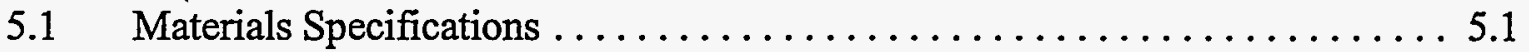

$5.2 \quad$ Materials Properties $\ldots \ldots \ldots \ldots \ldots \ldots \ldots \ldots \ldots \ldots \ldots \ldots \ldots \ldots .1$

5.3 Materials Performance ................................. 5.2

5.3 .1 Cladding and End Plug Material $\ldots \ldots \ldots \ldots \ldots \ldots \ldots \ldots \ldots .2$

5.3 .2 Pencils $\ldots \ldots \ldots \ldots \ldots \ldots \ldots \ldots \ldots \ldots \ldots \ldots \ldots \ldots \ldots . . \ldots$

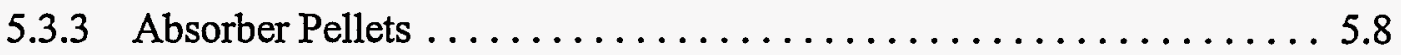

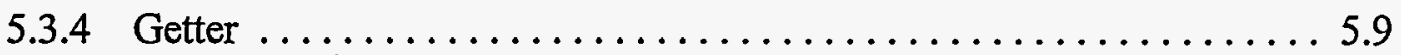

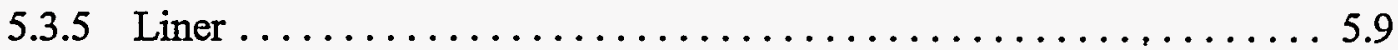

5.3.6 Plenum Subassembly and Getter Disk .............. 5.10

5.3 .7 LTA Hold-Down Assembly . . . . . . . . . . . . . . . 5.10

$5.4 \quad$ Nondestructive Examination . . . . . . . . . . . . . . . . . . . . . 5.10

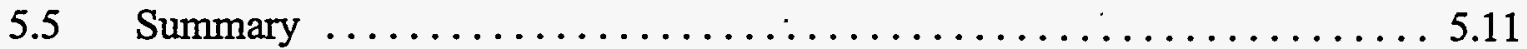




\section{CONTENTS (cont'd.)}

5.6. References

6 OPERATIONAL IMPACTS OF LTAS

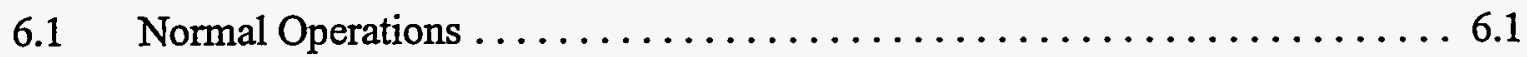

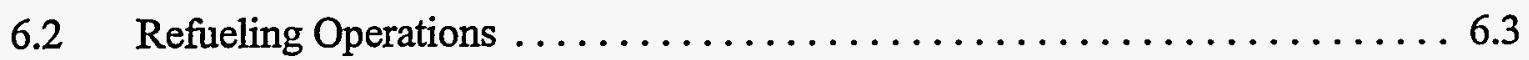

6.2.1 TPBAR Assembly Storage in Fuel Pool or New Fuel Storage . . . . . 6.4

6.2.2 On-Site TPBAR Assembly Movement and Handling . . . . . . . 6.4

6.2.3 Occupational Exposure During Refueling $\ldots \ldots \ldots \ldots \ldots \ldots \ldots .6$

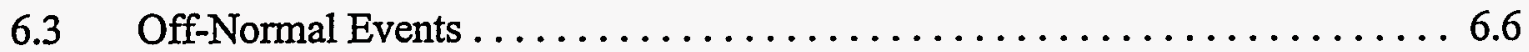

6.3.1 Impacts of TPBAR Absorber Relocation $\ldots \ldots \ldots \ldots \ldots \ldots \ldots .6 .6$



6.3.3 Radiological Consequences of a TPBAR Cladding Breach ....... 6.7

6.3.4 Inadvertent Loading and Operation of an LTA in an Improper Position 6.8

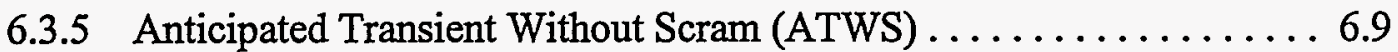

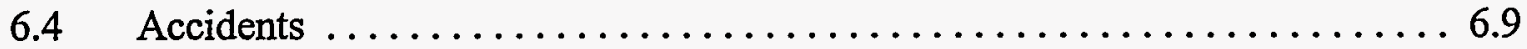

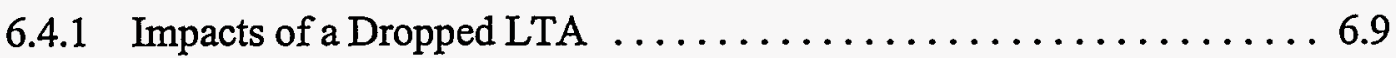

6.4.2 Impact of Design Tritium Leakage on Radiological Consequences of a

Steam Generator Tube Rupture or Steam Line Break ......... 6.10

6.4.3 Impacts of LTAs in the Event of a LOCA ................ 6.11

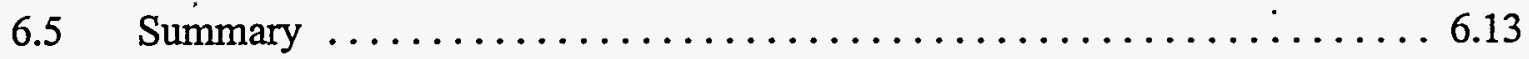

$6.6 \quad$ References ....................................... 6.19

7 QUALITY ASSURANCE

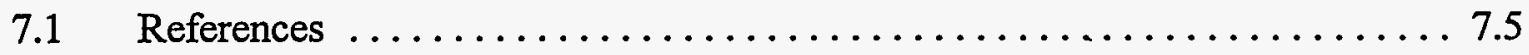

8 SAFEGUARDS AND SECURITY

$8.1 \quad$ Materials Accountability ............................... 8.1

8.2 Physical Security of Classified Hardware $\ldots \ldots \ldots \ldots \ldots \ldots \ldots \ldots \ldots . \ldots \ldots \ldots$

8.3 Control of Classified Documents and Hardware $\ldots \ldots \ldots \ldots \ldots \ldots \ldots .3$

8.4 References $\ldots \ldots \ldots \ldots \ldots \ldots \ldots \ldots \ldots \ldots \ldots \ldots \ldots \ldots \ldots .4 .4$ 
PNNL-11419, Rev. 1

March 12, 1997

\section{CONTENTS (cont'd.)}

9 REGULATORY ANALYSIS

9.1 Effect on Plant Technical Specifications . . . . . . . . . . . . . 9.1

9.2 Effect on Plant Final Safety Analysis Report (FSAR) . . . . . . . . 9.2

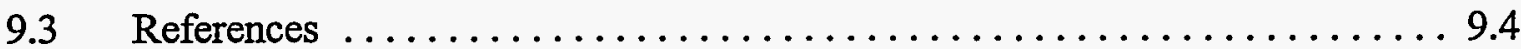

10 CONCLUSIONS

10.1 


\section{List of Tables}

2-1 Comparison of TPBAR with Burnable Absorber Rod Design Parameters . . . . . . 2.20

2-2 TPBAR Design Bounding Parameters for Conditions $I, I I, I I I$, and $I V \ldots \ldots \ldots 2$.

2-3 Allowable Stress Limits for ASME Code Service Level Conditions . . . . . . . . 2.22

2-4 Transient Conditions for Normal Reactor Operations . . . . . . . . . . . . 2.23

2-5 Comparison of Irradiation Conditions for the Tritium Test Rods and the TPBAR . . 2.24

2-6 Summary of Test Results for Lithium Aluminate Pellets Irradiated in the Advanced Test

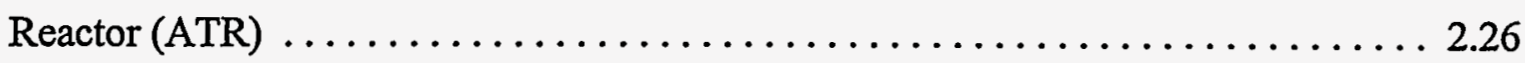

4-1 TPBAR Comparison to BPRA and WABA Rods ............... 4.6

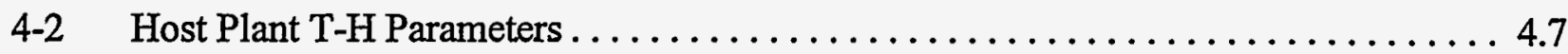

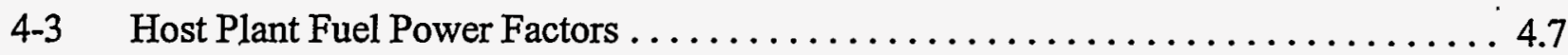

4-4 Thermal and Hydraulic Comparison Table $\ldots \ldots \ldots \ldots \ldots \ldots \ldots \ldots \ldots \ldots$

5-1 Summary of Test Results for Lithium Aluminate Pellets Irradiated in the Advanced Test

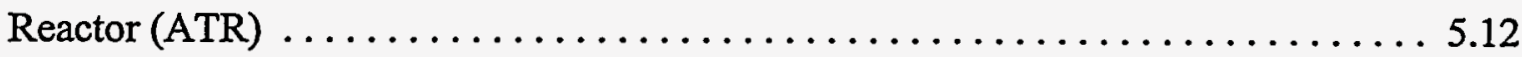

5-2 Nondestructive Testing Techniques and Applicable Standards for Acceptance of TPBAR and TPBAR Components . . . . . . . . . . . . . . . . . 5.13

6-1 Summary of Off-Site Radiological Consequences for the TPBARs in the Host Plant 6.16

6-2 Refueling Occupational Exposures for a Constant Design Goal Tritium Release from

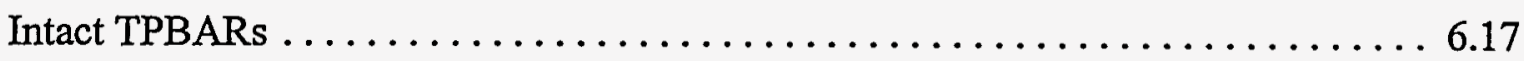

6-3 Refueling Occupational Exposures Assuming a Release of the Inventory of 1 TPBAR . During the Cycle at a Constant Rate $\ldots \ldots \ldots \ldots \ldots \ldots \ldots \ldots \ldots \ldots \ldots \ldots \ldots \ldots \ldots$

7-1 CLWR Lead Test Assembly Program Responsibilities . . . . . . . . . . . 7.2 


\section{List of Figures}

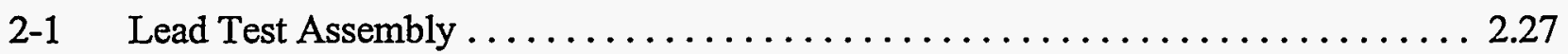

2-2 TPBAR Assembly $\ldots \ldots \ldots \ldots \ldots \ldots \ldots \ldots \ldots \ldots \ldots \ldots \ldots \ldots \ldots \ldots \ldots \ldots \ldots \ldots .28$

2-3 Sketch of TPBAR Components.............................. 2.29

2-4 Effect of Irradiation Creep on TPBAR Cladding Diameter Due to RCS Pressure and

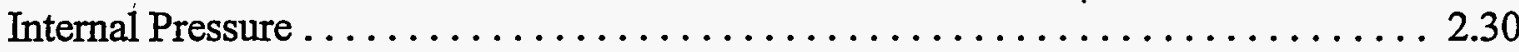

3-1 Depletion Curves for TPBAR and WABA Rod $\ldots \ldots \ldots \ldots \ldots \ldots \ldots \ldots \ldots .7$

3-2 WIMS-PHOENIX Reactivity Comparison, No Burnable Poison $\ldots \ldots \ldots \ldots \ldots . .$.

3-3 , WIMS-PHOENTX Reactivity Comparison, 24 TPBAR $\ldots \ldots \ldots \ldots \ldots \ldots \ldots . . .6$

3-4 WIMS-PHOENIX Reactivity Comparison, 64 IFBA $\ldots \ldots \ldots \ldots \ldots \ldots \ldots \ldots \ldots \ldots \ldots . . .6$

3-5 WIMS-PHOENIX Reactivity Comparison, 8 TPBAR, 64 IFBA $\ldots \ldots \ldots \ldots \ldots .9 .9$

5-1 Comparison of Sm (ASME Code Allowable Stress) Values . . . . . . . . . . . . . 5.14

5-2 Effect of Temperature on Cladding Burst for $20 \%$ CW 316SS Tubing, Barrier-Coated Cladding, and Cladding Heat Treated to Simulate

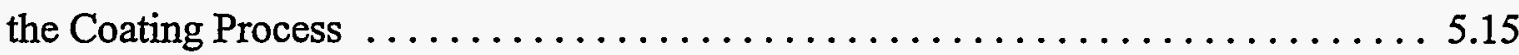

5-3 Compressive Stress to Crush 0.040-in.-Thick Absorber Pellets . . . . . . . . . . 5.16

6-1 TPBAR Contribution to the RCS Tritium Concentration $\ldots \ldots \ldots \ldots \ldots \ldots .18$

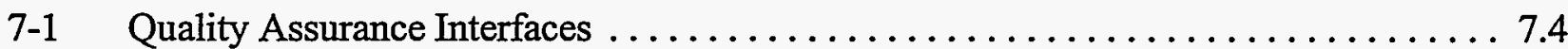


PNNL-11419, Rev. 1

March 12, 1997

\section{INTRODUCTION}

This report describes the design and fabrication requirements for tritium-producing burnable absorber rod (TPBAR) lead test assemblies (LTAs) and provides an evaluation of the impacts of four LTAs on the operation of a commercial light water reactor (CLWR). The design, fabrication, and irradiation of TPBARs are key elements in the U.S. Department of Energy's Commercial Light Water Reactor Tritium Production Project. The mission of the CLWR Tritium Production Project is to develop the production systems and capabilities necessary to safely produce and contain tritium in a CLWR using TPBAR LTAs. Revision 1 changes to the report are noted with revision bars in the right-hand margin.

\subsection{Background}

The U.S. Department of Energy (DOE) is pursuing a dual path to evaluating, developing, selecting, and establishing a primary tritium production capability. The two options under consideration are accelerator production of tritium and tritium production in a CLWR. The accelerator and CLWR options present fundamentally different technical and institutional issues that must be evaluated to provide a basis for selection. The intent of these parallel projects is to provide the technical; economic, and regulatory bases for the selection of the primary and backup technology approaches by 1998 .

Production of tritium in a heavy water reactor was the technical approach used by the United States for many years. Tritium was produced in reactors tailored to provide product as efficiently as possible. An alternative approach is to either procure or secure irradiation services from an existing CLWR. In either case, a qualified system capable of safely producing and containing tritium must be developed.

The U.S. Department of Energy has tasked the Pacific Northwest National Laboratory (PNNL) with developing and qualifying the CLWR TPBAR. The qualification process will involve demonstration of fabricability and safe irradiation under fully prototypic conditions. TPBAR design and fabrication is being done at PNNL to support irradiation at a host CLWR beginning in 1997 or 1998. Information from two representative CLWR plants has been used where plant-specific information was needed to support the initial LTA design, fabrication, and regulatory evaluation. Both plants use Westinghouse-designed, four-loop pressurized water 
reactors (PWRs). Specific Reference Plant designs and operational practices were considered in the LTA evaluations described in this report. Since the original version of this report was submitted to DOE, Watts Bar Nuclear Plant was selected as the host facility for LTA irradiation. Accordingly, except where noted otherwise, the data and evaluations provided in this revised report are based upon the design and operational practices of Watts Bar Nuclear Plant.

The TPBAR design has been developed to demonstrate production of desired levels of tritium - (up to $1.2 \mathrm{~g}$ per rod) and tritium leakage consistent with a TPBAR design goal ${ }^{\mathrm{A}}$ of $<6.7 \mathrm{Ci}$ per rod per year for a full production core. The TPBAR shares many characteristics with a standard Westinghouse burnable poison rod assembly (BPRA) rod and a wet annular burnable absorber (WABA) rod. Like the BPRA and WABA rods, the TPBARs will be attached to hold-down assemblies and inserted in fuel assembly guide thimbles. After a single operating cycle of irradiation, the TPBAR LTAs will be removed from the reactor and stored in the spent fuel pool. After cooldown, the TPBAR LTAs will be placed in shipping casks and transported off-site.

\subsection{Purpose}

Irradiation of TPBARs will be used to demonstrate the safe generation and containment of tritium for DOE in a CLWR licensed by the Nuclear Regulatory Commission (NRC). This technical report documents that irradiation of four LTAs can be accomplished at a commercial utility host reactor. As part of the process of incorporating TPBAR LTAs in a CLWR operating cycle, host reactor licensees and Westinghouse will perform plant-specific reload safety evaluations in support of a 10 CFR 50.59 process determination.

Because this demonstration program brings the DOE-developed technologies of the TPBAR into an NRC-licensed facility, the NRC has requested that this technical report be provided for NRC review prior to irradiation of the TPBARs. The stated objective of the NRC review of this technical report is to develop a safety evaluation report, available in the public domain, that

\footnotetext{
${ }^{\text {A }}$ This design goal is a parameter established to meet specific DOE, environmental safety and health, and occupational safety requirements. Actual TPBAR tritium leakage is expected to be below this value.
} 
documents the NRC staff's conclusion that commercial utility host reactors can safely conduct irradiation of a limited number of TPBARs.

\subsection{Scope}

One objective of the LTA program is to design, manufacture, irradiate, and obtain performance data for the TPBAR to demonstrate the feasibility of supporting the DOE tritium production mission. This report describes the TPBAR design and fabrication requirements and evaluates the impacts of LTAs on the operation of a CLWR. Post-irradiation processing and transportation of the TPBARs to and from the CLWR site are the responsiblity of the DOE. The impacts of fullcore tritium production (i.e., beyond LTA levels) will be addressed in separate documents in the future.

\subsection{Organization of this Report}

The topical areas for this report are defined to address applicable areas of review from the NRC's NUREG-0800, "Standard Review Plan for the Review of Safety Analysis Reports for Nuclear Power Plants, LWR Edition" (the SRP), as follows:

\begin{tabular}{clc} 
Chapter No. & \multicolumn{1}{c}{ Title } & \multicolumn{1}{c}{ SRP Section(s) } \\
\hline 2 & $\begin{array}{l}\text { Tritium-Producing Burnable Absorber Rod Lead Test } \\
\text { Assembly Design }\end{array}$ & 4.2 \\
3 & Nuclear Design Description & 4.3 \\
4 & Thermal and Hydraulic Design & 4.4 \\
5 & Materials & 4.5 .2 \\
& . & 6.1 .1
\end{tabular}


Chapter No.
Title

Operational Impacts of LTAs
SRP Section(s)

3.8.4(D)

6.2 .5

6.4

9.1 .2

9.1 .3

9.1 .4

12.2

15.1.5.A

15.6 .5

7

Quality Assurance

In addition, Chapter 8, "Safeguards and Security," is included to address measures to provide for accountability of TPBARs, physical security of classified material, and access to classified material at the host utility site(s). Chapter 9 addresses the regulatory issues associated with LTA irradiation at an NRC-licensed CLWR. Chapter 10 provides the conclusions of this report. Acronyms and abbreviations are defined in the Appendix.

Certain aspects of the TPBAR design and design analysis are classified as Confidential Restricted Data (CRD) or Unclassified Controlled Nuclear Information (UCNI) as defined in Section 148 of the Atomic Energy Act of 1954. Other data related to the design of the TPBAR is Westinghouse proprietary information. This report is an unclassified, non-proprietary TPBAR LTA Technical Report and has been prepared to facilitate public access to information related to the irradiation of the TPBAR Lead Test Assemblies in a commercial light water reactor. 


\section{TRITIUM-PRODUCING BURNABLE ABSORBER ROD LEAD TEST ASSEMBLY DESIGN}

This section addresses the mechanical design of the tritium-producing burnable absorber rod (TPBAR) lead test assembly (LTA) and its acceptability. It encompasses the design description . (Section 2.1), mechanical design evaluation (Section 2.2), surveillance program (Section 2.3), and testing and inspection program (Section 2.4).

\section{$2.1 \quad$ LTA Design Description}

The LTA is designed to meet the operating requirements of a large four-loop Westinghouse reactor under Conditions I, II, III, and IV as established in the host plant Safety Analysis Report [Ref. 2-1].

The LTA is compatible with the fuel assembly; reactor vessel internals, reactor coolant chemistry, refueling system and tools, and spent fuel storage facility of the host plant. The LTA is a removable reactor core component which resides in a fuel assembly. An LTA will not reside in a fuel assembly that contains a rod cluster control assembly.

The analysis and engineering of the LTA draw upon the results of prior in-reactor and ex-reactor testing. The LTA design ensures that: a) the LTA will not be damaged nor will it damage the fuel system during Condition I or Condition II events; $b$ ) the LTA will not adversely impact control rod insertion; c) the LTA will not adversely impact reactor core coolability; and d) tritium release shall be within acceptable limits. During Conditions III and IV, the only TPBAR function is to maintain a barrier to tritium release.

Each LTA consists of a Westinghouse hold-down assembly that supports 8 TPBARs and 16 dually compatible Westinghouse thimble plugs, as illustrated in Figure 2-1. The TPBAR design, as illustrated in Figure 2-2, is similar in form and function to a Westinghouse BPRA rod. The exterior dimensions of the TPBAR are similar to those of the Westinghouse BPRA rod, as shown in Table 2-1. The absorber material is in the form of annular lithium aluminate $\left(\mathrm{LiAlO}_{2}\right)$ absorber pellets enriched in ${ }^{6} \mathrm{Li}$ to produce specific quantities of tritium. The irradiation design criterion for the TPBAR is 550 effective full-power days (EFPD). The neutron fluence levels associated with the 550 EFPD design criteria are identified in Table 2-5. The LTA will reside in 
the reactor core for one fuel cycle and therefore exposure is expected to be from 450 to 500 EFPD.

The TPBAR design consists of concentric cylindrical subcomponents clad with Type 316 stainless steel (316 SS), as illustrated in Figure 2-3. The 316 SS tubular cladding provides structural strength and is the pressure barrier between the TPBAR internals and the reactor coolant system. To retain the tritium within the TPBAR and prevent the inward diffusion of hydrogen from the reactor coolant, the inner surface of the cladding is coated with a permeationresistant aluminized barrier.

The TPBAR internal subcomponents are a plenum subassembly, twelve pencils and a lower getter disk. A pencil consists of a Zircaloy-4 liner around which are stacked absorber pellets that are confined in a getter tube, as illustrated in Figure 2-2. The annular absorber pellets are comprised of $\mathrm{LiAlO}_{2}$ enriched in ${ }^{6} \mathrm{Li}$. The getter tube surrounds the absorber pellets and is composed of nickel-plated Zircaloy-4 (NPZ). The nickel coating maintains the getter effectiveness for tritium absorption by preventing the formation of a permeation-resistant zirconium oxide film on the getter surface. Tritium produced in the absorber pellets is released and reacts with the getter to form solid zirconium tritide precipitates in the Zircaloy-4.

The Zircaloy-4 liner inside the annular $\mathrm{LiAlO}_{2}$ pellets scavenges any free oxygen and water vapor by reacting to form an oxide on its surface. Free oxygen is generated by transmutation of the $\mathrm{Li}$ in the $\mathrm{LiAlO}_{2}$ matrix. The reaction of the liner and the barrier with tritiated water vapor:

$$
2{ }^{3} \mathrm{H}_{2} \mathrm{O}+\mathrm{Zr} \rightarrow 2{ }^{3} \mathrm{H}_{2}+\mathrm{ZrO}_{2} \text {. }
$$

releases tritium that is absorbed by the getter. A small fraction of the tritium inventory is stored in the liner. The liner also provides mechanical support to prevent relocation of the $\mathrm{LiAlO}_{2}$ pellet material.

The upper getter disc and an attached getter tube enclose a stainless steel plenum spring which is located above the top pencil in the cladding tube. This plenum subassembly provides an axial force to restrain the pencils during handling and shipping operations, while permitting irradiation, hydriding, and thermal axial growth of the pencils in the reactor. The upper getter disc subassembly and the lower getter disc maintain low tritium partial pressure at the ends of the 
TPBAR to minimize tritium leakage through the uncoated weld preparation zones of the cladding and end plugs.

For closure of the TPBAR, end plugs are welded to each end of the cladding tube. The end plugs are manufactured from $316 \mathrm{SS}$ and replicate Westinghouse BPRA rod end plugs. The upper end plug provides for the attachment of the TPBAR to a hold-down assembly in the same manner used to attach a BPRA rod. Prior to the final closure weld, the TPBAR is evacuated and repressurized to one atmosphere with helium.

The TPBAR dimensions and tolerances are specified to provide sufficient clearances between components for assembly; at beginning of life.(BOL) and at end of life (EOL) for normal operations; and to accommodate the fuel assembly tolerances. The clearances were established to provide for dimensional changes due to thermal, irradiation, creep and hydriding effects. Properties of the TPBAR component materials used for design and analyses are compatible with the reactor coolant environment.

Experimental irradiation tests of tritium targets were performed from 1982 to 1992 in the Advanced Test Reactor (ATR) at the Idaho National Engineering Laboratory. Experience and data from these tests are described in this chapter as they relate to the evaluation of the TPBARs. An objective of the TPBAR LTA irradiation is to obtain sufficient irradiation data under commercial PWR conditions to support full scale production irradiation of TPBARs. The ATR test data, although-limited in some respects, are sufficient to support the evaluation of irradiating a small number of LTAs in non-limiting core locations. Experimental irradiation experience, as related to the TPBAR design, is summarized in Tables 2-5 and 2-6. The experimental data bound expected LTA irradiation conditions with regard to pellet burnup (expressed in GVR ${ }^{A}$ which is analogous to fuel MWD/MTU) and thermal neutron fluence. The TPBAR will be exposed to higher fast neutron fluence and time at operating temperature and pressure than was achieved during the ATR experimental tests. The experimental test data together with substantial TPBAR design improvements, large design margins, and conservative analysis provide a high degree of confidence in the performance of the LTAs.

${ }^{A}$ GVR is the ratio of STP gas volume to pellet volume and is directly proportional to the number of ${ }^{6} \mathrm{Li}$ reactions. 


\subsection{Mechanical Design Evaluation}

This section provides an evaluation of the TPBAR design for credible combinations of chemical, thermal, neutronic, mechanical, and hydraulic interactions. The TPBAR is evaluated for structural integrity of the pressure boundary (cladding and end plugs) and for absorber pellet stability. All components are evaluated for reaction with and impact on the reactor coolant. Evaluation of the interactions includes the effects of Conditions I, II, III, and IV as established in the host plant Safety Analysis Report [Ref. 2-1].

The most conservative temperatures and pressure design limits of Conditions I, II, III, and IV for the host plant are used in the evaluation of the LTA. For example, the maximum internal pressure associated with the desired tritium production is used as the expected TPBAR internal operating pressure. These temperatures and pressures are presented in Table 2-2. The TPBAR maximum internal design pressure is 3000 psia at an average gas temperature of $675^{\circ} \mathrm{F}$. The cladding design temperature of $650^{\circ} \mathrm{F}$ and external design pressure of 2500 psia are based upon the host plant FSAR [Ref. 2- 1]. The temperature of $660^{\circ} \mathrm{F}$ used in the mechanical stress analysis design parameters summarized in Table 2-2 was selected to bound the thermal hydraulic analysis maximum TPBAR cladding temperatures.

The densification and swelling of TPBAR components impact the design tolerances and clearances between component surfaces during operation. Clearances between components are sufficient to prevent mechanical interactions throughout the life cycle of the TPBARs.

Criterion - Swelling or shrinking of internal TPBAR components shall be accommodated by the TPBAR design.

Evaluation - Based on the specified tolerances and clearances and considering the extensive documentation of the behavior of the selected materials in the reactor environment, it is concluded that in the aggregate the design adequately addresses swelling and shrinking of the TPBAR components for the design irradiation lifetime. The swelling and shrinking of each TPBAR component is discussed in the following sections. 


\subsubsection{Cladding and Top and Bottom End Plugs}

The cladding and end plugs are manufactured from $20 \%$ cold worked 316 SS. The cladding is fabricated from seamless tubing coated on the inner surface with an aluminized permeation barrier, and the end plugs are fabricated from bar stock. Credit is taken for the structural benefits of the $20 \%$ cold work, with a detractor for recovery of the cold work due to the barrier coating process. The mechanical properties of the TPBAR cladding are provided in the cladding specification ASTM A 771 [Ref. 2-3].

Criterion - The structural integrity of the TPBAR shall be maintained during Conditions I through IV, and shipping and handling, with the exception of the LBLOCA.

Evaluation - The cladding, end plugs and associated welds form the pressure boundary of the TPBAR. The integrity of the pressure boundary during Conditions I, II, III, and IV events is discussed below. These discussions lead to the conclusion that the structural integrity of the TPBAR is acceptable and is maintained during all events under Coriditions I through IV (including shipping and handling), with the exception of the LBLOCA.

\subsubsection{Stress-Strain}

Criterion- The TPBAR cladding stresses and the end plug weld stresses shall not result in cladding collapse, excess ovality, or cracking over the irradiation life of the TPBAR.

Evaluation - The structural members (cladding and top and bottom end plugs) of the LTA were designed using stress and fatigue criteria and methodology consistent with the ASME Boiler \& Pressure Vessel Code [Ref. 2-4]. The external pressure criteria of the Code were excluded because the LTA is not a reactor core structural component. Also, strength values used to calculate the TPBAR stresses are based upon material data from [Ref. 2-3], because the material properties of ASTM A $771316 \mathrm{SS}$ are not included in the Code. The stress correlation shown in [Ref. 2-5] is used to evaluate the discontinuity stress at the weld junction between the cladding and end plug. 
The loads on a BPRA rod or TPBAR due to worst-case pressures or to handling and shipping eclipse those due to seismic events. Therefore, operating basis earthquake (OBE) and safe shutdown earthquake (SSE) loads were not analyzed in the cladding stress analysis.

The cladding was analyzed for the most conservative pressure, temperature, and dimensional tolerances for Conditions I, II, III, and IV. For each design condition, the internal design pressure was assumed to be the worst case internal pressure (accounting for non-ideal gas behavior) at the temperature of concern. The factor of safety to yield for each design condition exceed the requirements of the ASME Boiler and Pressure Vessel Code [Ref. 2-4].

The results indicate that, except for the LBLOCA where the TPBARs are assumed to fail, the lowest factor of safety to yield for an in-reactor condition is 1.70 , which corresponds to the reactor coolant system (RCS) pressure during the hydrostatic test at 1.25 times the reactor design pressure. Stress analyses of the TPBAR provided the following results:

- Critical buckling pressures were verified to be greater than the RCS design pressure and temperature of $2500 \mathrm{psia}$ and $660^{\circ} \mathrm{F}$.

- The TPBAR was verified not to collapse or exhibit excess ovality due to the effects of pressure, external temperature, and irradiation-induced creep.

- $\quad$ The TPBAR was verified not to collapse under hydrostatic pressure test conditions (external pressure of 3125 psia at $100^{\circ} \mathrm{F}$ and 14.7 psia internal pressure), with a factor of safety to yield of 1.70 .

- $\quad$ A pressurized TPBAR was verified to withstand a $4 \mathrm{~g}$ axial and a $6 \mathrm{~g}$ lateral shipping and handling load at EOL (external pressure of 14.7 psia and internal pressure of 1413 psia at $72^{\circ} \mathrm{F}$ ).

Based on cladding stress calculations, cladding breach is not expected during a small break loss of coolant accident (SBLOCA). Because high values of cladding 
pressure stresses occur at elevated temperatures during a LBLOCA, it is likely that the TPBAR cladding will fail. Burst testing of specimens indicates that the cladding will burst at about $1500^{\circ} \mathrm{F}$ and 5228 psia. See Chapter 6 for an assessment of the effects of a TPBAR rupture.

Cold worked $316 \mathrm{SS}$ cladding is stable at the irradiation temperatures and neutron fluence encountered during the in-core residence period for the TPBAR, $660^{\circ} \mathrm{F}$ and $5 \times 10^{21} \mathrm{n} / \mathrm{cm}^{2}(\mathrm{E}>1 \mathrm{MeV})$. The irradiation creep and volumetric swelling strains are $<0.2 \%$. Nominal changes in cladding diametric dimensions due to irradiation creep are plotted in Figure 2-4, and are less than 0.0004 in. $(0.0102 \mathrm{~mm})$. This is much less than the design limit of $1 \%$ on cladding strain.

\subsubsection{Cladding Collapse}

Criterion - The cladding shall be free standing and shall not collapse due to external pressure or creep for a design life of 550 EFPD.

Evaluation - External pressure tests of barrier-coated cladding are described in Chapter 5. The tests demonstrate that the cladding has adequate strength to resist mechanical collapse from the reactor coolant pressure.

The calculated change in ovality of a TPBAR as a function of time, neutron flux, and uniform external pressure caused by cladding creepdown shows that the TPBAR cladding resists collapse by creep.

\subsubsection{Vibration Fatigue, Design Cycle Fatigue, and Fretting Wear}

Criterion - Neither the TPBAR nor its associated guide thimble shall fail due to vibration fatigue, design cycle fatigue, or fretting wear resulting from reactor coolant flow-induced vibration.

Evaluation - Reactor coolant flowing axially through the annulus between the TPBAR and the fuel assembly guide thimble imposes bending stresses that cause the TPBAR to vibrate. The maximum credible vibration stress was calculated to 
be an alternating stress which is bounded by the gap between the TPBAR and the guide thimble. This stress is significantly less than the endurance limit of 24,000 psi specified by the ASME Code [Ref. 2-6] and therefore, the number of cycles a TPBAR may be subjected to without failure is well in excess of $1 \times 10^{11}$. To exceed $1 \times 10^{11}$ cycles during an 18 month fuel cycle (550 EFPD) would require the TPBAR to oscillate at $2100 \mathrm{~Hz}$. Tests have shown that a BPRA rod constrained within a guide thimble oscillates at less than $1 \mathrm{~Hz}$. A TPBAR and BPRA rod are dimensionally the same and similar in weight and stiffness, and should exhibit similar frequencies of oscilliation. BPRA rods used in PWRs have not experienced failure from vibration fatigue. Therefore, failure of a TPBAR due to vibration fatigue is not plausible.

Flow-induced vibration of a TPBAR within a guide thimble could cause wear of the contacting surfaces. The TPBAR and a BPRA rod are dimensionally similar and are similarly constrained by the guide thimble while vibrating. Experience and available test data for BPRA rods, including austenitic SS clad.BPRA rods, have shown the wear to be acceptable. The similarity in resistance to wear of 304 SS and 316 SS further ensures that the wear for the LTA will be acceptably small.

The conclusions are consistent with the absence of BPRA rod failures by these mechanisms.

The cladding was evaluated for design cycle fatigue failure due to changes in pressure and temperature during the reactor duty cycle, using the rules of the ASME Code [Ref. 2-4]. The cladding satisfies the conditions of NG-3222.4(d), and therefore has the ability to withstand the cyclic service, and an analysis in accordance with NG-3222.4(e) is not required. The design cycle fatigue evaluation is based on the transient conditions and design cycles for the host plant, shown in Table 2-4. 


\subsubsection{Chemical Properties of the Cladding}

Criterion - Corrosion and erosion of the TPBAR outer surface shall not cause material transfer into the reactor coolant in excess of rates comparable with other reactor internal components.

Evaluation - The cladding is resistant to chemical attack from the chemical species normally present in the reactor coolant. Because $316 \mathrm{SS}$ has not been extensively used for corrosion studies, data for the uniform corrosion of 304 SS were used to estimate the cladding wastage from corrosion by the reactor coolant. Based on the corrosion rates for 304 SS in PWRs and in the Engineering Test Reactor, it was estimated that the corrosion rate for the TPBAR 316 SS cladding is $<0.0001$ in./y as discussed in [Ref. 2-7]. A conservative value of 0.0003 in. for an 18-month fuel cycle (550 EFPD) was applied to the TPBAR. As discussed in Chapter 5, $316 \mathrm{SS}$ is more corrosion resistant than 304 SS. Consequently, the wastage estimate used in the design evaluation is conservative for $316 \mathrm{SS}$.

TPBARs are designed to be free of crevices and therefore crevice corrosion is not of concern.

Stress corrosion cracking (SCC) in Series 300 stainless steel requires sensitization, an aggressive environment, and high stresses; and may be aggravated by neutron fluences, hydrogen, and high temperatures. The formation of oxidizing species is effectively suppressed in PWR coolant as demonstrated in [Ref. 2-7]. Austenitic SS is not susceptible to SCC in PWR coolant, because of the low oxygen concentration ( $<100 \mathrm{ppb})$. A more detailed discussion of SCC is provided in Chapter 5.

No significant chemical reaction is expected between the 316 SS TPBAR cladding or end plugs and the reactor coolant. Experience with SS-clad fuel and BPRAs in PWRs indicates that with the current PWR water chemistry, crud deposition is acceptably low [Ref. 2-8]. 
Experience has shown erosion of austenitic SS clad BPRA rods to be insignificant. The wear resistance of 316 SS further ensures that the erosion of the LTAs will be acceptably small.

\subsubsection{Absorber Pellets}

The thermal and physical properties of the absorber pellet are summarized in Chapter 5 .

Criterion - The absorber pellet structural integrity will be maintained while producing tritium.

Evaluation - The following two sections address the chemical properties and the stability of the absorber pellet. These discussions lead to the conclusion that the structural integrity of the absorber pellet is acceptable, and except for localized structural damage at the breach site during a LBLOCA, will be maintained during all Condition I, II, III, and IV events.

\subsubsection{Chemical Properties of the Absorber Pellets}

The absorber pellets are nonreactive with the TPBAR components. In the event of a cladding breach, water ingress would dissolve a microscopic layer of lithium from the surface of absorber pellets; otherwise, the absorber pellets are insoluble in the coolant water.

\subsubsection{Stability of the Absorber Pellets}

The strength of the absorber pellets enables the pellets to resist fracture during TPBAR handling and to resist cracking due to substantial thermal cycling during reactor operations. Lithium aluminate is a high-temperature ceramic and is very stable at elevated temperatures. Thermal expansion and swelling strains are accommodated by the TPBAR design. No densification or significant phase change of the absorber pellets is predicted over the range of temperatures encountered during Conditions I through IV. 
PNNL-11419, Rev. 1

March 12, 1997

Absorber pellet disintegration, major cracking, and relocation is not expected below the design goal of 215 GVR. As indicated in Table 2-5, the maximum calculated GVR is 209 . The average GVR is 174 .

\subsubsection{Getters and Liners}

The thermal and physical properties of the getters and liners are discussed in Chapter 5.

\subsubsection{Chemical Properties of the Getters and Liners}

The getters and liners are nonreactive with the other TPBAR components. The Zircaloy-4 getter and liner are insoluble in the reactor coolant.

\subsubsection{Stability of the Getters and Liners}

Dimensional changes in Zircaloy-4 getters and liners result from thermal expansion, irradiation growth, and hydride induced swelling.

The irradiation growth of the Zircaloy-4 getters and liners at EOL is $<0.5 \%$, therefore the irradiation stability of the getter materials is acceptable. Hydriding cannot deform the cladding or the pellets because the hydrided getter is brittle and lacks strength relative to the cladding and pellets. The TPBAR dimensional design accommodates this growth and the swelling from hydriding.

\subsubsection{Plenum Spring}

Criterion - The plenum spring shall have sufficient preload and spring rate to prevent movement of the pencil column stack during fabrication, shipping, and handling, considering a $4 \mathrm{~g}$ axial acceleration loading at BOL.

Evaluation - The spring is made from 302 SS and is similar in design to those used in BPRA rods and fuel rods. The spring load stress has been established to be less than $60 \%$ of the yield stress, providing a safety factor of 1.66 after consideration has been given to tolerance stackup, internal and external pressure, thermal and radiation growth, 
compressed height of the spring, and pencil buckling. Based on a conservative safety margin and satisfactory commercial reactor experience with the material in this application, the spring is expected to provide the bearing load required for shipping and handling. No credit is taken for the spring in operational or reactor accident analysis.

\subsubsection{Chemical Properties of the Plenum Spring}

The plenum spring is constructed of $302 \mathrm{SS}$ and is nonreactive with the other TPBAR components. The spring is only slightly soluble in the reactor coolant. In the event of a cladding breach, a very small quantity of SS will dissolve in the reactor coolant.

\subsubsection{Stability of the Plenum Spring}

Dimensional changes in the plenum spring result from thermal expansion and irradiation growth. These phenomena are described in Chapter 5 .

\subsubsection{TPBAR Analytical Models}

This section summarizes the analytical models used to calculate TPBAR operating temperatures, rod internal total pressure, pellet tritium release, gettering (tritium absorption.by the NPZ), and consequent tritium partial pressure.

The software used to calculate the TPBAR performance parameters is MATHCAD by Mathsoft Corporation. MATHCAD is an interactive spreadsheet, which permits calculations to be displayed and annotated, and displays the results in an ongoing logical stream. In this way, axial peak values such as peak getter loading and peak tritium release can be identified.

The application of MATHCAD containing the subject analytical models is PRFM version 2.96. The models and their application are described under separate headings below. 
The modeling in MATHCAD is based on ex-reactor gettering rates and cladding permeation data, and is supported by some additional burnable absorber test data. The uncertainty in modeling test rods for some phenomena is therefore relatively large. These uncertainties are accommodated in the conservatism of the TPBAR design. The MATHCAD model will be updated whenever post-irradiation examination (PIE) data become available.

\subsubsection{TPBAR Component Operating Temperatures}

Heat is generated in the TPBAR from two sources: the ${ }^{6} \mathrm{Li}[\mathrm{n}, \alpha]^{3} \mathrm{H}$ reaction in the absorber pellets, which produces $4.8 \mathrm{MeV}$ of energy per disintegration; and gamma heating in the cladding, getter, liner, and the pellets. The heating from hydriding of the liner is negligible.

The TPBARs reside in guide thimbles within the fuel assembly, and are cooled by reactor coolant that flows up the annulus between the TPBAR and the guide thimble. The coolant in the annulus is heated slightly by the TPBAR, but gains significantly more heat from the guide thimble, which is heated by gamma radiation and heat transfer from the coolant outside the guide thimble. The coolant temperature rises from $559^{\circ} \mathrm{F}\left(293^{\circ} \mathrm{C}\right)$ at the bottom of the TPBAR to $620^{\circ} \mathrm{F}\left(327^{\circ} \mathrm{C}\right)$ at the top of the TPBAR.

\subsubsection{Calculation of TPBAR Internal Pressure}

The internal pressure of the TPBAR is determined by the internal gas concentration and the gas temperature. Essentially all of the tritium generated in the TPBAR is absorbed by the getter and liner, therefore the internal pressure is due to the helium generated in the TPBAR. The generation of helium in the absorber pellet results from the ${ }^{6} \mathrm{Li}[\mathrm{n}, \alpha]^{3} \mathrm{H}$ reaction and can be equated to the ${ }^{6} \mathrm{Li}$ depletion. The limiting design criterion for the internal gas pressure at $675^{\circ} \mathrm{F}$ $\left(357^{\circ} \mathrm{C}\right)$ is 3000 psia. 


\subsubsection{TPBAR Performance}

2.2.6.1 TPBAR Bowing Due to Thermal Effects, Irradiation, Coolant Flow, and Creep

Criterion - The TPBAR shall be sufficiently straight to allow insertion into a fuel assembly and shall maintain dimensional integrity to allow removal from an irradiated fuel assembly without excessive force.

Evaluation - Significant bowing of the TPBAR is precluded by the uniformity of its circumferential temperatures during irradiation, combined with the very small thermal creep, irradiation induced creep, and swelling strains under the low stresses, temperatures, and neutron fluences encountered. TPBARs are restrained by the guide thimble so that the bowing is limited to that permitted by the width of the annular region between the outer surface of the TPBAR and the inner surface of the guide thimble. This amount of bowing is accommodated by the TPBAR design without causing damage to the components. Analyses were performed to verify that the changes in internal component dimensions due to thermal, irradiation, coolant flow, and creep effects did not result in interferences between components. Based on BPRA rod experience and the analysis of TPBAR bowing, the thermal, irradiation, coolant flow, and creep effects are small enough not to inhibit the insertion of an LTA into an unirradiated fuel assembly or the removal of an LTA from an irradiated fuel assembly.

The flow through a guide thimble containing a BPRA rod or a TPBAR is a function of the guide thimble and rod cross-sectional areas. The external dimensions of the TPBAR are similar to those of a BPRA rod, therefore guide thimbles containing either a TPBAR or a BPRA rod will have similar flow rates. Dimensional changes throughout the fuel cycle have an insignificant impact on flows. Therefore the contribution to bowing of the TPBAR by reactor coolant flow is considered negligible, considering the structural strength of the TPBAR. 


\subsubsection{Compatibility of the TPBAR Internal and Cladding Materials}

The TPBAR components are mechanically, chemically, and metallurgically compatible during PWR irradiation conditions. The absorber pellet melting temperature of $3182^{\circ} \mathrm{F}\left(1750^{\circ} \mathrm{C}\right)$ exceeds all anticipated and design basis temperatures.

\subsubsection{Water-Logging Rupture}

\section{Potential for Chemical Interaction}

Chemical reactions internal to the TPBAR include burnup-induced release of tritium and moisture from the lithium aluminate absorber pellets, oxidation of the liner, and hydriding of the getters. The TPBAR design requires that these reactions be limited to minimize internal pressurization with tritium gas and steam.

Oxidation of the 316 SS cladding by the PWR coolant is discussed in Section 2.2.1.4. Oxidation of the coated inner surface of the cladding is limited by the quantity of oxygen and moisture released from the lithium aluminate absorber pellets and remaining after reaction with the Zircaloy-4 liner.

Breach of the TPBAR cladding is unlikely. In the event that a TPBAR is breached, water is expected to partially dissolve the aluminide barrier, releasing insignificant amounts of $\mathrm{Al}_{2} \mathrm{O}_{3}$, water soluble $\mathrm{AlCl}_{3}$, and other barrier constituents. Lithium aluminate is insoluble in water. A microscopic layer of lithium may be leached from the surface of the absorber pellets. However, given the high density and stability of the absorber pellets, and that they are contained within a getter tube within the cladding, the possibility of pellet dissolution is extremely remote.

In the event of a sudden temperature transient with a water-logged TPBAR, the low level of heat generation in the TPBAR would cause pressure changes to be sufficiently slow to allow the internal TPBAR pressure to equalize with the RCS 
pressure without further cladding damage or ejection of internal material. Also, boiling of the water would not occur because of the low heat generation and the increase in heat transfer caused by the replacement of He inside the TPBAR with water. Radiological consequences associated with a postulated breached TPBAR are presented in Chapter 6.

\section{Water-Logged TPBAR in Dry Cask Storage}

If a water-logged TPBAR is placed in dry cask storage, there is a potential for an increase in TPBAR temperature and pressure due to internal heat generation of the TPBAR. The concern is that the water in the TPBAR could boil and cause overpressurization. The TPBAR generates about 3 watts of heat 150 hours after shutdown. An analysis of TPBARs stored in a dry cask shows that the maximum temperature increase of a TPBAR due to internal heat generation is less than $3^{\circ} \mathrm{F}$ and boiling will not occur in the TPBAR.

\subsubsection{Mechanical Interaction Between Absorber Pellets and Cladding}

Pellet-cladding interactions do not occur in the TPBAR because: 1) cladding creepdown is insufficient to close the gap between the cladding and the getter; 2) the getter encloses the pellets and thereby restricts pellet movement; 3 ) the annular pellets surround the liner which further restricts the movement of the pellets; 4) the pellets are dimensionally stable; and 5) design clearances were selected to ensure that interference does not occur.

\subsubsection{Failure and Burnup Experience}

A review of the failure and burnup experience during testing of absorber pellets and tritium target test rods is provided in Table 2-5 and Table 2-6. No failures were observed. 


\subsubsection{TPBAR Component and Cladding Temperatures}

TPBAR component and cladding temperatures are compatible with the operating environment of the host plant.

\subsubsection{Potential Effect of Sudden Temperature Transients}

Sudden temperature changes during startup, shutdown, or power spikes do not cause significant thermal or differential thermal expansion stresses, because the TPBAR component walls are thin and the component thermal time constants are much less than the durations of any transients.

\subsection{Surveillance Program}

An LTA surveillance program is not planned because there will be no subsequent irradiation of the LTAs. In support of the tritium production program, a thorough post-irradiation examination of the LTAs at a DOE facility is planned. The operations surveillance program of the host plant will provide adequate monitoring of the LTA performance in the reactor. No surveillance is required or necessary during subsequent spent fuel pool storage.

\subsection{Testing and Inspection Plan}

Testing and inspection of the LTAs will verify that critical characteristics meet design tolerances and that the LTAs arrive at the plant site and are loaded into the reactor without damage.

\subsubsection{Inspection of Critical Characteristics During Fabrication}

Components of the TPBAR will be inspected to verify compliance with specifications and drawings during receipt and fabrication activities. Component attributes will be verified commensurate with their significance to fabricability and TPBAR function. 


\subsubsection{Reactor Site Receiving Inspection}

A visual inspection of the LTAs for shipping damage (similar to current BPRA inspections) will be conducted following receipt at the host reactor site.

Freedom-of-motion tests will be performed to verify straightness and ease of removal and insertion of the TPBAR.

\subsubsection{Monitoring Program}

No special testing or monitoring program will be required for the LTAs. Standard reload startup tests and routine flux mapping and power monitoring for surveillance of fuel performance are sufficient to monitor the neutronic performance of the TPBARs and the fuel assemblies containing them. The normal reactor coolant sampling program provides for monitoring of tritium concentration on a routine basis.

\subsubsection{Post-Irradiation Inspection Program}

Following removal from the reactor, the LTAs will be visually examined for obvious damage that would require special measures during handling and storage in the spent fuel pool. This examination will be similar to those done when control rod assemblies are moved between fuel assemblies.

Since no further irradiation of the LTAs is planned, no other post-irradiation inspections are planned for the host plant. DOE will ship the LTAs to a DOE facility where postirradiation examinations are planned to evaluate TPBAR performance.

\subsection{Summary}

The TPBARs maintain their integrity during Condition I, I, III, and IV events except LBLOCA. Accordingly, it can be concluded that the TPBAR LTAs during test irradiation will not: increase the probability of occurrence or the consequences of accidents previously evaluated; increase the probability of malfunctions of equipment important to safety previously evaluated; create an accident or malfunction of equipment important to safety of a different type from those 
PNNL-11419, Rev. 1

March 12, 1997

previously evaluated; nor reduce the margin of safety as defined in the bases for any technical specification at the host reactor. (See Chapter 6 for evaluation of LBLOCA consequences.) 
TABLE 2-1

Comparison of TPBAR with Burnable Absorber

Rod Design Parameters

\begin{tabular}{|c|c|c|c|}
\hline Parameter & $\begin{array}{c}\text { WABA Rod } \\
\text { 17x17 FA }\end{array}$ & $\begin{array}{l}\text { BPRA Rod } \\
\text { 17x17 FA }\end{array}$ & $\begin{array}{r}\text { TPBAR } \\
17 \times 17 \text { FA }\end{array}$ \\
\hline Overall Length, in. & $150^{\mathrm{A}}$ & 152 & 152 \\
\hline Total Weight, lbs & 1.9 & .1 .8 & 2.26 \\
\hline Absorber Length, in. & $134^{\mathrm{A}}$ & 142 & $\sim 142$ \\
\hline $\begin{array}{l}\text { Absorber O.D., in. } \\
\text { Thickness, in. }\end{array}$ & $\begin{array}{l}{[]^{(a)}} \\
{[]^{(a)}}\end{array}$ & $\begin{array}{l}{[]^{(\mathrm{a})}} \\
{[]^{(\mathrm{a})}}\end{array}$ & $\begin{array}{l}0.303 \\
0.040\end{array}$ \\
\hline Absorber Material & $\mathrm{Al}_{2} \mathrm{O}_{3}-\mathrm{B}_{4} \mathrm{C}$ & $\mathrm{SiO}_{2}-\mathrm{B}_{2} \mathrm{O}_{3}$ & $\mathrm{LiAlO}_{2}$ \\
\hline $\begin{array}{l}\text { Outer Cladding O.D., in. } \\
\text { Thickness, in. }\end{array}$ & $\begin{array}{c}0.381 \\
{[]^{(a)}}\end{array}$ & $\begin{array}{c}0.381 \\
{[]^{(a)}}\end{array}$ & $\begin{array}{c}0.381 \\
0.0225 \\
\end{array}$ \\
\hline $\begin{array}{l}\text { Inner Cladding O.D., in. } \\
\text { Thickness, in. }\end{array}$ & $\begin{array}{l}{[]^{(\mathrm{a})}} \\
{[]^{(\mathrm{a})}}\end{array}$ & None & None \\
\hline Cladding Material & Zircaloy-4 & 304SS & $316 \mathrm{SS}$ \\
\hline $\begin{array}{l}\text { Fuel Assembly Guide } \\
\text { Thimble I.D., in. }\end{array}$ & {[]$^{(a)}$} & {[]$^{(a)}$} & {[]$^{(a)}$} \\
\hline $\begin{array}{l}\text { Fuel Assembly Dashpot } \\
\text { I.D., in. }\end{array}$ & {[]$^{(\mathbf{a})}$} & {[]$^{(\mathrm{a})}$} & {[]$^{(\mathrm{a})}$} \\
\hline
\end{tabular}

[]$_{(a)}$ Denotes Westinghouse proprietary data.

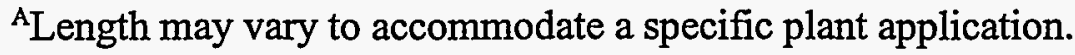


TABLE 2-2

TPBAR Design Bounding Parameters for Conditions I, II, III, and IV

\begin{tabular}{|c|c|c|c|}
\hline Operating Condition & $\begin{array}{c}\text { Cladding Design } \\
\text { Temperature, }{ }^{\circ} \mathrm{F} \\
\left({ }^{\circ} \mathrm{C}\right)\end{array}$ & $\begin{array}{c}\text { External } \\
\text { Pressure, psia } \\
\text { (MPa) }\end{array}$ & $\begin{array}{c}\text { Internal Design }^{\mathrm{A}} \\
\text { Pressure, psia } \\
\text { (MPa) }\end{array}$ \\
\hline \multicolumn{4}{|c|}{ Design } \\
\hline Design Conditions & $650(343)$ & $2500(17.2)$ & $3000(20.68)$ \\
\hline \multicolumn{4}{|c|}{ Condition I } \\
\hline Normal Operating & $660(349)$ & $2500(17.2)$ & $14.7(0.1)$ \\
\hline Shutdown & $200(93)$ & $14.7(0.1)$ & $1755(12.10)$ \\
\hline \multicolumn{4}{|c|}{ Condition II } \\
\hline $\begin{array}{l}\text { Loss of Load Without } \\
\text { Reactor Trip }\end{array}$ & $660(349)$ & $2600(17.93)$ & $14.7(0.1)$ \\
\hline BOL Reactivity Event & $620(327)$ & $1780(12.27)$ & $2877(19.84)$ \\
\hline Depressurization & $430(221)$ & $340(2.3)$ & $2370(16.34)$ \\
\hline \multicolumn{4}{|c|}{ Conditions III and IV } \\
\hline $\begin{array}{l}\text { Reactor Coolant Pump } \\
\text { Locked Rotor }\end{array}$ & $650(343)$ & 2670 (18.41) & $14.7(0.1)$ \\
\hline SBLOCA & $650(343)$ & $14.7(0.1)$ & 2957 (20.39) \\
\hline LBLOCA Blowdown ${ }^{B}$ & $1500(816)$ & $14.7(0.1)$ & $5228(36.04)$ \\
\hline
\end{tabular}

${ }^{A}$ Design criteria for internal pressure is 3000 psia at $675^{\circ} \mathrm{F}$ average internal gas temperature. Design bounding internal pressures for the operating conditions are chosen to maximize stress on the cladding. The pressure chosen is dependent upon the design temperature of concern or is set equal to atmospheric pressure to maximize differential pressure on the cladding.

${ }^{B}$ These are the conditions at which the TPBAR is assumed to fail. The LBLOCA peak temperature is significantly higher. 
PNNL-11419, Rev. 1

March 12, 1997

TABLE 2-3

Allowable Stress Limits for ASME Code Service Level Conditions [Ref. 2-9]

\begin{tabular}{||c|c|c|c|c||}
\hline $\begin{array}{c}\text { FSAR } \\
\text { Temperature } \\
{ }^{\circ} \mathbf{F}\left({ }^{\circ} \mathrm{C}\right)\end{array}$ & \multicolumn{5}{|c||}{ Allowable Stress Limits for 20\% CW 316 SS Cladding, } \\
kpsi (MPa)
\end{tabular}

ATPBARs are assumed to fail during LBLOCA. TPBAR failure is accounted for in the accident evaluations in Chapter 6.

${ }^{\mathrm{B}}$ Temperature corresponds to a shipping cask fire.

$\mathrm{C}_{\text {Hydrostatic pressure test conditions. }}$ 
PNNL-11419, Rev. 1

March 12, 1997

TABLE 2-4

Transient Conditions for Normal Reactor Operations

\begin{tabular}{|c|c|c|c|}
\hline Transient Condition & $\begin{array}{c}\text { Temperature } \\
\text { Range }\end{array}$ & $\begin{array}{c}\text { Pressure } \\
\text { Range }\end{array}$ & $\begin{array}{l}\text { Design } \\
\text { Cycles }\end{array}$ \\
\hline $\begin{array}{l}\text { Heatup/Cooldown @ } 100^{\circ} \mathrm{F} / \mathrm{h} \\
\left(55.5^{\circ} \mathrm{C}\right) / \mathrm{h}\end{array}$ & $\begin{array}{c}72 \text { to } 650^{\circ} \mathrm{F} \\
\left(22 \text { to } 343^{\circ} \mathrm{C}\right)\end{array}$ & $\begin{array}{l}14.7 \text { to } 2500 \mathrm{psi} \\
(0.1 \text { to } 17.2 \mathrm{MPa})\end{array}$ & 15 \\
\hline $\begin{array}{l}\text { Loading/Unloading } \\
15 \% \text { to } 100 \%\end{array}$ & $\begin{array}{l}500 \text { to } 650^{\circ} \mathrm{F} \\
\left(260 \text { to } 343^{\circ} \mathrm{C}\right)\end{array}$ & $\begin{array}{c}1800 \text { to } 2500 \mathrm{psi} \\
(12.4 \text { to } 17.2 \mathrm{MPa})\end{array}$ & 2175 \\
\hline $\begin{array}{l}\text { Step Load Increase/Decrease } \\
\text { (10\% of Full Power) }\end{array}$ & $\begin{array}{l}500 \text { to } 650^{\circ} \mathrm{F} \\
\left(260 \text { to } 343^{\circ} \mathrm{C}\right)\end{array}$ & $\begin{array}{l}1800 \text { to } 2500 \mathrm{psi} \\
(12.4 \text { to } 17.2 \mathrm{MPa})\end{array}$ & 150 \\
\hline $\begin{array}{l}\text { Step Load Reduction } \\
\text { (from } 100 \% \text { to } 50 \% \text { Load) }\end{array}$ & $\begin{array}{l}650 \text { to } 500^{\circ} \mathrm{F} \\
\left(343 \text { to } 260^{\circ} \mathrm{C}\right)\end{array}$ & $\begin{array}{c}2500 \text { to } 1800 \mathrm{psi} \\
(17.2 \text { to } 12.4 \mathrm{MPa})\end{array}$ & 30 \\
\hline Reactor Trip from Full Power & $\begin{array}{l}650 \text { to } 500^{\circ} \mathrm{F} \\
\left(343 \text { to } 260^{\circ} \mathrm{C}\right)\end{array}$ & $\begin{array}{l}2500 \text { to } 14.7 \mathrm{psi} \\
\text { (17.2 to } 0.1 \mathrm{MPa})\end{array}$ & 30 \\
\hline $\begin{array}{l}\text { Hydrostatic Test Pressure } \\
@ 3107 \text { psia }\end{array}$ & $\begin{array}{l}100^{\circ} \mathrm{F} \\
\left(38^{\circ} \mathrm{C}\right)\end{array}$ & $\begin{array}{l}3107 \mathrm{psia} \\
(21.4 \mathrm{MPa})\end{array}$ & 1 \\
\hline Leakage Test & $\begin{array}{c}400^{\circ} \mathrm{F} \\
\left(205^{\circ} \mathrm{C}\right)\end{array}$ & $\begin{array}{l}2500 \mathrm{psia} \\
(17.2 \mathrm{MPa})\end{array}$ & 30 \\
\hline $\begin{array}{l}\text { Steady State Fluctuations, } \\
\text { Random Fluctuations, } \\
\text { 6-min. Period }\end{array}$ & $\pm 0.5^{\circ} \mathrm{F}$ & $\pm 6 \mathrm{psi}$ & 13,200 \\
\hline $\begin{array}{l}\text { Reactor Coolant Pump Startup } \\
\text { and Shutdown }\end{array}$ & $\begin{array}{l}500 \text { to } 650^{\circ} \mathrm{F} \\
\left(260 \text { to } 343^{\circ} \mathrm{C}\right)\end{array}$ & $\begin{array}{c}1800 \text { to } 2500 \mathrm{psi} \\
(12.4 \text { to } 17.2 \mathrm{MPa})\end{array}$ & 110 \\
\hline
\end{tabular}


PNNL-11419, Rev. 1

March 12, 1997

TABLE 2-5

Comparison of Irradiation Conditions for the Tritium Test Rods and the TPBAR

\begin{tabular}{|c|c|c|c|c|c|}
\hline Parameter & WC-1 Test & S-1 Test & B-1 Test & Loop-1 Test & TPBAR \\
\hline Total Exposure, EFPD & 281 & 143 & 143 & 217 & $\begin{array}{l}450 \text { to } 500 \\
550 \mathrm{Max}\end{array}$ \\
\hline $\begin{array}{l}\text { Axial Peak Thermal Neutron } \\
\text { Flux, } \\
10^{13} \mathrm{n} / \mathrm{cm}^{2} / \mathrm{s}\end{array}$ & 4 & 4 & 6 & 3 & $\sim 1$ \\
\hline $\begin{array}{l}\text { Axial Peak Thermal Neutron } \\
\text { Fluence, } \\
10^{21} \mathrm{n} / \mathrm{cm}^{2}\end{array}$ & 0.98 & 0.5 & 0.75 & 0.56 & $\sim 0.5$ \\
\hline $\begin{array}{l}\text { Axial Peak-to-Average } \\
\text { Thermal Neutron Flux Ratio }\end{array}$ & 1.3 & 1.3 & 1.3 & 1.46 & 1.2 \\
\hline $\begin{array}{l}\text { Cladding Fast Neutron Flux, } \\
10^{13} \mathrm{n} / \mathrm{cm}^{2} / \mathrm{s} \\
(\mathrm{E}>1 \mathrm{MeV})\end{array}$ & 0.7 & 0.7 & 0.7 & 14 & 10 \\
\hline $\begin{array}{l}\text { Fast Neutron Fluence, } 10^{21} \\
\mathrm{n} / \mathrm{cm}^{2}(\mathrm{E}>1 \mathrm{MeV})\end{array}$ & 0.17 & 0.09 & 0.09 & 2.60 & $\sim 5$ \\
\hline $\begin{array}{l}\text { Axial Peak } n-\alpha \text { Power Level, } \\
\mathrm{kW} / \mathrm{ft}(\mathrm{kW} / \mathrm{m})\end{array}$ & $0.60(2.0)$ & $0.60 \cdot(2.0)$ & $0.9(3.0)$ & $0.45(1.5)$ & $\begin{array}{l}\text { BOLO.60 }(2.0) \\
\text { EOL } 0.40(1.3)\end{array}$ \\
\hline $\begin{array}{l}\text { Axially Averaged } n-\alpha \text { Power } \\
\text { Level, } \mathrm{kW} / \mathrm{ft}(\mathrm{kW} / \mathrm{m})\end{array}$ & $0.43(1.4)$ & $0.43(1.4)$ & $0.63(2.1)$ & $0.32(1.05)$ & $\begin{array}{l}\mathrm{BOL} \\
0.50(1.64) \\
\text { EOL } \\
0.35(1.15)\end{array}$ \\
\hline Rod Average GVR & 116 & 53 & 80 & $68^{\circ}$ & 174 \\
\hline Axial Peak GVR ${ }^{A}$ & 159 & 73 & 110 & 99 & 209 \\
\hline Rod Average ${ }^{6} \mathrm{Li}$ Burnup, $\%$ & 15.7 & 7.2 & 10.8 & 8.4 & 65 \\
\hline${ }^{6} \mathrm{Li}$ Enrichment, at.\% & 57 & 57 & 57 & 59.2 & $\sim 22^{\mathrm{B}}$ \\
\hline
\end{tabular}

${ }^{A}$ See Table 2-6 for bounding GVR data.

${ }^{\mathrm{B}}$ The nominal ${ }^{6} \mathrm{Li}$ loading is $0.0247 \mathrm{~g} / \mathrm{in}$. 
PNNL-11419, Rev. 1 March 12, 1997

TABLE 2-5

Comparison of Irradiation Conditions for the

Tritium Test Rods and the TPBAR

\begin{tabular}{|l|c|c|c|c|c||}
\hline Parameter & WC-1 Test & S-1 Test & B-1 Test & Loop-1 Test & TPBAR \\
\hline $\begin{array}{l}\text { Tritium Produced per 4 ft } \\
\text { (1.22 m) Rod, Ci (g) }\end{array}$ & $\begin{array}{l}2700 \\
(0.28)\end{array}$ & $\begin{array}{c}1240 \\
(0.13)\end{array}$ & $\begin{array}{c}1860 \\
(0.19)\end{array}$ & $\begin{array}{c}1559 \\
(0.16)\end{array}$ & $\begin{array}{l}3900 \\
(0.40)\end{array}$ \\
\hline $\mathrm{pH}$ of Water & 5.5 to 9.4 & 5.5 to 10 & 5.5 to 10 & $6.65 \pm 0.2$ & 6.5 to 7.0 \\
\hline
\end{tabular}


TABLE 2-6

Summary of Test Results for Lithium Aluminate Pellets Irradiated in the Advanced Test Reactor (ATR)

\begin{tabular}{|l|c|c|c|c|l|l||}
\hline $\begin{array}{l}\text { Pin } \\
\text { No. }\end{array}$ & $\begin{array}{l}{ }^{6} \mathbf{L i}, \\
\%\end{array}$ & $\begin{array}{l}\text { Life-Average } \\
\text { Calculated } \\
\text { Temp., }\end{array}$ & ${ }^{\circ} \mathbf{F}$ & $\begin{array}{l}\text { Pellet Stack } \\
\text { Elongation, }^{\mathrm{A}}\end{array}$ & $\begin{array}{l}\text { Gaps Between }^{\mathrm{B}} \\
\text { Pellets }^{\mathrm{B}}\end{array}$ & $\begin{array}{l}\text { Observations From } \\
\text { Neutron Radiographs }\end{array}$ \\
\hline 11 & 50 & $773-864$ & 239 & 0.9 & none detected & pellets intact \\
\hline 12 & 50 & $773-864$ & 239 & 1.3 & none detected & pellets intact \\
\hline 19 & 95 & $.994-1167$ & 154 & 0.9 & none detected & axial crack in one pellet \\
\hline 20 & 95 & $994-1167$ & 154 & 1.3 & none detected & pellets intact \\
\hline 25 & 25.1 & $794-836$ & 165 & 0.9 & none detected & pellet intact \\
\hline 26 & 25.1 & $794-836$ & 165 & 0.9 & none detected & pellets intact \\
\hline \hline
\end{tabular}

A GVR was based on theoretical density. GVR based on actual pellet density is approximately $10 \%$ lower (216 GVR for pins 11 and 12). Absorber Pellets Theoretical Density is 90 to $91 \%$; 0.022 in. Wall Thickness; Preirradiated Stack Length $=9.989$ in .

${ }^{\mathrm{B}}$ Determined by neutron radiography. 
PNNL-11419, Rev. 1 .

March 12, 1997


Figure 2-1 Lead Test Assembly 


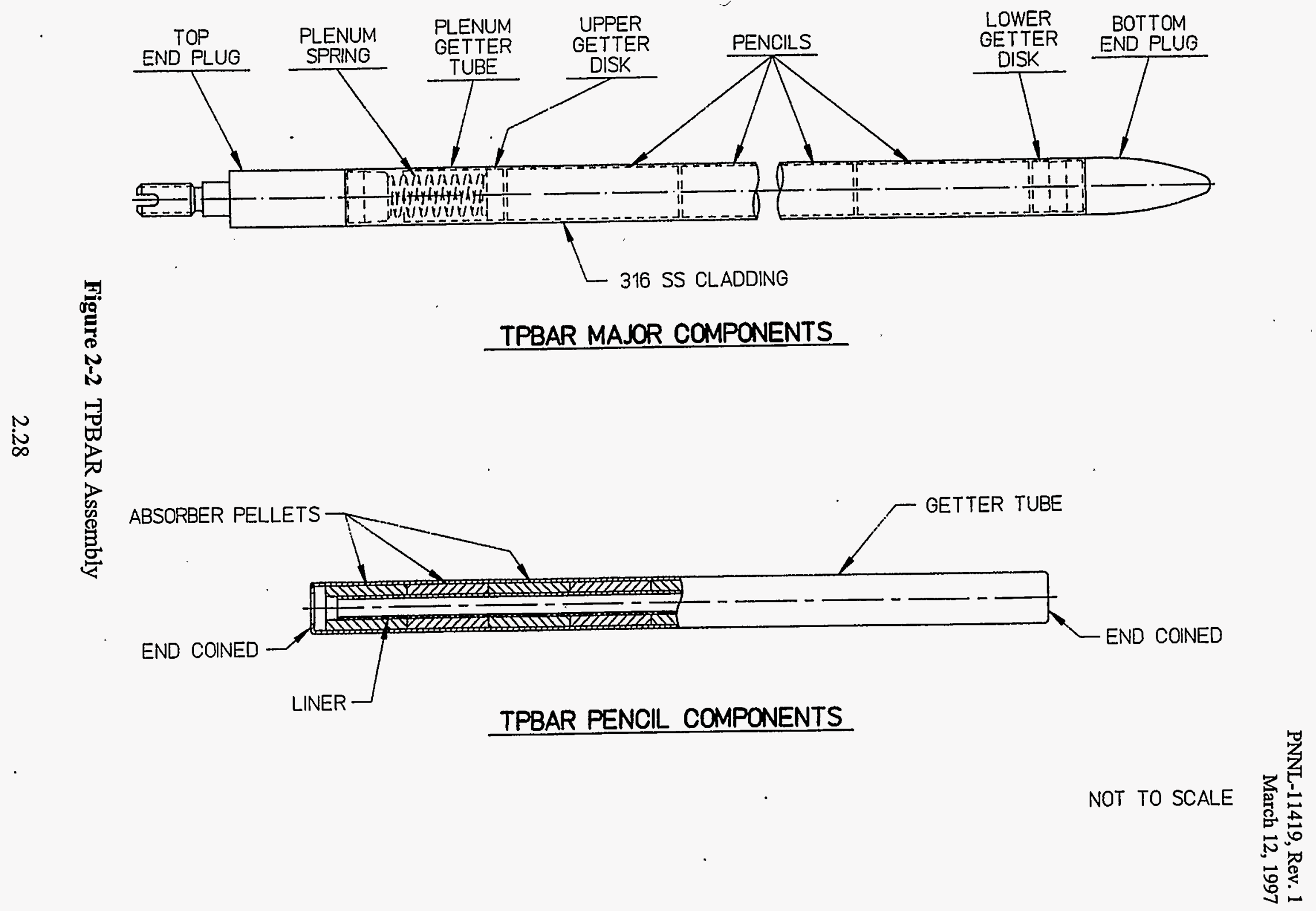


PNNL-11419, Rev. 1

March 12, 1997



Figure 2-3 Sketch of TPBAR Components 
PNNL-11419, Rev. 1

March 12, 1997

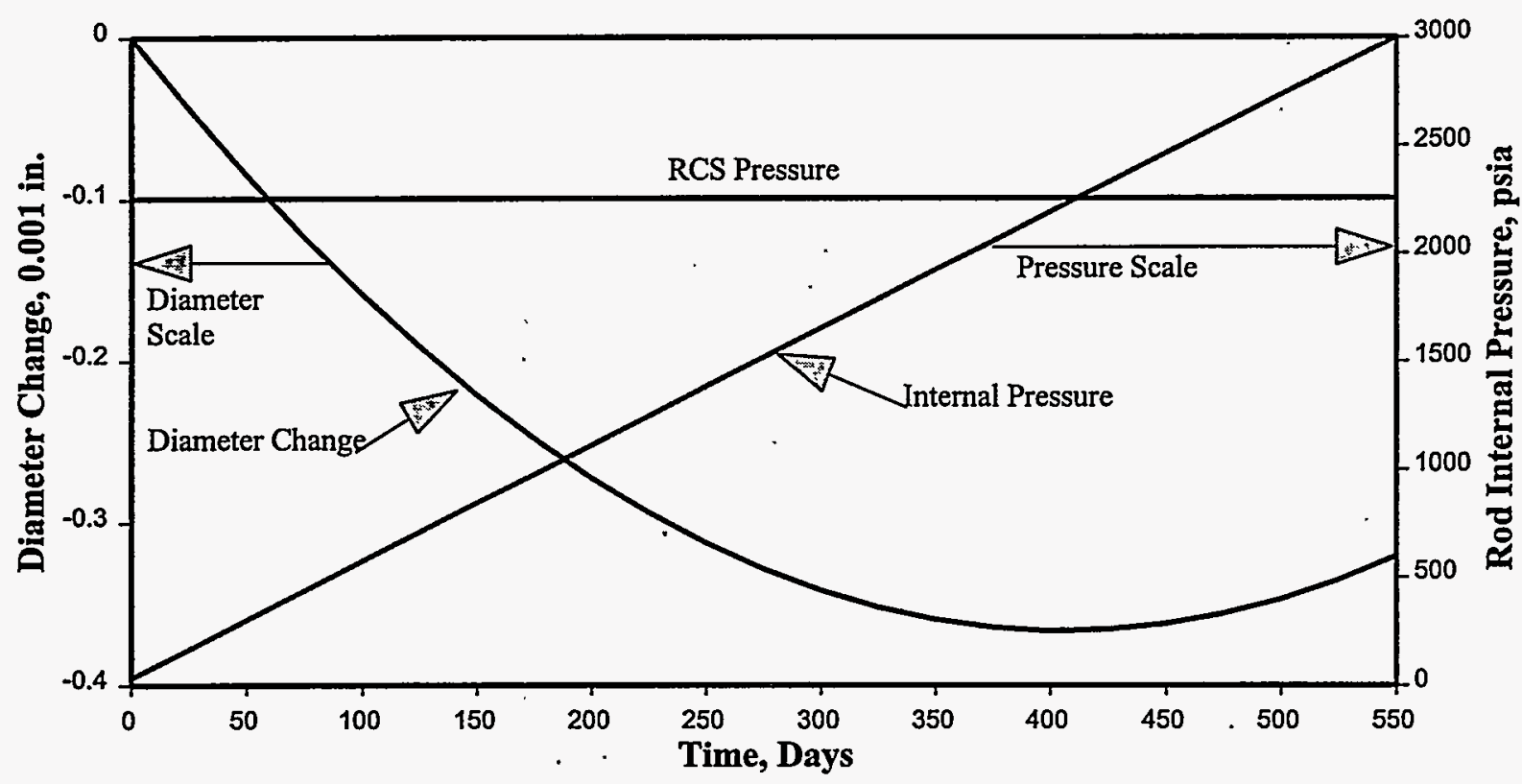

Figure 2-4 Effect of Irradiation Creep on TPBAR Cladding Diameter Due to RCS Pressure and Internal Pressure 


\subsection{References}

2-1. Final Safety Analysis Report. Tennessee Valley Authority (TVA). 1994, 1995. Final Safety Analysis Report for Watts Bar Plant. Docket Number 390/391, Chattanooga, - Tennessee.

2-2. Deleted.

2-3. ASTM. 1988. Standard Specification for Austenitic Stainless Steel Tubing for Breeder Reactor Core Components. ASTM A771-88, Table 2.

2-4. ASME. 1995. ASME Boiler \& Pressure Vessel Códe, Section III, Divisịon 1, Subsection NG, Article 3220.

2-5. M.M. Hall, Jr. et. al. 1978. Fusion Welding of Irradiated 304L Stainless Steel Tubing. Weldments: Physical Metallurgy and Failure Phenomena, Proceedings of the Bolton Landing Conference, ASM, AWS, and AIME, The General Electric Company, Schnechtady, New York.

2-6. ASME. 1995. ASME Boiler \& Pressure Vessel Code, Figure I-9.2.2.

2-7. Strasser, A., et al. 1982. An Evaluation of Stainless Steel Cladding for Use in Current Design LWRs. NP-2642, Electric Power Research Institute, Palo Alto, California.

2-8 Cunningham, M.E., E.R.Gilbert, A.B. Johnson, Jr., and M.A. McKinnon. 1996. Evaluation of Expected LWR Stainless Steel-Clad Fuel Behavior in Long-Term Dry Storage, EPRI-TR-106440, Electrical Power Research Institute, Palo Alto, California.

2-9 ASME. 1995. ASME Boiler \& Pressure Vessel Code, Section II, Part D, Appendix 2, Article 2-110. 
PNNL-11419, Rev. 1

March 12, 1997

\section{NUCLEAR DESIGN DESCRIPTION}

This chapter discusses the nuclear design of the LTAs. The effects of the LTAs are discussed in terms of nuclear design (Section 3.1), power distribution (Section 3.2), reactivity control (Section 3.3), and reload safety analysis (Section 3.4). Section 3.5 summarizes the nuclear design evaluation.

TPBARs will replace some of the burnable poison in a reload core. The TPBAR is similar in its nuclear characteristics to BPRA rods and, from the standpoint of fuel assembly reactivity, will satisfy the same nuclear design requirements.

The neutron absorber in the TPBAR is ${ }^{6} \mathrm{Li}$ contained in absorber pellets. The absorber pellet material is $\mathrm{LiAlO}_{2}$, enriched in the naturally occurring isotope ${ }^{6} \mathrm{Li}$. The ${ }^{6} \mathrm{Li}$ enrichment is dictated by tritium production requirements and in-core TPBAR performance requirements.

\subsection{Effects on Reactor Nuclear Design}

The LTAs will have a minimal impact on the global core design. This is ensured by mimicking, to the extent feasible, the behavior of BPRAs; using a limited number of TPBARs in any one fuel assembly; using a limited number of LTAs in the core; and placing LTAs in core regions which are not limiting with respect to core thermal hydraulic performance.

Figure 3-1 illustrates how the overall reactivity contribution characteristics of TPBARs are similar to those of a conventional absorber throughout the operating cycle. As shown in the figure, TPBARs have a somewhat higher worth at end of life than wet annular burnable absorber (WABA) rods with an equivalent beginning of life worth. This is due to slower TPBAR absorber depletion and the increased parasitic neutron absorption of TPBAR stainless steel cladding as compared to Zircaloy cladding. Given the small number of TPBARs being installed in the reload core (four LTAs, each having eight TPBARs) and the distribution of the LTAs in the core, operation within fuel design limits is ensured.

The absorber behavior of the TPBARs will be accounted for in the reload core design of the host reactor including coordination of absorber characteristics and fuel enrichment to achieve the 
planned energy production from the core, as is the case for other burnable absorbers. The core design analysis for the reload core with LTAs will be performed by the host reactor licensee and Westinghouse, using an NRC-approved core design methodology that models the neutronic behavior of the TPBARs. Operation within core design limits will be confirmed as part of the reload safety evaluation. Incorporating the neutronic behavior of the TPBARs in the core design methodology is discussed in Section 3.4 of this chapter.

\subsubsection{Methodology Used for Scoping Calculations}

A two-dimensional neutronics model was developed and used to perform scoping calculations during the design and evaluation of the TPBARs. The tritium production in the TPBARs was estimated assuming various host reactor reload designs, and the lithium enrichments required to meet design goals were determined. Scoping calculations were performed to determine LTA neutronic behavior and to assess the effects of LTAs on core performance. These scoping calculations established confidence that the reload safety analysis performed for the host reactor core will demonstrate that the reload core with LTAs meets all specified fuel design limits. A complete three-dimensional model of the host LTA reactor core (see Section 3.4) will be used for the final reload safety analysis.

The neutronics model used for scoping calculations was developed using the WIMS-E computer code [Ref. 3-1]. The WIMS-E code has been validated for use on previous new production reactor design efforts [Ref. 3-2]. The model is a two-dimensional multi-group integral-transport model with depletion. The WIMS-E code version used employs the 69 energy group Winfrith data library. This library was modified by PNNL to incorporate depletion of ${ }^{6} \mathrm{Li}$ using the ${ }^{6} \mathrm{Li}[\mathrm{n}, \alpha]^{3} \mathrm{H}$ reaction and the ${ }^{3} \mathrm{He}[\mathrm{n}, \mathrm{p}]^{3} \mathrm{H}$ reaction. Decay of tritium is also included in the library.

The neutronic models for the LTA design are based on a Westinghouse $17 \times 17$ fuel assembly design. Fuel assemblies containing LTAs are modeled by placing eight TPBARs in fresh fuel assemblies in place of burnable absorber material. The general reactor data used for the model was taken from the Final Safety Analysis Reports (FSARs) for large Westinghouse PWRs including the host plant FSAR [Ref. 3-3]. Other 
data required for the calculations are taken from standard references [Ref. 3-4], [Ref. 35], and [Ref. 3-6].

PNNL is not aware of any critical experiments that provide suitable data for benchmarking neutronics codes which include ${ }^{6} \mathrm{Li}$ neutron absorber. Such a benchmark was not considered necessary since ${ }^{6} \mathrm{Li}$ is a simple, non-resonant (i.e., linear $1 / \mathrm{v}$ crosssection) absorber. Due to the lack of data on LWR tritium-producing lattice configurations, WIMS-E was compared to MCNP [Ref. 3-7]. The comparison between the two codes indicates differences in reactivity calculations of about $0.5 \%(5 \mathrm{mK}),{ }^{6} \mathrm{Li}$ capture rate difference of $2.3 \%$, and a maximum fuel rod fission rate difference of $2.8 \%$ in the lattice. The WIMS-E code is a deterministic, transport theory code and MCNP employs a statistical, Monte Carlo solution methodology. In addition, each code uses an independent set of nuclear cross section data libraries (European vs. ENDF/B, respectively). Considering the substantial differences in calculation methodologies and the use of independent nuclear data libraries, some differences in calculated reactivity are to be expected, and in this case the difference is considered small.

\subsection{Effects on Power Distribution}

The impact of the LTAs on overall core power distributions will be similar to that of BPRAs and WABA rod assemblies currently used in PWRs. As discussed in Section 3.1, global TPBAR absorber effects, including effects on overall power distributions, will be accounted for in the LTA reload core design. Although there are no unique considerations for TPBARs with regard to global core power distributions, there is a potential for local power distribution effects resulting from TPBAR design features. The remainder of this section addresses these potential local power distribution effects.

\subsubsection{TPBAR Fabrication Gaps}

TPBAR absorber pellets are contained in "pencils." The pencil consists of a stack of pellets loaded into a getter tube with the ends of the getter tube coined to contain the pellets. These pencils are stacked in a column in the TPBAR. The interfaces between pencils at their coined ends result in gaps between segments of absorber pellet material. A small local axial power peak in the adjacent fuel rods results from each gap. The gaps 
PNNL-11419, Rev. 1

March 12, 1997

are affected by manufacturing tolerances, irradiation, and temperature. Evaluation of these parameters resulted in a maximum gap of less than 400 mils.

DORT, a two-dimensional discrete ordinates transport auxiliary routine of the TORT code [Ref. 3-8], was used to evaluate the degree of local power peaking due to absorber pellet gaps. The model used was a cylindrical version of a $3 \times 3$ array with a TPBAR in the center. Fresh target and fuel rods at hot clean operating conditions were modeled in order to maximize the gap effects. The model was used to analyze the effects of $100 \mathrm{mil}$, $200 \mathrm{mil}, 300 \mathrm{mil}$, and $400 \mathrm{mil}$ gaps. The analysis included host plant ${ }^{6} \mathrm{Li}$ enrichments and fuel rod ${ }^{235} \mathrm{U}$ enrichments.

The evaluation indicates that the $400 \mathrm{mil}$ gap case results in the highest localized power peaking in fuel rods immediately adjacent to the guide thimble containing a TPBAR, and that this local power peaking is less than $4.5 \%$. This power peak affects, at most, a oneinch height of the neighboring fuel rods. Since peaking of this order typically occurs in PWR fuel assemblies due to various factors, including grid spacer effects, there is a high degree of confidence that the absorber pellet gaps will not adversely affect the results of the reload safety evaluation. LTAs will be located in non-limiting reactor core locations where TPBAR absorber pellet gaps would not cause fuel design limits to be exceeded.

\subsubsection{Sensitivity to Pellet Fabrication Tolerances}

Dimensional and material variations occurring in the TPBAR pellet fabrication process have the potential to cause local power peaking in adjacent fuel rods. The fabrication variations considered to have the potential to contribute to this power peaking are TPBAR dimensional tolerances, ${ }^{6} \mathrm{Li}$ loading tolerances, and impurity specifications.

The WIMS-E model described in Section 3.1 was used to perform sensitivity studies of pellet fabrication tolerances and to determine the summed effect of worst-case variations on power peaking. Parameter variations were modeled in one of the eight TPBARs in an LTA. These studies concluded that power peaking due to TPBAR fabrication tolerances is $<1 \%$. LTAs will be located in non-limiting reactor core locations where TPBAR fabrication tolerances would not cause fuel design limits to be exceeded. 
PNNL-11419, Rev. 1

March 12, 1997

\subsubsection{Summary of TPBAR Effects on Local Power Distribution}

LTAs will be located in non-limiting reactor core locations, the effects of TPBARs on local power distribution are small, and local power in fuel pins adjacent to the TPBAR are suppressed due to the neutron absorber. The evaluation of potential local power peaks resulting from TPBAR design features provides confidence that a host reactor reload core with LTAs can be designed and operated within existing fuel design limits. A reload safety analysis will be performed by the host reactor licensee and Westinghouse to demonstrate that allowable core safety limits will not be exceeded by the reload core incorporating LTAs.

\subsection{Effects on Control Requirements}

Figure 3-1 illustrates how the overall reactivity contribution of ${ }^{6} \mathrm{Li}$ in the LTAs will be similar to that of a burnable absorber rod assembly. The effect of ${ }^{6} \mathrm{Li}$ depletion on reactivity is roughly linear. The cross-section of ${ }^{6} \mathrm{Li}$ is not particularly sensitive to temperature variations, and has no resonance behavior that could affect reactivity. Because of the limited number and distribution of LTAs and the similarity of their reactivity worth to that of BPRAs, the worths of control rods and soluble boron poison are not changed significantly, and the LTAs will not impact control requirements.

As with other burnable absorber rods, changes in reactivity due to absorber burnout are within the capabilities of the reactor makeup and boration systems so that throughout the operating cycle, control rod movement beyond insertion limits is not required. The core design evaluation performed by the host reactor licensee and Westinghouse will confirm that reactor control requirements will be met with the LTAs installed.

\subsection{Changes in Reload Safety Analysis}

The core design analysis for the host reactor core with LTAs will be performed by the host reactor licensee and Westinghouse, using existing NRC-approved core design methodology. Westinghouse will use the PHOENLX/ANC code suite to perform LTA reload core calculations. PHOENIX-P is a two-dimensional lattice code normally used to provide pin power and depletion 
data to the three-dimensional PHOENIX/ANC code. To support design and evaluation of the TPBAR LTA core, Westinghouse is modifying the PHOENIX-P code to model ${ }^{6} \mathrm{Li}$ depletion in the TPBARs, and will further modify the code to account for ${ }^{3} \mathrm{H}$ decay and ${ }^{3} \mathrm{He}$ production/depletion. This modified version of the PHOENLX-P code has been designated PHOENIX-L.

The PHOENIX-L codes and models were compared to PNNL WIMS-E models to assess reactivity as a function of fuel depletion. The comparison cases include calculated reactivity for a fuel assembly: (a) without burnable absorbers or TPBARs, (b) with 24 TPBARs, (c) with 64 integral fuel burnable absorbers (IFBAs), and (d) with eight TPBARs and 64 IFBAs. The results of these comparisons are presented in Figures 3-2 through 3-5. The comparisons are in excellent agreement and establish confidence that PHOENIX-L will provide acceptable predictions of the reload core incorporating LTAs. Westinghouse is currently in the process of verifying and validating the PHOENIX-L code for use during the reload safety evaluation performed for the LTA host reactor. Westinghouse will benchmark PHOENIX-L with MCNP as part of their verification and validation process. The differences between the PHOENIX-L and PHOENIX-P codes will be documented in a report provided to PNNL and the host utility. Such changes are subject to the reporting criteria imposed on the host utility by 10 CFR 50.46(a)(3). These differences will also be documented internally at Westinghouse in computer software verification and validation documentation. Auditable files will be available that document calculations performed for the core reload safety analysis.

\subsection{Summary}

TPBARs mimic the neutronic behavior of conventional burnable absorbers currently used in PWRs. The reload safety analysis performed for the host plant core with LTAs will demonstrate that all established fuel design limits will met. Accordingly, it can be concluded that neutronic behavior of the TPBAR LTAs during test irradiation will not: increase the probability of occurrence or the consequences of accidents previously evaluated; increase the probability of malfunctions of equipment important to safety previously evaluated; create an accident or malfunction of equipment important to safety of a different type from those previously evaluated; nor reduce the margin of safety as defined in the bases for any technical specification at the host reactor. 
PNNL-11419, Rev. 1

March 12, 1997

TPBAR - WABA Reactivity

$4.0 \%$ fuel

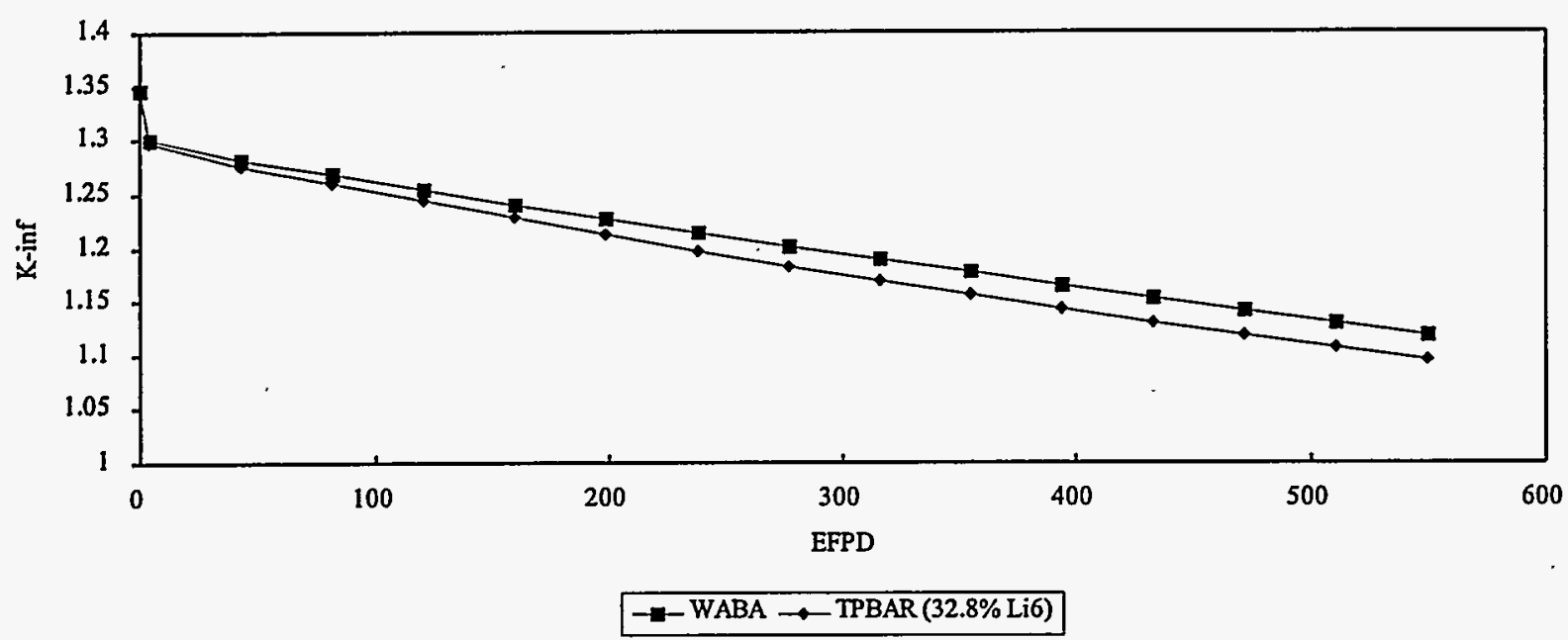

Figure 3-1, Depletion Curves for TPBAR and WABA Rod ${ }^{A}$

${ }^{\mathrm{A}}$ This figure illustrates a comparison of the reactivity of a fuel assembly, as a function of exposure, when hosting WABA rods and when hosting TPBARs. In this illustration, the BOL worth of the WABA and the LTA have been set equal by selection of an appropriate ${ }^{6} \mathrm{Li}$ loading in the TPBARs. 
PNNL-11419, Rev. 1

March 12, 1997

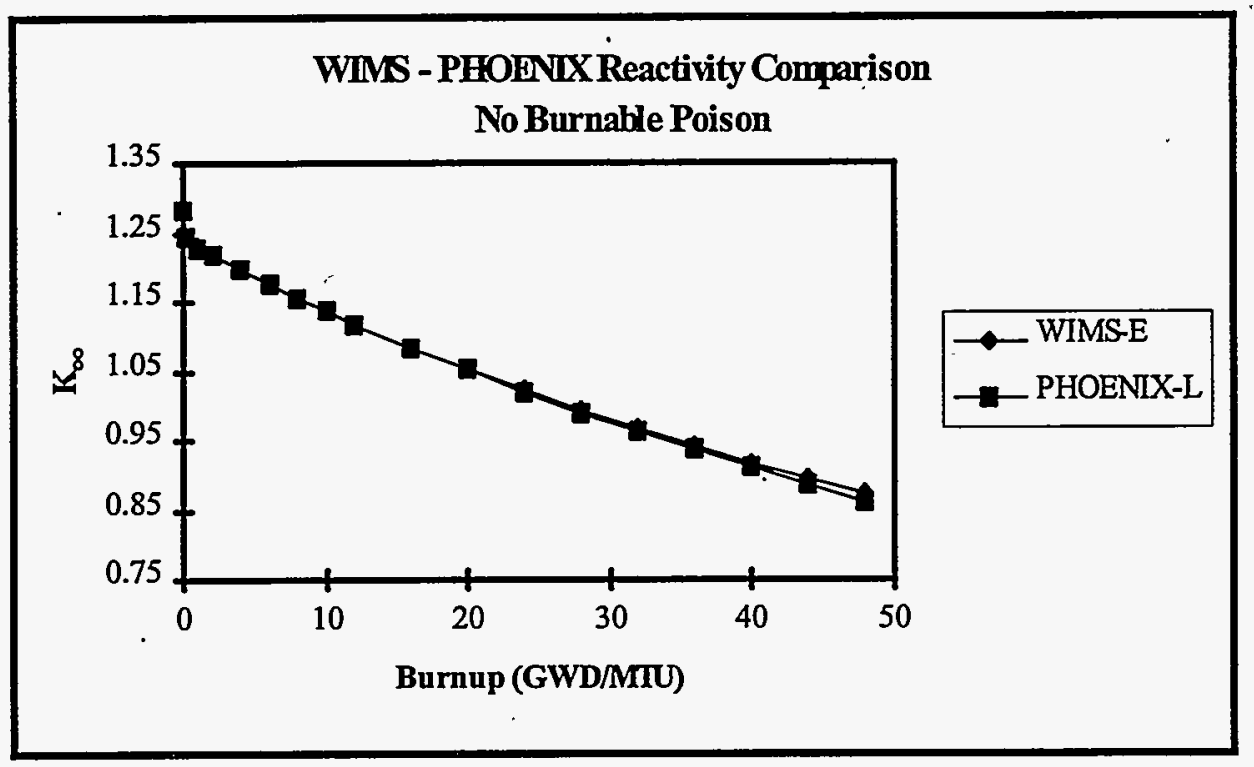

FIGURE 3-2

WIMS - PFOENIX Reactivity Comparison

24 TPBAR

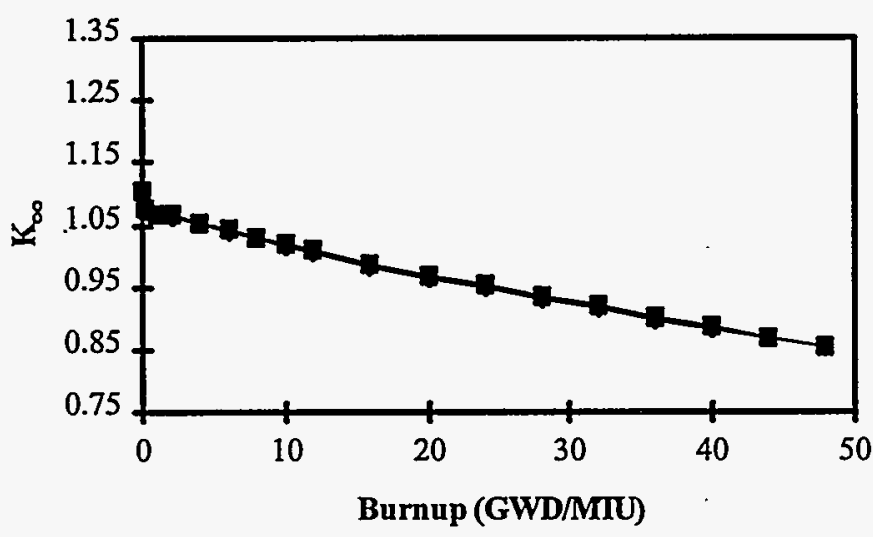

FIGURE 3-3 
PNNL-11419, Rev. 1

March 12, 1997

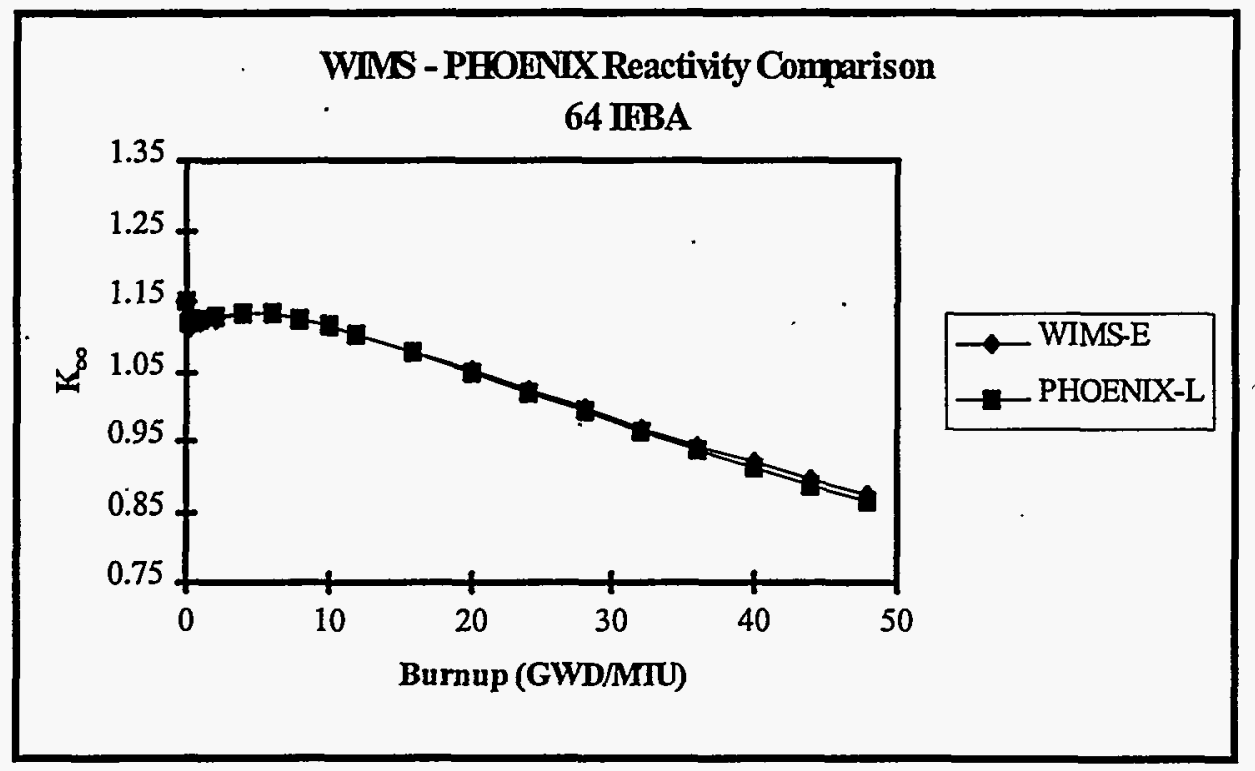

FIGURE 3-4

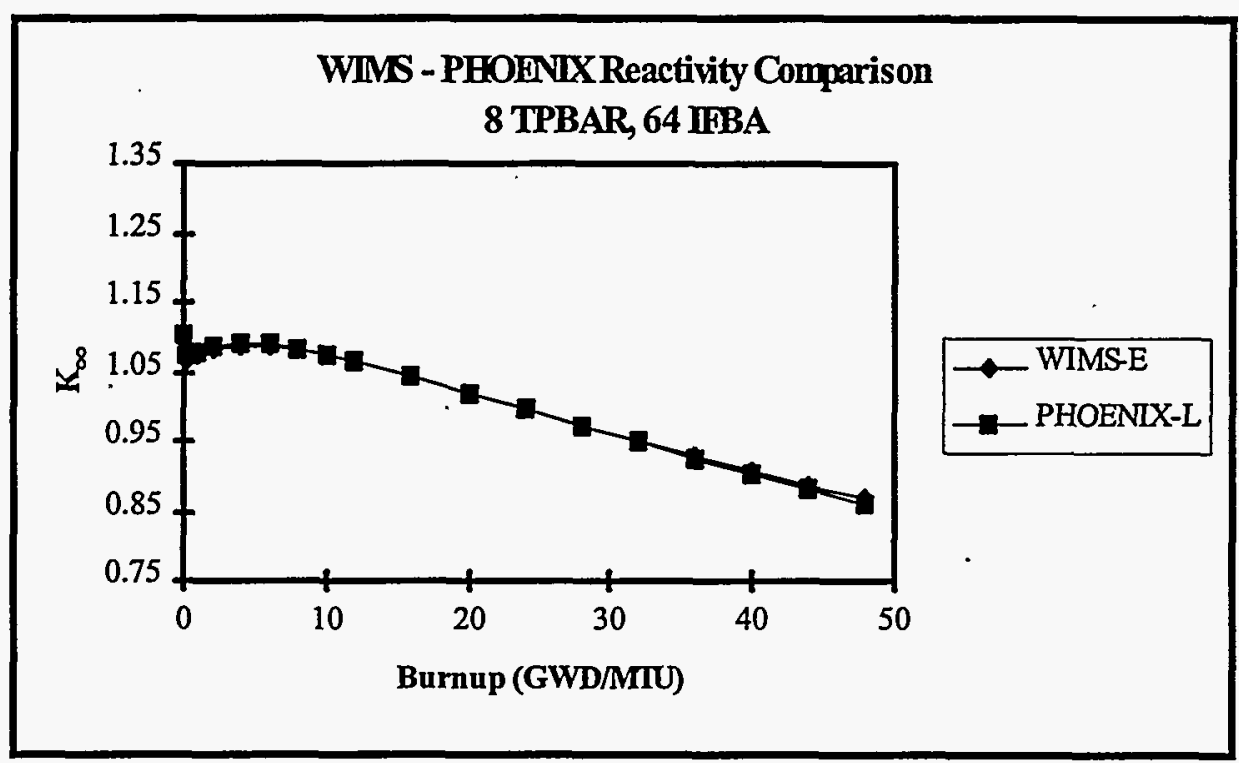

FIGURE 3-5 


\subsection{References}

3-1. Askew, J. R., and M. J. Roth, WIMS-E A Scheme For Neutronics Calculations, Winfrith, June 1982.

3-2. Reid, B. D., et.al., The WIMS-E Benchmark Of The Light Water New Production Reactor Diamond Cell, PNL-SA-20559, Pacific Northwest Laboratory, Richland, WA, January 1992.

3-3. Tennessee Valley Authority (TVA). 1994, 1995. Final Safety Analysis Report for Watts Bar Nuclear Power Plant. Docket Number 390/391, Chattanooga, Tennessee.

3-4. 'Nuclides and Isotopes - Chart Of The Nuclides Fourteenth Edition," GE Nuclear Energy, San Jose, CA, 1989.

3-5. Keenan, J. H., et. al., Steam Tables - Thermodynamic Properties of Water Including Vapor, Liquid and Solid Phases, John Wiley and Sons, 1969.

3-6. Reppond, E. B., Criticality Safety Analysis Resource Book Part Two: Atom Densities And Dimensional Parameters, Pacific Northwest Laboratory, Richland, WA, 1977.

3-7. Briemeister, J.F., ed., MCNP - Monte Carlo N-Particle Transport Code, Version 4A, LA 12625, Los Alamos National Laboratory, Los Alamos, NM, 1993.

3-8. Rhoades, W.A., The TORT Three-Dimensional Discrete Ordinates Neutron/Photon Transport Code, ORNL-6268, November 1987. 
PNNL-11419, Rev. 1

March 12, 1997

\section{THERMAL AND HYDRAULIC DESIGN}

This chapter addresses the TPBAR thermal hydraulic design and the impact of the LTA on the reactor core thermal hydraulic design. The host plant reactor core parameters were used in evaluating the LTA impact on reactor core thermal hydraulic performance. This chapter discusses TPBAR thermal hydraulic design (Section 4.1), and its impact on reactor core thermal hydraulic design (Section 4.2). Section 4.3 summarizes the thermal hydraulic design evaluation.

\subsection{TPBAR Thermal Hydraulic Design}

Analytical methods commonly used in the nuclear industry were used to ensure that bulk boiling or hydrodynamic instability does not occur during Condition I or Condition II events, and to ensure an acceptable safety margin in the thermal hydraulic design of the TPBARs.

\subsubsection{TPBAR Thermal Hydraulic Design Bases}

The thermal and hydraulic design bases of the TPBARs ensure that the TPBAR cladding will not be breached during Condition I or Condition II events. Four thermal hydraulic criteria were applied, specific to the TPBAR design. The first three criteria are similar to those that apply to the Westinghouse BPRA rods [Ref. 4-1] and wet annular burnable absorber (WABA) rods [Ref. 4-2]. The fourth criterion, that the LTA not be placed in the limiting fuel assembly, is based on the Standard Technical Specification provisions relative to lead test assemblies. The four criteria are as follows:

1) The maximum TPBAR coolant outlet temperature from the guide thimble shall not exceed the coolant bulk boiling temperature during Condition I.

2) The maximum TPBAR cladding temperature shall not exceed the temperature associated with the onset of subcooled nucleate boiling during Condition I and II events.

3) The core bypass flow through the guide thimbles shall be limited to ensure that sufficient coolant flow is provided to the fuel rod channels to meet fuel and thermal hydraulic design criteria. 
4) The TPBARs shall not be placed (inserted) in a limiting core location.

The following is a discussion of thermal hydraulic parameters which were evaluated to ensure that cladding integrity is maintained during Conditions $I$ and $\Pi$. Design parameters for the TPBAR, BPRA rod, and WABA rod are compared in Table 4-1.

\subsubsection{TPBAR Temperatures}

The TPBAR cladding design limit of not exceeding the temperature associated with the onset of subcooled nucleate boiling ensures acceptable thermal-hydraulic performance of the TPBAR. Calculated TPBAR temperatures are verified to be below the temperatures assumed in the mechanical stress analysis of the rod. This ensures that the cladding does not fail due to internal gas pressure. TPBAR. cladding stresses and internal temperatures are discussed in Chapter 2.

\subsubsection{Reactor Core Bypass Flow}

The flow through a guide thimble containing a BPRA rod or a TPBAR is a function of the guide thimble and rod cross-sectional areas. The external dimensions of the TPBAR are similar to those of a BPRA rod, thereby ensuring that reactor core bypass flow will not be impacted by the presence of the TPBARs in the core. Those guide thimbles containing TPBARs will have similar flows to guide thimbles containing BPRAs, and core bypass flows will remain within the limits established for the host plant. Dimensional changes throughout the fuel cycle have an insignificant impact on flows.

Core flow is not significantly affected by the addition of the TPBARs. Therefore, existing analyses of core pressure drop and hydraulic loads are valid. The TPBAR pressure drop and hydraulic load will be similar to those for the BPRA rod, since the dimensions and flow rates are the same. 
PNNL-11419, Rev. 1

March 12, 1997

\subsubsection{Hydrodynamic Stability}

Based on the thermal-hydraulic design criteria discussed above and the similarity of mechanical design features to those of a BPRA, no hydrodynamic instability will occur in the TPBAR cooling channels during Conditions I or $\Pi$.

\subsubsection{Other Considerations}

The LTAs will not be placed in the limiting core locations. This is consistent with Standard Technical Specification conditions on fuel lead test assemblies. The TPBAR thermal hydraulic characteristics, coolant flow velocity, and coolant distribution are not inherently limiting. Each of these parameters is incorporated into the thermal and hydraulic models to ensure that the design criteria are met. LTA uplift forces will be similar to those for other burnable absorber rod assemblies. This will be verified as part of the reload safety analysis.

\subsubsection{Description of TPBAR Thermal and Hydraulic Design}

The TPBARs are inserted in the fuel assembly guide thimbles. The TPBAR design evaluation assumes Westinghouse standard fuel with the TPBAR external dimensions similar to those of a standard Westinghouse BPRA rod.

Thermal hydraulic analysis of the TPBAR design was performed by hand calculation, assisted by MATHCAD software. Flow and core pressure drop data used in the analysis were provided by the host plant utility and Westinghouse. Conservative values were used to bound the host plant core [Ref. 4-3], and to define the host plant coolant and operating boundary conditions. These are summarized in Table 4-2 and Table 4-3. The results of the analysis show that the thermal-hydraulic criteria of Section 4.1.1 are met with the TPBAR located in an assembly with a total power peaking of up to 1.42 and with the TPBAR adjacent to a fuel rod with an $F_{\mathrm{dh}}$ of 1.65 or less.

The analysis described above is preliminary. If final thermal-hydraulic calculations are more limiting for the host reactor, the updated results will be evaluated as part of the host utility 10 CFR 50.59 evaluation performed for the reload core with LTAs. The final 
calculations will be documented in an auditable calculation file. The analysis will be reviewed by Westinghouse during the performance of the core reload safety evaluation.

\subsubsection{Thermal Effects of Operational Transients}

During Condition I events that result in a reactor trip (scram), heat production within the TPBAR drops significantly following the decay of neutron flux in the core. Margins with respect to the TPBAR thermal design limits are sufficient to ensure no damage to the TPBAR.

During Condition II events that result in a reactor trip (scram), or during steady-state $118 \%$ over-power, margins with respect to the TPBAR thermal design limits are sufficient to ensure no damage to the TPBAR.

With a maximum of four LTAs, the thermal effects of operational transients on the reactor are negligible, provided that: 1) LTAs are not installed in peak assemblies, 2) LTAs are not installed in an assembly where a fuel rod adjacent to a TPBAR has an $F_{d h}$ greater than 1.65 , and 3) the LTA is not installed in an assembly with a total power peaking greater than 1.42 . These limits are based on preliminary calculations. Fuel assemblies containing LTAs will remain within reactor thermal-hydraulic design limits.

\subsection{Impact on Reactor Core Thermal Hydraulic Design}

The thermal and hydraulic design parameters for the host plant were used as evaluation points to determine if there would be any impacts of the LTA on the reactor core thermalhydraulic design.

The analyses concluded that the LTA will not impact the reactor core thermal-hydraulic design provided the LTAs are not installed in an assembly where a fuel rod adjacent to a TPBAR has an $F_{\text {dh }}$ greater than 1.65 and the LTA is not installed in an assembly with a total power peaking greater than 1.42: As can be seen in Table 4-4, the design parameters for the host plant are unchanged by the LTA. Therefore, there is reasonable assurance that a reactor core with LTAs will remain within established design parameters. 


\subsection{Summary}

The thermal and hydraulic design bases of the TPBARs ensure that the TPBAR cladding will not be breached during Condition I or Condition II events.

Analytical methods commonly used in the nuclear industry were used to evaluate conditions such as bulk boiling and hydrodynamic instability during Condition I and II events to ensure an acceptable safety margin in the thermal-hydraulic design of the TPBARs. Specific to the TPBAR design, four thermal-hydraulic design criteria were applied. Three of the criteria are similar to those that apply to the Westinghouse BPRAs and the fourth criterion is based on the standard industry practice relative to lead test assemblies.

The analyses concluded that the insertion of the LTA into the reactor core will not impact the thermal-hydraulic design of the host reactor. Accordingly, it can be concluded that the thermal-hydraulic behavior of the TPBAR LTAs during test irradiation will not: increase the probability of occurrence or the consequences of accidents previously evaluated; increase the probability of malfunctions of equipment important to safety previously evaluated; create an accident or malfunction of equipment important to safety of a different type from those previously evaluated; nor reduce the margin of safety as defined in the bases for any technical specification at the host reactor. 
PNNL-11419, Rev. 1

March 12, 1997

TABLE 4-1

TPBAR Comparison to BPRA and WABA Rods

\begin{tabular}{|l|l|l|l|}
\hline \multicolumn{1}{|c|}{ Parameter } & \multicolumn{1}{c|}{ TPBAR } & BPRA & WABA \\
\hline Guide Thimble ID, in & 0.442 & 0.442 & 0.442 \\
Rod OD, in & 0.381 & 0.381 & 0.381 \\
Rod ID & $\mathrm{NA}$ & $\mathrm{NA}$ & {[]$^{(\mathrm{a})}$} \\
Nominal Guide Thimble & {[]$^{(\mathrm{a})}$} & {[]$^{(\mathrm{a})}$} & {[]$^{(\mathrm{a})}$} \\
Flow 17x17 & & & \\
Nominal Absorber Power & $0.58 \mathrm{BOL}$ & {[]$^{(\mathrm{a})}$} & {[]$^{(\mathrm{a})}$} \\
kW/ft avg. & & & {[]$^{(\mathrm{a})}$} \\
Peak Linear Absorber & .70 & {[]$^{(\mathrm{a})}$} & 149.83 \\
Power kW/ft & & 152.59 & $134.0^{\mathrm{B}}$ \\
Rod Length, in & 152.35 & 142.0 & \\
Poison Length, in & $\sim 142.0$ & & \\
\hline
\end{tabular}

[]$^{(a)}$ Denotes Westinghouse proprietary data.

${ }^{A}$ Generic values based on $28.8 \mathrm{~W} / \mathrm{cm}^{3}$ in absorber and $14.1 \mathrm{~W} / \mathrm{cm}^{3}$ in steel.

${ }^{\text {B}}$ Length may vary to accommodate a specific plant specification. 
TABLE 4-2

Host Plant T-H Parameters

\begin{tabular}{||l|c|c||}
\hline Parameter & $\begin{array}{c}\text { Condition I } \\
\text { Event Analysis } \\
\text { Value }\end{array}$ & $\begin{array}{c}\text { Condition II } \\
\text { Event Analysis } \\
\text { Value }\end{array}$ \\
\hline Power & $102 \%$ & $118 \%$ \\
Pressure, psia & 2204 & 2250 \\
Inlet Temperature, ${ }^{\circ} \mathrm{F}$ & 564.5 & 559 \\
Assembly Coolant Flow & {[]$^{(\mathrm{a}) \mathrm{A}}$} & {[]$^{(\mathrm{a})}$} \\
Guide Thimble Flow & {[]$^{(\mathrm{a})}$} & {[]$^{(\mathrm{a})}$} \\
\hline
\end{tabular}

[]$^{(a)}$ Denotes Westinghouse proprietary data.

TABLE 4-3

Host Plant Fuel Power Factors

\begin{tabular}{|lc||}
\hline Core power, $\mathrm{MW}_{\text {th }}$ & 3411 \\
Core ALHGR @ $100 \%(\mathrm{~kW} / \mathrm{ft})$ & 5.45 \\
Direct moderator heating & $2.6 \%$ \\
Core $\mathrm{F}_{\mathrm{dh}}$ Limit & $1.60-1.65^{\mathrm{B}}$ \\
\hline
\end{tabular}

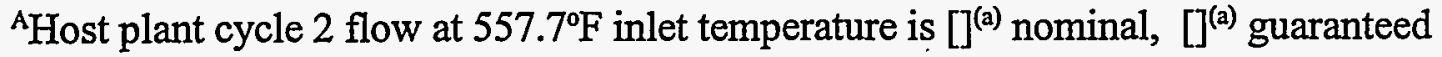
minimum.

${ }^{B}$ Dependent on results of best estimate LOCA analysis. TPBAR analysis supports $\mathrm{F}_{\mathrm{dh}}$ of 1.65 . 
PNNL-11419, Rev. 1

March 12, 1997

TABLE 4-4

Thermal and Hydraulic Comparison Table

\begin{tabular}{|c|c|c|}
\hline Design Parameters & $\begin{array}{l}\text { Host Plant } \\
\text { w/o LTA }\end{array}$ & With LTAs \\
\hline Reactor core heat output, $\mathrm{MW}_{\mathrm{t}}$ & 3,411 & No change \\
\hline Reactor core heat output, $10^{6} \mathrm{Btu} / \mathrm{hr}$ & $11,641.7$ & No change \\
\hline Heat generated in Fuel, \% & 97.4 & No change \\
\hline System Pressure, nominal, psia & 2,250 & No change \\
\hline System pressure, minimum steady state, psia & 2,204 & No change \\
\hline \multicolumn{3}{|l|}{ Coolant Flow } \\
\hline Total thermal flow rate, $10^{6} \mathrm{lb}_{\mathrm{m}} / \mathrm{hr}$ & 144.7 & No change \\
\hline Effective flow rate for heat transfer, $10^{6} \mathrm{lb}_{\mathrm{m}} / \mathrm{hr}$ & 131.7 & No change \\
\hline Effective core flow, gpm & 372,400 & No change \\
\hline Average flow per assembly, gpm & {[]$^{(a)}$} & No change \\
\hline Effective flow area for heat transfer, $\mathrm{ft}^{2}$ & 51.3 & No change \\
\hline Average velocity along fuel rods, $\mathrm{ft} / \mathrm{sec}$ & 15.4 & No change \\
\hline Average mass velocity, $10^{6} \mathrm{Ib}_{\mathrm{m}} / \mathrm{hr}-\mathrm{ft}^{2}$ & 2.57 & No change \\
\hline \multicolumn{3}{|l|}{ Coolant Temperature } \\
\hline Nominal inlet, ${ }^{\circ} \mathrm{F}$ & 559.0 & No change \\
\hline Average rise in vessel, ${ }^{\circ} \mathrm{F}$ & 58.4 & No change \\
\hline Average rise in core, ${ }^{\circ} \mathrm{F}$ & 63.5 & No change \\
\hline Average in core, ${ }^{\circ} \mathrm{F}$ & 592.5 & No change \\
\hline Average temperature in vessel, ${ }^{\circ} \mathrm{F}$ & 588.2 & No change \\
\hline \multicolumn{3}{|l|}{ Heat Transfer } \\
\hline Active heat transfer surface area, $\mathrm{ft}^{2}$ & 59,700 & No change \\
\hline Average heat flux, Btu/hr- $\mathrm{ft}^{2}$ & 189,800 & No change \\
\hline
\end{tabular}

[]$^{(a)}$ Denotes Westinghouse proprietary data. 
PNNL-11419, Rev. 1

March 12, 1997

TABLE 4-4

Thermal and Hydraulic Comparison Table

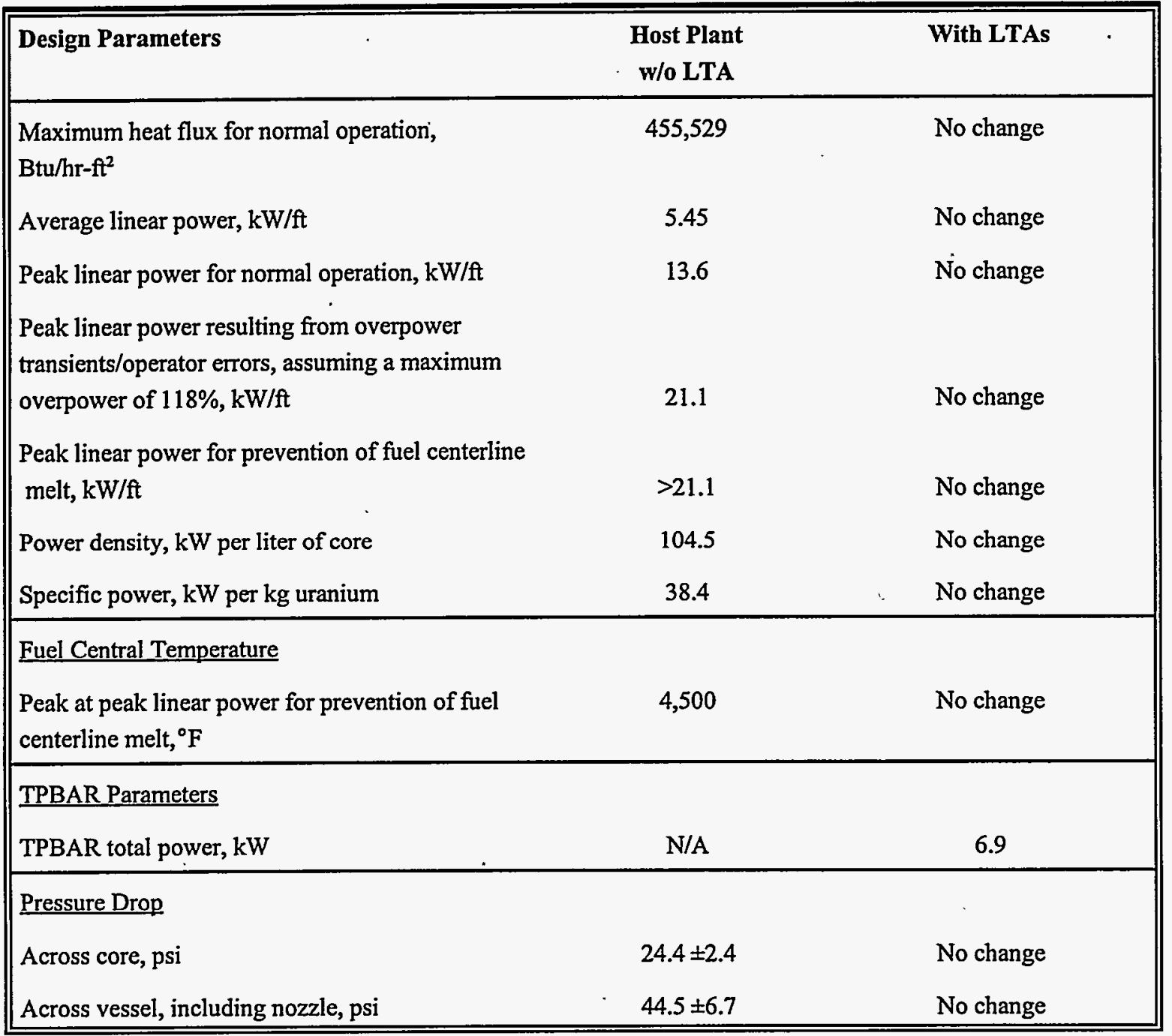


PNNL-11419, Rev. 1

March 12, 1997

\subsection{References}

4-1. WCAP-7113, Use of Burnable Poison Rods in Westinghouse Pressurized Water Reactors, October 1967.

4-2. WCAP-10377-A, Westinghouse Wet Annular Burnable Absorber Evaluation Report, October 1983.

4-3. Tennessee Valley Authority (TVA). 1994, 1995. Final Safety Analysis Report for Watts Bar Nuclear Power Plant. Docket Number 390/391, Chattanooga, Tennessee. 
PNNL-11419, Rev. 1

March 12, 1997

\section{MATERIALS}

The LTA materials are specified to ensure properties sufficient to meet functional requirements and to ensure material compatibility with other reactor components, reactor coolant, emergency core cooling fluids, fuel pool components, and fuel pool cooling systems. This chapter addresses materials specifications (Section 5.1), materials properties (Section 5.2), materials performance (Section 5.3), and nondestructive examination (Section 5.4).

\subsection{Materials Specifications}

The LTA is constructed of materials that have been chosen for their ability to perform successfully based on results from in-reactor and ex-reactor test programs, and for their compatibility with the other reactor internals, fuel assemblies, the reactor coolant system, fuel pool components, and fuel pool cooling systems. The LTA hold-down assembly (upper structure illustrated in Figure 2-1) is a Westinghouse component used in burnable poison rod assemblies (BPRAs) and is, therefore, not unique to the LTA. The materials of the TPBAR have been specified to reflect design characteristics suitable for the production and retention of tritium. Earlier tritium target rod designs were irradiated in the Advanced Test Reactor. Based on experience with those designs, material requirements for the tritium producing rods have continued to evolve. Numerous improved design features and materials have been incorporated into the TPBAR to ensure that the functional requirements will be met.

Quality standards for material selection, fabrication, handling, storage, and inspection are specified to ensure that important functions are maintained. To verify that materials are in compliance with specifications, materials and components are subjected to quality inspections by the vendor and by Pacific Northwest National Laboratory (PNNL). Certified Material Test Reports (CMTRs) are provided by the vendors for all TPBAR components.

\subsection{Materials Properties}

TPBAR cladding and component dimensions were specified to prevent interactions caused by thermal expansion, irradiation growth, and swelling. The cladding and components were designed to prevent excessive changes in dimensions that could result in degradation. The design is described in Chapter 2. 


\subsection{Materials Performance}

The key materials that enable a TPBAR to generate and store tritium are: 1) permeation-resistant 316 SS barrier-coated cladding and end plugs, 2) oxidation-resistant nickel-plated Zircaloy-4 getters, 3) lithium aluminate absorber pellets, and 4) Zircaloy-4 liner. Other materials include the ASTM 302 stainless steel (302 SS) spring and He gas. The opportunity for material degradation of the TPBAR is limited by the in-core residence period of one fuel cycle.

\subsubsection{Cladding and End Plug Material}

Type 316 stainless steel has been the material historically used for tritium target cladding, and the TPBAR has evolved from those designs. Type-316 SS with $20 \% \mathrm{CW}$ was specified to establish adequate strength while staying within the experience base established for 300-series SS.

Type 316 stainless steel ( $316 \mathrm{SS}), 20 \%$ cold worked ( $20 \% \mathrm{CW}$ ), was specified for all TPBAR components that form the pressure boundary (cladding and end plugs) with the reactor coolant. Tubing used for fabricating TPBAR cladding is seamless (non-welded). When compared with Type 304 stainless steel (304 SS), which has been extensively used in PWRs for BPRA cladding and fuel cladding, 316 SS exhibits better general corrosion resistance and better resistance to pitting corrosion [Ref. 5-1]; higher resistance to transgranular stress corrosion cracking (TGSCC) [Ref. 5-2] and to intergranular stress corrosion cracking (IGSCC) in aggressive environments [Ref. 5-3]; and greater strength and resistance to creep. Figure 5-1 shows that the allowable stress for the ASTM A 771 316 SS [Ref. 5-4] between 100 and $850^{\circ} \mathrm{F}$ is much higher than the allowable stress for 304 SS [Ref. 5-5].

\subsubsection{Coolant/316 SS Compatibility}

Experience in operating PWR and BWR plants with stainless steel cladding of fuel rods, control rods, and structural components (e.g., end plate castings and support grids) confirms that uniform corrosion of stainless steel is negligible, $<0.0001$ in./y [Ref. 5-6]. The cladding wastage in a CLWR due to uniform 
corrosion of the TPBAR external surface during 550 effective full power days (EFPD) is $<0.0003 \mathrm{in}$.

\subsubsection{Stress Corrosion Cracking}

Stress corrosion cracking (SCC) in 300-Series stainless steel requires: 1) thermal sensitization or irradiation-induced susceptibility; 2) high stresses (near or above the yield stress); and 3) an aggressive environment (e.g., reactive species such as $\mathrm{O}, \mathrm{Cl}$, and/or $\mathrm{F}$ in an aqueous medium at concentrations much higher than typical levels in PWR coolant; typical levels are $<5 \mathrm{ppb} \mathrm{O,}<50 \mathrm{ppb} \mathrm{Cl}$, and $<50 \mathrm{ppb} \mathrm{F}$ ). Each of these factors is described below.

\section{Material Susceptibility}

Thermal treatments in the temperature range of $800^{\circ} \mathrm{F}\left(425^{\circ} \mathrm{C}\right)$ to $1500^{\circ} \mathrm{F}$ $\left(815^{\circ} \mathrm{C}\right)$ have the potential to sensitize 304 or $316 \mathrm{SS}$. The process of applying an aluminide coating to the internal surface of TPBAR cladding requires temperatures within this range. Therefore, TPBAR cladding may be thermally sensitized.

Irradiation of 300 Series stainless steel to neutron fluence greater than 1 to $2 \times 10^{21} \mathrm{n} / \mathrm{cm}^{2}(\mathrm{E}>1 \mathrm{MeV})$ may decrease $\mathrm{Cr}$ concentrations at grain boundaries by promoting $\mathrm{Cr}$ diffusion away from the grain boundary region, thereby increasing the susceptibility to SCC [Ref. 5-7]. The peak neutron fluence expected for the TPBAR cladding is approximately $5 \times 10^{21} \mathrm{n} / \mathrm{cm}^{2}(\mathrm{E}>1 \mathrm{MeV})$. Therefore, TPBAR cladding may be subject to some reduction in grain boundary $\mathrm{Cr}$ during irradiation, resulting in irradiation-induced susceptibility.

$\underline{\text { Stress }}$

The TPBAR design inner pressure limit of 3000 psia is approximately $750 \mathrm{psi}(5.2 \mathrm{MPa}$ ) above the reactor system external pressure of $2250 \mathrm{psia}$ (15.5 MPa). Therefore, the tensile hoop stresses from internal 
pressurization remain very low throughout the period of irradiation. Irradiation-induced swelling of the pellets and irradiation growth of the getters are insufficient to stress the cladding. The absorber pellets generally do not fracture during irradiation, but if a pellet fractured, localized stresses in the cladding due to interaction of the cladding with pellet fragments would be prevented by the intervention of the getter, which confines the absorber pellet material. The thin walls of the absorber pellets, nominally 0.040 in., will prevent mechanical damage from interaction between pellets and cladding, such as could result from fracturing of solid absorber pellets or fuel. The stress in the TPBAR cladding is insufficient to cause or propagate SCC.

\section{Environment}

The external operating environment for the TPBAR during irradiation will be standard PWR coolant maintained within Technical Specification chemistry limits for oxygen and reactive compounds. Austenitic stainless steel is not considered susceptible to SCC in this environment [Ref. 5-7 and 5-8]: Severely sensitized stainless steels do not undergo any intergranular attack in Westinghouse PWR coolant environments [Ref. 5-11 and Ref. 5-12]. Issues such as boiling, crevices, highly borated solutions, and stagnant flow that can result in more severe environmental conditions are not present in the TPBAR operating environment.

During reactor shutdown and cooldown the TPBAR cladding is not susceptible to SCC because the temperature is below $200^{\circ} \mathrm{F}\left(90^{\circ} \mathrm{C}\right)$ and the stresses are low. Experience with SS-clad spent nuclear fuel at temperatures below $200^{\circ} \mathrm{F}\left(90^{\circ} \mathrm{C}\right)$ has shown that for storage periods up to 25 years, there is no measurable degradation of stainless steel cladding in pool water typical of PWR spent fuel pools.[Ref. 5-9].

Type 304 stainless steel has been used extensively and successfully as cladding for BPRA rods, an application very similar to TPBAR cladding. Barrier-coated 
316 stainless steel clad target rods were irradiated in the Advanced Test Reactor (ATR). Three rods were irradiated in static water capsule tests and eight rods were irradiated in a flowing water loop test (see Chapter 2, Table 2-5 regarding these tests). Coolant conditions for the loop test were approximately representative of commercial PWR conditions. No mechanical failure of the test rods occurred during the experimental irradiations. There have been no indications of mechanical failure during water storage of the test rods over the last five years. The WC-1 capsule test rod was irradiated for 281 EFPD with 222 EFPD accumulated at test goal temperatures and pressures. Extensive visual and metallographic examinations performed for the WC-1 test rod showed that the cladding and end-plugs (including the weld heat affected zone) were in excellent mechanical condition and showed no signs of cracking or other mechanical deterioration. Puncture tests have recently been performed on four of the irradiated test rods (three LOOP-1 rods and the B-1 capsule test rod) in order to analyze gases in the rods. All four rods were found to be pressurized after five years of storage. Since the mechanical design of the TPBARs is similar to that of the tested rods, it can be reasonably expected that TPBARs will have similar mechanical stability.

In summary, although the TPBAR material may become sensitized or susceptible, SCC is not anticipated because:

- The TPBAR has very low tensile stress.

- PWR reactor coolant chemistry control program ensures a nonaggressive environment [Ref. 5-7 and Ref. 5-12]. There are no special environmental conditions that will promote SCC (e.g., stagnant coolant, crevices, etc:).

- The TPBAR will only be resident in the reactor for one cycle of plant operation.

- No SCC problems have been identified for stainless steel clad BPRA rods extensively used in PWRs. 
PNNL-11419, Rev. 1

March 12, 1997

- No mechanical failures have occurred in 316 stainless steel clad ATR test rods.

\subsubsection{Effect of Barrier Coating on Cladding Performance}

The strength of the barrier-coated cladding is adequate to prevent collapse of the cladding at the beginning of life (BOL) before a TPBAR has generated sufficient internal pressure to support the external coolant pressure.

\subsubsection{Results of Cladding Burst Tests}

Cladding burst tests were conducted to support evaluation of cladding performance under design basis accidents. The results shown in Figure 5-2 indicate that the burst stresses and temperatures for uncoated $20 \% \mathrm{CW}$ tubing and for coated cladding are indistinguishable. Therefore, burst tests conducted on $20 \% \mathrm{CW}$ tubing (or on heat-treated cladding that simulates the coating process) are applicable to barrier-coated cladding used in TPBARs.

For the operating design pressure of 3000 psia, the hoop stress at $1500^{\circ} \mathrm{F}\left(815^{\circ} \mathrm{C}\right)$ is $43,800 \mathrm{psi}$ (302 $\mathrm{MPa}$ ). These pressure-temperature conditions approach the cladding breach curve presented in Figure 5-2. These results indicate that $1500^{\circ} \mathrm{F}$ is a threshold temperature for burst of TPBAR cladding. In all of these burst tests, the cladding strain exceeded $6 \%$, considerably in excess of the $1 \%$ minimum strain design criterion to ensure adequate cladding ductility.

\subsubsection{Weld Qualification}

Containment of the internal contents is provided by welding plugs to each end of the TPBAR cladding. . Welding results in a sound metallurgical and structural joint between the end plug and the stainless steel cladding. The welding procedure specifies the requirements for qualification of the welding operator and the welding process parameters to produce weldments that meet specifications. Testing for weldment quality is performed in accordance with ASTM E2 for 
metallographic examination, ASME requirements for He leak testing, internal PNNL specifications, and radiographic examination.

The TPBAR end plugs are attached to the cladding using an autogenic (no filler metal added) weld process; therefore, the conditions of Regulatory Guide 1.31 [Ref. 5-10] do not apply.

\subsubsection{Hydrogen Isotope Permeation}

The cladding inner surface is aluminized to limit the permeation of tritium through the cladding into the reactor coolant and the permeation of hydrogen from the coolant into the TPBAR. This is accomplished by application of an aluminized barrier on the inner surface of the cladding.

\subsubsection{Materials Compatibility}

The TPBAR materials do not interact chemically below their melting temperatures. The stainless steel cladding provides structural strength to withstand reactor irradiation, flow, pressure, and temperature conditions. Inreactor and ex-reactor test results indicate that the aluminide barrier will not peel or blister.

In the abnormal event of a TPBAR becoming water-logged from a cladding breach, aluminum, chlorine, suspended solids, tritium, and helium would be released by dissolution of the aluminide barrier on the inner surface of the cladding. A very small quantity of nickel contained in the getter will dissolve when exposed to reactor coolant. For simultaneous breach of 32 TPBARs, the maximum concentrations released to the reactor coolant are predicted to occur between 200 and 300 hours following the breach. The maximum contributions are orders of magnitude below the RCS chemistry limits for the host plant. Therefore, cladding breach of 32 TPBARs would have no impact on the chemistry of the reactor coolant. An assessment of the impacts of tritium release to the reactor coolant is presented in Chapter 6 . 
PNNL-11419, Rev. 1

March 12, 1997

\subsubsection{Pencils}

The TPBAR's main internal subassemblies, shown in Figure 2-2, are a stack of subcomponents, referred to as "pencils." The getters provide the outer structure for the pencils. The pencils are coined on the ends to confine the absorber pellets, but are not hermetically sealed.

\subsubsection{Absorber Pellets}

Within each pencil is a stack of right cylindrical high density, annular, lithium aluminate $\left(\mathrm{LiAlO}_{2}\right)$ absorber pellets enriched with ${ }^{6} \mathrm{Li}$. The nominal ${ }^{6} \mathrm{Li}$ loading is $0.0247 \mathrm{~g} / \mathrm{in}$., but higher or lower loadings of ${ }^{6} \mathrm{Li}$ are accommodated. The physical properties of absorber pellets are insensitive to the ${ }^{6} \mathrm{Li}$ content. The absorber pellets are ceramic and have a melting point of $3182^{\circ} \mathrm{F}\left(1750^{\circ} \mathrm{C}\right)$, a temperature that is not expected to be reached . during normal operating or design basis accident conditions.

\subsubsection{Absorber Pellet Mechanical Properties}

Characteristics that affect pellet mechanical performance include strength, density, irradiation, swelling, and gas release. The absorber pellets are resistant to thermal shock. Thermal shocking of the pellets by ramping from ambient temperature to $1652^{\circ} \mathrm{F}\left(900^{\circ} \mathrm{C}\right)$ within two minutes did not have an observable effect on microstructure or strength. The axial compressive fracture strength of absorber pellets is in the range of $80,000 \mathrm{psi}(550 \mathrm{MPa})$ to $130,000 \mathrm{psi}(900 \mathrm{MPa})$ at ambient temperature, as indicated in Figure 5-3. The increased fracture strength shown in Figure 5-3 for several pellets tested at $1652^{\circ} \mathrm{F}\left(900^{\circ} \mathrm{C}\right)$ was caused by the onset of high-temperature plasticity.

Pellets are capable of withstanding loads of 150 pounds per linear inch applied in the radial direction. The mechanical strength of the pellets supports the conclusion that they will withstand shipping and handling load requirements without damage. 


\subsubsection{Absorber Pellet Irradiation Performance}

As shown in Table 5-1, the absorber pellets evaluated by post-irradiation examinations (PIE) were intact after irradiation to 154 to 239 gas volume ratio ${ }^{\mathrm{A}}$ (GVR). Only minor microcracking, negligible grain growth, and small $(<1 \mu \mathrm{m})$ as-fabricated porosity was observed. Therefore pellet disintegration, major cracking, or redistribution is not expected below the TPBAR peak design goal of 215 GVR. Chapter 2 discusses the GVR expected during in-core residence.

Absorber pellets are insoluble and do not disintegrate in water. Therefore, in the event of a cladding breach, absorber pellets remain intact and ${ }^{6} \mathrm{Li}$ is not redistributed.

\subsubsection{Getter}

The pencils are enclosed by a getter tube of Zircaloy- 4 plated with nickel. The getter maintains a low tritium partial pressure by absorbing tritium as it is released from the absorber pellets. The nickel protects the Zircaloy- 4 from oxidation, thereby enhancing the absorption of tritium.

\subsubsection{Liner}

Absorber pellets generally do not fragment, but if fragments were generated, the Zircaloy- 4 liner provides additional assurance that the fragments will be confined. The liner functions to control oxygen and moisture by reacting with $\mathrm{T}_{2} 0$ and $\mathrm{H}_{2} \mathrm{O}$. Zircaloy-4 liners are insoluble in water and do not impact the reactor coolant in the event of a cladding breach.

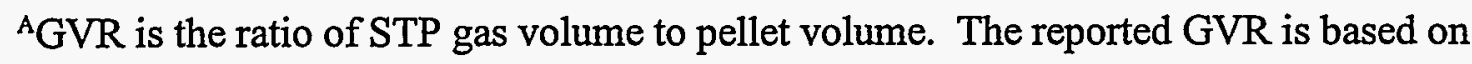
theoretical density. If based on actual density, the GVR value of 239 is revised to 216 GVR. 


\subsubsection{Plenum Subassembly and Getter Disk}

As illustrated in Figure 2-2, the plenum subassembly includes a 302 SS spring enclosed by a getter tube, with an upper getter disk attached to the lower end of the getter tube. The plenum subassembly is supported by the top pencil and prevents axial movement of the pencils during TPBAR shipping and handling. The spring is similar to springs in PWR fuel rods and BPRAs. Because the weld areas and the top and bottom end plugs are not coated, the upper getter tube and getter disk and the lower getter disk maintain low tritium pressure at the extremities of the TPBAR. These materials are insoluble in water.

\subsubsection{LTA Hold-Down Assembly}

The hold-down assembly (shown in Figure 2-1) is provided by Westinghouse and meets Westinghouse material specifications.

\subsection{Nondestructive Examination}

Nondestructive examination of tubular products and fittings shall be sufficient to ensure that the critical characteristics of the material meet specified acceptance criteria. TPBAR materials and components are inspected for compliance with specifications. Inspection methods range from standard visual inspections to discrete and unique methodologies sppecific to particular characteristics of a component.

While the internal components of each rod serve distinct functions for the production of tritium, the rod's cladding and end plugs form the pressure boundary between the TPBAR components and the reactor coolant system. The principal methods employed to examine the TPBAR cladding and end plugs are ultrasonic, eddy current, radiography, and He leak testing. Testing of the cladding and end plugs is conducted in conformance with applicable codes and standards. After application of the barrier coating, nondestructive examinations are performed to verify the acceptability of the barrier coating in terms of key parameters such as the coating thickness, coating integrity, and coating consistency. Table 5-2.identifies the nondestructive examination techniques and applicable standards used during TPBAR fabrication. Contamination of the TPBARs is minimized during assembly, and testing is performed prior to shipment to confirm that the specified cleanliness requirements are met. 


\subsection{Summary}

TPBAR materials are compatible with the range of conditions they will be subjected to and analysis shows they will perform satisfactorily during LTA irradiation. In the unlikely event that TPBAR internals are exposed to reactor coolant during operation, reactor coolant chemistry limits are still met. Accordingly, it can be concluded that the TPBAR LTAs will not: increase the probability of occurrence or the consequences of accidents previously evaluated; increase the probability of malfunctions of equipment important to safety previously evaluated; create an accident or malfunction of equipment important to safety of a different type from those previously evaluated; nor reduce the margin of safety as defined in the bases for any technical specification at the host reactor. 
TABLE 5-1

Summary of Test Results for Lithium Aluminate Pellets Irradiated in the Advanced Test Reactor (ATR)

\begin{tabular}{|l|c|l|l|l|l|l||}
\hline \begin{tabular}{|} 
Pin \\
No.
\end{tabular} & $\begin{array}{l}{ }^{6} \mathbf{L i}, \\
\%\end{array}$ & $\begin{array}{l}\text { Life-Average } \\
\text { Calculated } \\
\text { Temp., }\end{array}$ & ${ }^{\circ} \mathbf{F}$ & GVR $^{\mathbf{A}}$ & $\begin{array}{l}\text { Pellet Stack } \\
\text { Elongation, } \\
\%^{\mathbf{B}}\end{array}$ & \begin{tabular}{l} 
Gaps Between $_{\text {Pellets }^{\mathbf{B}}}$ \\
\hline \multicolumn{7}{|c||}{$\begin{array}{l}\text { Observations from } \\
\text { Neutron Radiographs }\end{array}$}
\end{tabular} \\
\hline 11 & 50 & $773-864$ & 239. & 0.9 & none detected & pellets intact \\
\hline 12 & 50 & $773-864$ & 239 & 1.3 & none detected & pellets intact \\
\hline 19 & 95 & $994-1167$ & 154 & 0.9 & none detected & axial crack in one pellet \\
\hline 20 & 95 & $994-1167$ & 154 & 1.3 & none detected & pellets intact \\
\hline 25 & 25.1 & $794-836$ & 165 & 0.9 & none detected & pellet intact \\
\hline 26 & 25.1 & $794-836$ & 165 & 0.9 & none detected & pellets intact \\
\hline \hline
\end{tabular}

A GVR was based on theoretical density. GVR based on actual pellet density is approximately $10 \%$ lower (216 GVR for pins 11 and 12).

${ }^{B}$ Determined by neutron radiography. 
TABLE 5-2

Nondestructive Testing Techniques and Applicable Standards for Acceptance of TPBAR and TPBAR Components

\begin{tabular}{|l|l|l|l||}
\hline TPBAR Component & \multicolumn{1}{|c|}{ Method } & \multicolumn{1}{|c||}{$\begin{array}{c}\text { Applicable } \\
\text { Standard }\end{array}$} & \multicolumn{1}{|c||}{ Characteristic } \\
\hline \multicolumn{3}{|c||}{ Nondestructive Tests Performed by PNNL } \\
\hline Coated Cladding & $\begin{array}{l}\text { Eddy Current } \\
\text { A }\end{array}$ & & $\begin{array}{l}\text { Coating thickness, } \\
\text { uniformity of thickness } \\
\text { along the tube, and inter- } \\
\text { metallic phases }\end{array}$ \\
\hline $\begin{array}{l}\text { Final TPBAR } \\
\text { Assembly }\end{array}$ & Radiography & NE-F3-10 ${ }^{\text {B }}$ & $\begin{array}{l}\text { Welds, component } \\
\text { placement }\end{array}$ \\
\hline $\begin{array}{l}\text { Final TPBAR } \\
\text { Assembly }\end{array}$ & Helium Leak Test & $\begin{array}{l}\text { ASME B\&PV, } \\
\text { Section V, }\end{array}$ & $\begin{array}{l}\text { Rod cladding integrity } \\
\text { (leak tightness) }\end{array}$ \\
\hline Article 10 & Nondestructive Tests Performed by Subvendors \\
\hline 316 SS Bar Stock & Ultrasonic & ASTM E213-93 & Defects \\
\hline 316 SS Bar Stock & Liquid Penetrant & ASTM E165-95 & End defects \\
\hline Cladding tubing & Ultrasonic & ASTM E213-93 & Wall thickness, flaws \\
\hline $\begin{array}{l}\text { Plated getters (tubes } \\
\text { and disks }\end{array}$ & $\begin{array}{l}\text { X-ray } \\
\text { spectrometry }\end{array}$ & ASTM B568-91 & $\begin{array}{l}\text { plating thickness and } \\
\text { coverage }\end{array}$ \\
\hline
\end{tabular}

${ }^{\text {AAll }}$ personnel performing acceptance inspections will be certified to ASNT-TC-1A.

${ }^{B}$ DOE specification developed for fast breeder reactor program. 
PNNL-11419, Rev. 1

March 12, 1997

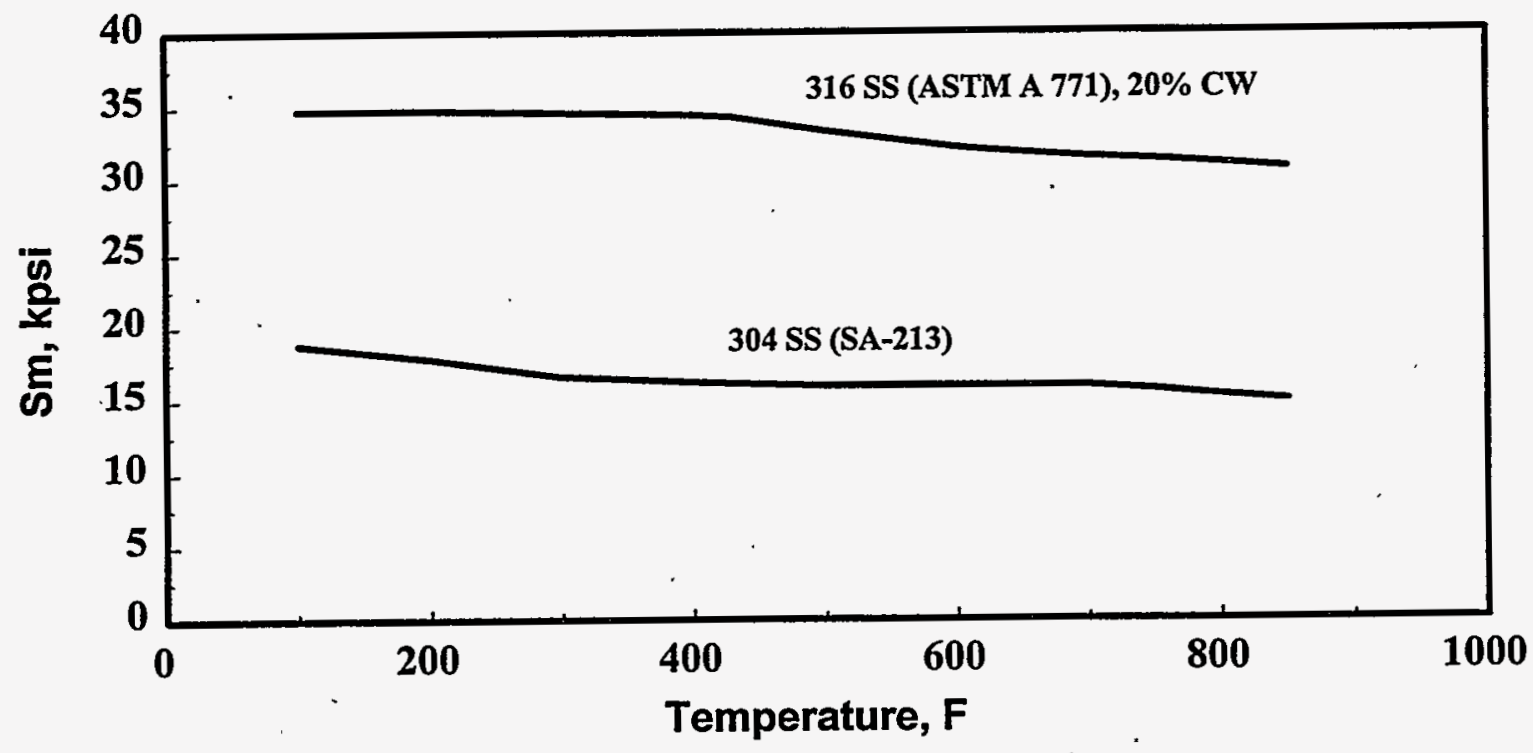

Figure 5-1 Comparison of Sm (ASME Code Allowable Stress) Values. ${ }^{\text {A }}$

A304SS (SA-213) [Ref. 5-5] and 20\% CW 316SS (ASTM A 771) [Ref. 5-4]. 
PNNL-11419, Rev. 1 March 12, 1997

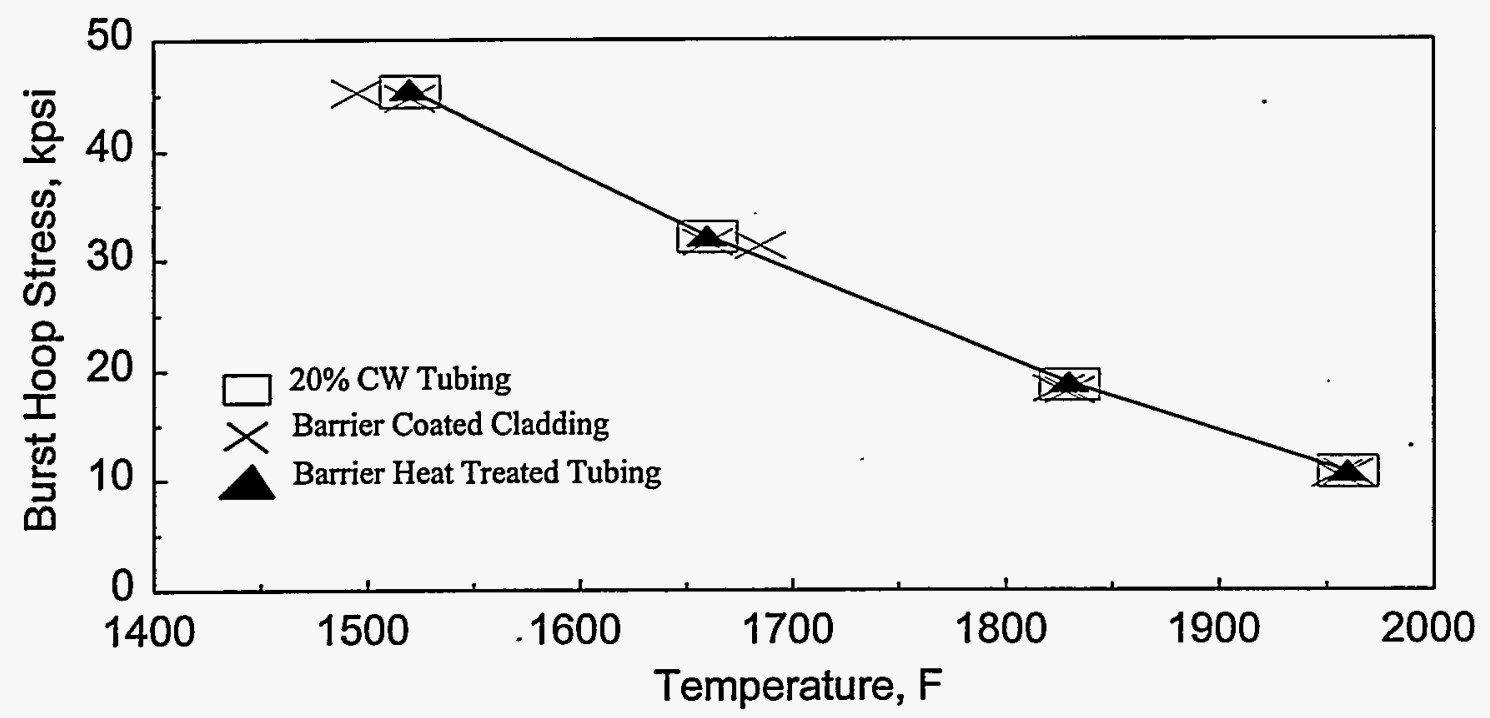

Figure 5-2 Effect of Temperature on Cladding Burst for 20\% CW 316SS Tubing, Barrier-Coated Cladding, and Cladding Heat Treated to Simulate the Coating Process 
PNNL-11419, Rev. 1

March 12, 1997

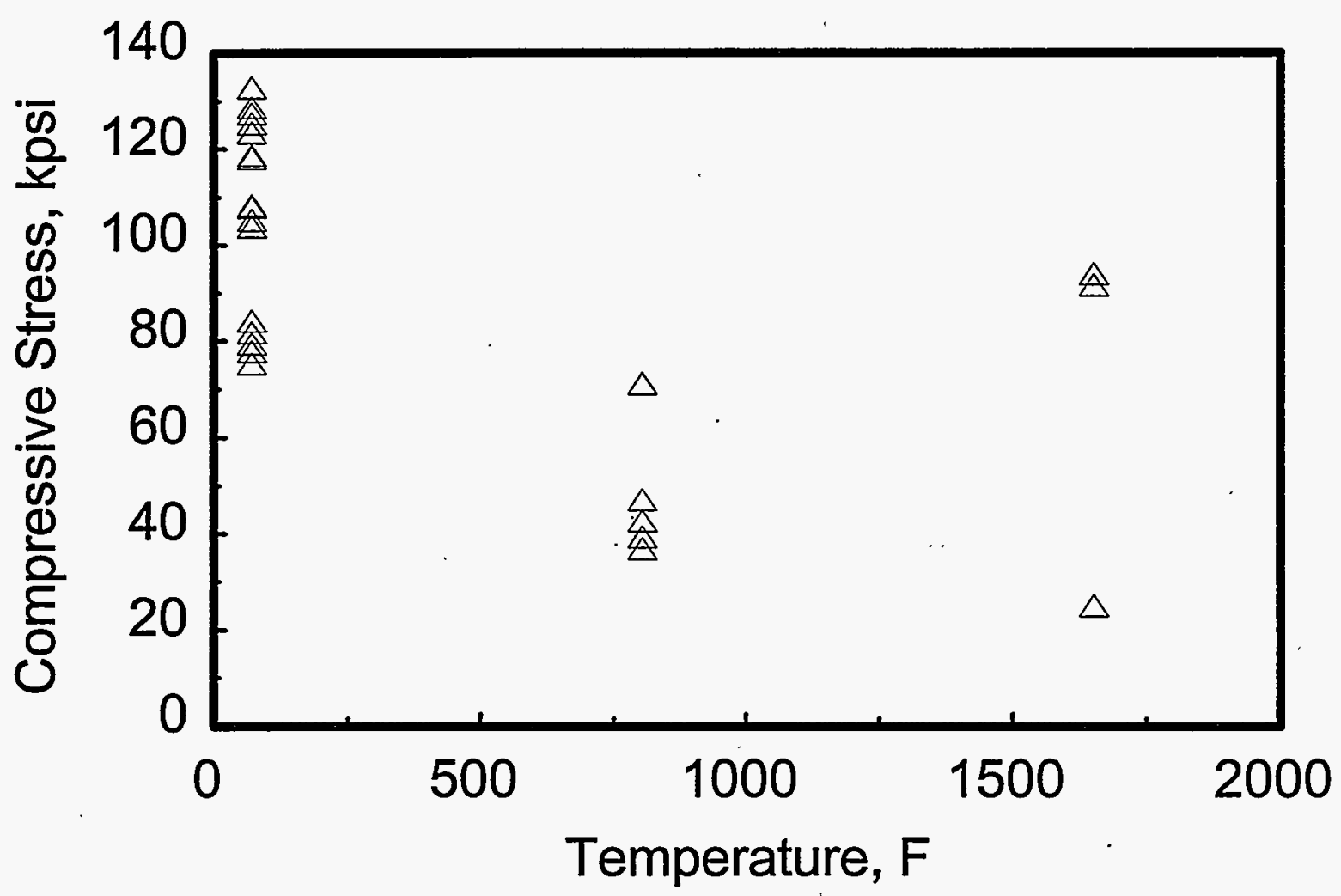

Figure 5-3 Compressive Stress to Crush 0.040-in.-Thick Absorber Pellets 


\subsection{References}

5-1. Bruemmer, S.M. 1989. "Grain Boundary Chemistry and Intergranular Failure of Austenitic Stainless Steels." Material Science Forum. Vol. 46, pp 309-334. Trans. Tech Publications, Switzerland.

5-2. Jones, R.H. and S.M. Bruemmer. 1989. "Assessment of Stress-Corrosion Cracking in a Water-Cooled ITER." In the Sixth Semiannual Progress Report on Fusion Reactor Materials. DE91 005517. Department of Energy. Washington, D.C.

5-3. Scott, P. 1994. "A Review of Irradiation Assisted Stress Corrosion Cracking." J. Nucl. Mater. 211:101-122. Elsevier Science B.V.

5-4. ASTM. 1988. Standard Specification for Austenitic Stainless Steel Tubing for Breeder Reactor Core Components. ASTM A 771-88. American Society for Testing Materials. Philadelphia, Pennsylvania.

5-5. ASME. 1995. ASME Boiler \& Pressure Vessel Code. The ASME. New York

5-6. Strasser, A., et al. 1982. An Evaluation of Stainless Steel Cladding for Use in Current Design LWRs. NP-2642. Electric Power Research Institute. Palo Alto, California.

5-7. Scott, P. 1994. "A Review of Irradiation Assisted Stress Corrosion Cracking," Journal of Nuclear Materials, 211:101-122.

5-8. USNRC. 1984. Report of the U.S. Nuclear Regulatory Commission Piping Review Committee. Investigation and Evaluation of Stress Corrosion Cracking in Piping of Boiling Water Reactors. NUREG-1061, Vol. 1. U.S. Nuclear Regulatory Commission, Washington, D.C.

5-9. Cunningham, M.E., E.R. Gilbert, A.B. Johnson, Jr., and M.A. McKinnon. 1996. Evaluation of Expected LWR Stainless Steel-Clad Fuel Behavior in Long-Term Dry Storage. EPRI-TR-106440. Electric Power Research Institute. Palo Alto, California. 
PNNL-1 1419, Rev. 1

March 12, 1997

5-10. NRC. 1978. Control of Ferrite Content in Stainless Steel Weld Metal. Regulatory Guide 1.31. U.S. Nuclear Regulatory Commission. Washington D.C.

5-11. Tennessee Valley Authority (TVA). 1994, 1995. Final Safety Analysis Report for Watts Bar Plant. Docket Number 390/391, Chatanooga, Tennessee.

5-12 Golik, M.A. 1971. Sensitized Stainless Steel in Westinghouse PWR Nuclear Steam Supply Systems. WCAP-7735 (NP), Westinghouse Electric Corporation, Pittsburgh, Pennsylvania. 
PNNL-11419, Rev. 1

March 12, 1997

\section{OPERATIONAL IMPACTS OF LTAS}

This chapter addresses the performance of the LTA during normal operations (Section 6.1), refueling operations (Section 6.2), off-normal events (Section 6.3), and accidents (Section 6.4). Conclusions are stated in the summary (Section 6.5).

\subsection{Normal Operations}

An objective of the LTA program is to validate tritium production and demonstrate adequate retention within the TPBAR. However, a small quantity of tritium is expected to be released from the rods to the primary coolant system. The TPBAR design goal of $<6.7 \mathrm{Ci} / y e a r$ for a single TPBAR correlates to an annual tritium release to the reactor coolant system (RCS) of $214 \mathrm{Ci}$ for the LTA core (up to 32 rods). For comparison, the maximum tritium inventory in the $\mathrm{RCS}$ of the host plant was $0.712 \mu \mathrm{Ci} / \mathrm{g}$ during first year of the current operating cycle (Cycle 1). As indicated in Figure 6-1, the maximum additional tritium inventory in the RCS resulting from a constant design goal release rate of tritium from all TPBARs would be $0.158 \mu \mathrm{Ci} / \mathrm{g}$. Thus, at the design goal for tritium leakage, the LTA could be postulated to increase the tritium inventory in the RCS less than $25 \%$ at the host plant. Tritium releases are a small fraction of the total offsite exposures at a commercial light water reactor (CLWR) and the total exposures are themselves a small fraction of regulatory limits.

The movement of tritium in the primary coolant system was modeled for the host plant, using plant-specific data. Non-accident off-site doses from a water discharge were calculated using the equations and values given in the host plant's Offsite Dose Calculation Manual [Ref. 6-1].

Any tritium that is released from the TPBARs during normal plant operation enters the RCS and is distributed throughout the RCS and chemical volume control system, liquid radwaste system, and the gaseous radwaste system. The rate of this accumulation depends on the coolant system capacities and water volume exchanges associated with the plant's required water chemistry and soluble boron adjustments. The tritium released into the RCS is processed along with the rest of the coolant, and this evolution provides the avenue for the transport and release of tritium outside the RCS. 
A constant release from the TPBARs to the coolant was modeled to determine the amount of tritium in the RCS over the entire operating cycle for two reference cases. The actual operating case is based upon the expected operational practices of the host plant which removes boron (and consequently tritium) by simple dilution and discharges the excess water. The BTRS case is based upon the operational practices of other nuclear plants which reclaim boron using a boron thermal regeneration system (BTRS), thereby recycling tritium into the RCS. The BTRS case is studied as an upper bound for end-of-cycle RCS tritium concentration. Water additions to the RCS for boron concentration control and as makeup for leakage from the system were modeled specifically for each case to account for dilution of the tritium.

For the case modeled, the boron concentration increases from $948 \mathrm{ppm}$ to $994 \mathrm{ppm}$ over the first 52.2 days. The boron concentration decreases such that the boron concentration is reduced to 5 ppm after 439 days and the reactor coasts down for the remainder of the 495-day cycle. Water additions below $5 \mathrm{ppm}$ boron are only to make up for leakage from the system. The water addition rate used in the model is the maximum of 1 ) the water addition to control boron concentration, or 2) the water addition to make up for leakage, as calculated for each day in the cycle. The maximum water addition rate is $70 \mathrm{gal} / \mathrm{min}$. The resulting tritium concentration in the RCS for $214 \mathrm{Ci}$ of tritium released to the RCS at a constant rate over the first year is shown in Figure 6-1.

Because tritium decays by low energy $\beta(18.6 \mathrm{keV})$, it does not result in a radiation hazard to . plant personnel when contained within plant systems. Personnel exposures from LTAs will be controlled in the same manner as for burnable poison assemblies under the plant health physics program. Potential off-site doses during normal operation are evaluated below.

The total off-site dose from a chronic waterborne tritium release of $214 \mathrm{Ci}$ directly to the environment over one year is tabulated in Table 6-1 ("Normal Operation" condition). The dose to the maximum exposed individual (MEI) during normal operation is changed by a negligible amount over current total doses near the host plant site. The tritium dose during normal operation represents a small increment to the total dose allowed in normal operation to meet the as low as reasonably achievable (ALARA) reference value of a $3 \mathrm{mrem}$ dose from liquid effluents per 10 CFR 50 Appendix I. 
Liquid effluent releases are limited to a tritium concentration of $1 \times 10^{-3} \mu \mathrm{Ci} / \mathrm{mL}$ in $10 \mathrm{CFR} 20$ Appendix B. At the host plant, releases at ten times the $10 \mathrm{CFR} 20$ value are allowed by Technical Specifications. The liquid releases are diluted at a minimum rate of $20,000 \mathrm{gpm}$ before being released to the river. The resulting peak tritium concentration of the effluent is $2.47 \times 10^{-5} \mu \mathrm{Ci} / \mathrm{mL}$ based on an annual release of $214 \mathrm{Ci}$.

\subsection{Refueling Operations}

It is expected that the LTAs will be shipped from the Westinghouse fuel fabrication facility directly to the host utility. In such a case, the method of shipment will be identical to shipment of burnable absorbers; that is, the LTAs will be inserted into fresh fuel assemblies, with the TPBARs in guide thimble locations, and both components will be shipped as a unit. No special shipping containers are required for the unirradiated LTAs. Westinghouse standard shipping containers for new fuel assemblies will be utilized, and the same acceleration limits that are imposed on new fuel assembly shipments will apply to the LTA/fuel assembly combination. Receipt of the LTA/fuel assembly combination at the utility will follow the utility's standard receiving, unloading and handling routines for burnable absorber and fuel assembly combinations.

Some potential exists that the LTAs will have to be assembled on-site. In this case, TPBARs, hold-down assemblies, and thimble plugs will be shipped to the site in suitable shipping containers. For TPBAR shipment, the same acceleration limits as for new fuel shipments are imposed to ensure that internal TPBAR components are not damaged. Procedures similar to those used by Westinghouse to assemble a burnable absorber will provide adequate controls to prevent TPBAR damage during assembly of the LTAs. Once assembled, the LTAs will be inserted into new fuel assemblies using the same tools, procedures, and inspections used for BPRAs.

Following irradiation, the LTAs will be loaded into shipping rigs that mimic the structural elements of a normal fuel assembly, but without fuel rods. The LTAs and shipping rigs will be transported in a shipping cask by DOE. 
PNNL-11419, Rev. 1

March 12, 1997

\subsubsection{TPBAR Assembly Storage in Fuel Pool or New Fuel Storage}

Prior to loading into the reactor, the LTA/fuel assembly combination will be placed in the utility's new fuel storage area or in the spent fuel pool. After irradiation, the LTAs will be stored in the spent fuel pool.

\subsubsection{Impact on Seismic Analysis of Racks}

The new and spent fuel storage racks are designed to meet plant-specific seismic standards for the protection of the fuel assemblies. The weight of an LTA, containing eight full-length TPBARS, is less than that of a fully populated (24 rods) burnable absorber or a rod cluster control assembly (RCCA) (see Section 6.4.1 for weight comparisons). Therefore, the existing seismic analysis of the fuel storage racks is valid for racks containing fuel assemblies with LTAs.

\subsubsection{Impact on Fuel Pool Heat Load}

The LTAs have no impact on the critical parameters affecting the spent fuel pool heat load. There is no discernible effect on the batch average energy release rate or the maximum local heat flux of the spent fuel assembly, nor on the fuel $\mathrm{rod} /$ water conduction film coefficient.

150 hours after reactor shutdown, the average fuel assembly decay heat is approximately $55 \mathrm{~kW}$. In comparison, the internal heat generation for an LTA (8 TPBARs) in the spent fuel pool is less than $0.024 \mathrm{~kW}$.

\subsubsection{On-Site TPBAR Assembly Movement and Handling}

Loading and shipping of the LTAs will be controlled in accordance with the plant's administrative policies and procedures. The equipment and tools normally used for movement and handling of fuel assemblies and burnable absorbers will be used for the movement and handling of the LTAs and LTA/fuel assembly combinations. No new or modified specific tooling will be required for handling of the LTAs. The external dimensions and materials of the LTAs are essentially identical to those of standard 
PNNL-11419, Rev. 1

March 12, 1997

BPRAs. The plant handling procedure for the burnable poison rod assembly handling tool contains a precaution stating that, if significant resistance is felt during removal, the assembly is either fully withdrawn or stuck, and visual verification of position must be made. The BPRAs are removed by a hand winch operated tool. There are no provisions for a load monitoring device to be attached to this tool. This tool is used to handle BPRAs containing as few as four full-length pins to as many as 24 full-length pins. The LTA weight is bounded by these conditions and no change to the procedure or handling equipment is warranted.

The shipping cask will contain a custom-built insert capable of receiving and holding the LTA as a complete unit. The insert will essentially duplicate the fuel assembly guide thimble geometries, as if the LTA were loaded inside a regular fuel assembly. The LTAs will be transferred to the shipping casks using the standard handling tools for burnable absorbers. A crane will be used to lift the cask in and out of the cask loading pit. Safe load paths and heights will be controlled in accordance with the plant's procedures, considering the bounds of their heavy loads evaluations.

\subsubsection{Occupational Exposure During Refueling}

During refueling, the tritium contained within the reactor coolant system as tritiated water is dispersed to the refueling cavity, fuel transfer canal, and spent fuel pool. The tritiated water evaporates to the air, resulting in a worker dose due to inhalation and skin absorption.

The annual occupational limits for tritium exposure are set in 10 CFR.20. The annual limit on intake (ALI) for tritium is set at $80 \mathrm{Ci}$ per individual. The ALI is the intake in a year by inhalation, ingestion, and/or skin absorption that will result in a committed effective dose equivalent to $5 \mathrm{rem}$. The derived air concentration (DAC) limit corresponding to the ALI limit is $2 \times 10^{-5} \mu \mathrm{Ci} / \mathrm{mL}$, assuming 2000 hours of exposure per year.

Evaporation of the tritiated water into the containment atmosphere just after the refueling cavity is flooded will create the highest concentration of tritium to which workers could be exposed. With worst-case conditions of $160^{\circ} \mathrm{F}$ water temperature, $100^{\circ} \mathrm{F}$ air 
temperature, and $100 \%$ humidity, the evaporation rate would be $407.3 \mathrm{~kg} / \mathrm{hr}$. Under expected conditions of $90^{\circ} \mathrm{F}$ water temperature, $70^{\circ} \mathrm{F}$ air temperature, and $75 \%$ humidity, the evaporation rate would be $34.8 \mathrm{~kg} / \mathrm{hr}$. Based on the design goal tritium leakage of less than $214 \mathrm{Ci} /$ year to the RCS, the resulting tritium air concentrations will not exceed the values presented in Table 6-2. Use of a BTRS would increase the refueling occupational doses by a factor of 1.6 over those in Table 6-2. The doses are higher in the BTRS case because the use of the BTRS limits the dilution of the tritium in the RCS. Because the exposure duration during refueling will be much less than 2000 hours, the additional occupational exposure to an individual under worst-case evaporation rate is not expected to exceed a few millirems even at design goal release rates. Note: The final boron curve for the host reactor second cycle has not been determined. However, the case modeled here results in 56 days coast down at the end of the cycle where no dilution occurs. As shown in Figure 6-1, the tritium concentration in the RCS builds during this period. Thus, the occupational doses evaluated here should be conservative relative to a cycle with a shorter coast-down period.

\subsection{Off-Normal Events}

No TPBAR failures are predicted during Condition I, II, III, and IV events, with the exception of a LBLOCA. Consideration of release of the entire inventory of tritium within a TPBAR is conservative.

\subsubsection{Impacts of TPBAR Absorber Relocation}

The absorber pellets will retain their original form throughout the irradiation cycle and are not subject to chipping or disintegration. No densification or significant phase changes of the absorber pellets are expected over the range of temperatures during Condition I, II, III, and IV events. Therefore, there is reasonable assurance that redistribution of absorber material is not a problem in the LTA (refer to Chapter 2 for analysis information). 
PNNL-11419, Rev. 1

March 12, 1997

\subsubsection{TPBAR Cladding Defects}

Past operating experience with the BPRA has been favorable. Since the advent of the BPRA, many improvements have been made in the use of SS cladding. The TPBAR uses a 316 SS material which is stronger and more corrosion resistant than the 304 SS material used in the BPRA rod (refer to Chapter 2 for analysis information). The TPBARs will be subject to tests and inspections to ensure that cladding defects do not occur.

As evaluated in Chapter 5, the amount of contaminants released to the RCS in the event of a TPBAR cladding defect will remain below normal chemistry limits and will not result in degradation of other components. In addition, the absorber pellets would lose a microscopic layer of $\mathrm{Li}$ to the coolant due to leaching. There is no loss of the absorber materials comparable to the $\mathrm{B}_{4} \mathrm{C}$ leaching from a WABA pellet.

\subsubsection{Radiological Consequences of a TPBAR Cladding Breach}

This section addresses the off-site doses and occupational exposure due to a TPBAR cladding breach.

\subsubsection{Off-Site Dose Consequences of a TPBAR Cladding Breach}

At the end of the irradiation cycle, each TPBAR is designed to contain $1.2 \mathrm{~g}$ of tritium, or approximately $11,544 \mathrm{Ci}$. Any tritium released from a failed TPBAR in the reactor under normal operating conditions will be captured in the reactor coolant and released to the environment over the cycle as a water discharge. Table 6-1 ("Cladding Breach" condition) presents the annual total body dose to the maximum exposed individual off-site with and without the release of the inventory of a breached TPBAR to the RCS. Even in the event of a breached TPBAR, the annual off-site exposure reference value of 3 mrem given in $10 \mathrm{CFR}$ 50 Appendix $I$ is not approached.

Based on the 20,000 gpm dilution at the host plant, the maximum effluent tritium concentration, using a constant release rate, would be $9.84 \times 10^{-4} \mu \mathrm{Ci} / \mathrm{mL}$. This 
concentration meets 10 CFR 20, Appendix B limits and the requirements of the host plant's Technical Specifications.

\subsubsection{Occupational Exposure Due to a TPBAR Cladding Breach}

The constant release of the tritium inventory of one TPBAR over the cycle would result in the occupational exposures during refueling given in Table 6-3. Use of a BTRS would increase the refueling occupational dose by a factor of 1.7 over those given in Table 6-3. The doses are higher in the BTRS case because the use of the BTRS limits the dilution of the tritium in the RCS. This system-specific difference represents the opposite ends of the spectrum relative to the dose . consequences from tritium releases. However, if the evaporation rate is less than $113 \mathrm{~kg} / \mathrm{hr}$, all of the tritium produced in a failed TPBAR could be released to the RCS without exceeding the $2000 \mathrm{hr}$ DAC limit.

\subsubsection{Inadvertent Loading and Operation of an LTA in an Improper Position}

TPBAR absorber pellet ${ }^{6} \mathrm{Li}$ loading errors are precluded by use of a single loading value for all pellets and administrative controls during fabrication of the TPBAR and TPBAR components. The LTAs are symmetrical, so there is no improper orientation. LTA loading errors are prevented by the same administrative procedures implemented by the host facility to prevent fuel assembly and burnable poison misloading. To preclude core misloading events, host utility procedures include confirmation of the final core configuration by videotaped documentation of the identification numbers of all fuel assemblies and baseplate-mounted inserts (such as the LTAs). Loading of an LTA in the wrong fuel assembly is bounded by host facility analysis for "Inadvertent Loading of a Fuel Assembly into an Improper Position."

In the unlikely event that an LTA loading error occurs, the resulting power distribution effects will either be readily detected by the in-core moveable detector system or the perturbation in core power distribution will be sufficiently small to be acceptable within the specified fuel design limits. The thermal-hydraulic analysis described in Chapter 4 demonstrates that the LTA would not exceed TPBAR design limits even if it were loaded in the limiting fuel assembly in the core. 
PNNL-11419, Rev. 1

March 12, 1997

\subsubsection{Anticipated Transient Without Scram (ATWS)}

The approach to the treatment of ATWS events for currently licensed PWRs is established in 10 CFR 50.62 in the form of prescriptive design requirements. The prescriptive design requirements of 10 CFR 50.62 are not explicitly applicable to the design of the TPBARs. During the consideration of ATWS events that formed the basis for $10 \mathrm{CFR} 50.62$, reactor coolant system (RCS) maximum pressures attained during the course of an ATWS and the potential for RCS failure were the principal concerns. TPBARs could affect maximum RCS pressures attained during an ATWS only by affecting the reactivity assumptions in the ATWS analysis. The cross-section of the ${ }^{6} \mathrm{Li}$ absorber is not particularly sensitive to temperature variations, and has no resonance behavior that could adversely affect reactivity assumptions during an ATWS.

Accordingly, the TPBAR mimics the neutronics behavior of conventional burnable absorber rods during a postulated ATWS event and has no impact on the existing ATWS neutronics analysis. Therefore, compliance with the requirements of 10 CFR 50.62 will continue to be sufficient to address postulated ATWS events.

\subsection{Accidents}

This section addresses the effects of a TPBAR on postulated accidents such as a dropped TPBAR assembly during refueling, TPBAR damage and radiological consequences during a design basis loss of coolant accident (LOCA), and off-site doses during accidents involving the release of reactor coolant (e.g., steam generator tube rupture). Accident off-site doses are calculated using the methods in the host plant FSAR.

\subsubsection{Impacts of a Dropped LTA}

The degree of shielding provided by the water level in those areas where the LTA will be moved or stored is the same as for spent fuel assemblies. The established minimum water depth above the spent fuel ensures adequate radiation shielding.

The TPBAR external features are the same as for a BPRA. The LTA is lighter than a fully rodded BPRA, and is not handled at any greater heights than other fuel insert 
components. The LTA with 8 TPBARs (2.26 lbs/TPBAR) and 16 thimble plugs weighs less than either the standard Westinghouse BPRA with 24 rodlets (1.8 lbs/rodlet) or the wet annular burnable absorber (WABA) with 24 rods $(1.9 \mathrm{lbs} / \mathrm{rod})$. Therefore, the impact of a dropped LTA on racks, spent fuel pool and fuel storage area is bounded by fuel assembly drop analyses.

At the spent fuel pool and refueling cavity water temperatures, a breached TPBAR will not release all of its tritium immediately. The tritium in the open pores of the pellet (tens of $\mathrm{Ci}$ ) will be released as soon as water comes in contact with the pellet. Further release, however, will not occur until the getters become saturated with hydrogen to the point of losing their structural integrity. Overall, the first signs of significant tritium release from the dropped TPBAR will not occur for approximately one to two years. This is adequate time to place the damaged LTA in a container that will prevent off-site releases.

\subsubsection{Impact of Design Tritium Leakage on Radiological Consequences of a Steam Generator Tube Rupture or Steam Line Break}

Analysis of the locked rotor Condition IV event demonstrates that the TPBAR will not fail during the event (locked rotor event as analyzed in Chapter 2). FSAR evaluation of the host plant's steam generator tube rupture (SGTR) and main steam line break events shows that RCS pressure and temperature conditions are less severe than those for the locked rotor event. Accordingly, TPBAR failure is not anticipated during a steam generator tube rupture or main steam line break.

As indicated in Figure 6-1, the maximum additional tritium concentration in the RCS resulting from a design goal release rate of tritium from all TPBARs would be $0.158 \mu \mathrm{Ci}$ tritium/g of water for the host plant. Assuming that $100 \%$ of the reactor coolant leakage through the ruptured tube is released to the environment, $8.9 \mathrm{Ci}$ would be released. Table 6-1 ("SGTR" condition) gives the off-site total body doses resulting from this event at the host plant with and without LTAs. The total body dose to an individual at the exclusion area boundary (EAB) would be essentially unchanged. These doses are less than the SRP acceptance criterion for either steam line break or SGTR. 


\subsubsection{Impacts of LTAs in the Event of a LOCA}

The potential for TPBAR failure during a design basis accident (DBA) is determined by the temperature and pressure of the TPBAR during the course of a postulated accident. As shown in Chapter 2, the TPBAR stresses remain acceptable during a design basis small break loss of coolant accident (SBLOCA) at the host reactor. For accident analyses described in the host plant's FSAR, maximum core temperatures occur in the large break loss of coolant accident (LBLOCA). Therefore, the LBLOCA represents the most limiting accident with regard to the potential for TPBAR failure.

\subsubsection{Impact on ECCS Performance}

Once the reactor is subcritical during a LBLOCA, the TPBARs will generate very little internal heat, thus limiting the potential for failure. However, the guide thimble and TPBAR are heated significantly by radiative heat transfer from the fuel pins while the core is uncovered. Because high values of cladding pressure stresses may occur during a LBLOCA at elevated temperature, there is some potential for the TPBAR cladding to rupture. Thermal-mechanical analysis of the TPBAR indicates that the TPBAR cladding will not burst if fuel temperatures during a LOCA do not exceed $1500^{\circ} \mathrm{F}$ (refer to Chapter 2 for analysis information).

10 CFR 50.46 requires that the emergency core cooling system (ECCS) for a commercial nuclear power plant meet the requirement that the peak fuel cladding temperature be held to less than $2200^{\circ} \mathrm{F}$ during a LBLOCA. If fuel cladding temperatures at the regulatory limit of $2200^{\circ} \mathrm{F}$ during a LOCA are assumed, the TPBAR temperatures will become high enough to cause single point, localized TPBAR cladding failure or rupture. The host guide thimble containing the TPBAR may also fail at this localized point. During a design basis LOCA, similar fuel cladding failures are expected.

Fuel cladding and TPBAR failures may cause some minor flow blockage. Considerable experimental work on the effects of flow blockage has been conducted by the NRC [Ref. 6-3] and the nuclear industry [Ref. 6-4].

\subsection{1}


PNNL-11419, Rev. 1

March 12, 1997

NUREG-1230 concludes that based on large-scale testing, local flow blockages up to $62 \%$ produce an insignificant effect on core heat transfer, and indicates that a coolable core geometry can be maintained with $100 \%$ blockage of some, but not all, channels. On this basis, the failure of 32 TPBARs is not expected to prevent adequate core cooling.

\subsubsection{Impact on Combustible Gas Control}

Design requirements stipulate that the combustible gas control system be able to accommodate at least 5 times the metal-water reaction predicted by the ECCS analysis. The maximum amount of hydrogen potentially generated by TPBARs in LTAs does not measurably increase the hydrogen gas concentration assumed under accident conditions, which would remain below the design capability of the combustible gas control system.

TPBARs contribute to combustible gas inventory following a LOCA as a result of the zirconium-water reaction and also from tritium contained in the TPBAR. The addition of zirconium from four LTAs represents no increase in the zirconium over that contained in the cladding of the same number of WABA rods. Tritium is anticipated to be released into the reactor coolant as HTO or $\mathrm{T}_{2} \mathrm{O}$, not as a gas. On this basis, there is no increase in hydrogen concentration as a result of TPBAR tritium release. Nevertheless, if all TPBAR tritium were released as a gas, the resulting addition of $0.0142 \mathrm{lb}$-moles ( 38.4 grams) of tritium to combustible gas concentrations is insignificant compared to the $15 \mathrm{lb}$-moles of hydrogen that would be generated from the metal-water reaction for a typical core (based on the Regulatory Guide 1.7 assumption of 1.5 percent zirconium-water reaction).

\subsubsection{Radiological Consequences of LBLOCA with TPBAR Rupture}

The integrated release from the containment was calculated using the method outlined in the host plant's FSAR. The release of the entire 369,500 Ci end-ofcycle LTA inventory to the containment would change the off-site total body doses near the host plant by a negligible amount, as shown in Table 6-1 ("LOCA" condition). Thus, the release of the entire tritium inventory from the LTA 
TPBARs during a LBLOCA does not significantly change the calculated radiological consequences of the accident to off-site individuals, and remains within the guidelines of 10 CFR 100.

\subsubsection{Control Room Exposures Following a LOCA with TPBAR Rupture}

The limits for control room exposures are $30 \mathrm{rem}$ total to the thyroid, $5 \mathrm{rem}$ gamma dose, and 30 rem beta skin dose, per Standard Review Plan Section 6.4 [Ref. 6-5] to meet General Design Criteria 19 of 5 rem whole body [Ref. 6-6]. The 10 CFR 20 Appendix B DAC value was used to convert tritium exposure to an equivalent whole body dose. The $\mathrm{DAC}$ limit of $2 \times 10^{-5} \mu \mathrm{Ci} / \mathrm{mL}$ corresponds to a 5 rem dose for a 2000 hour exposure, and accounts for both inhalation and skin absorption. Thus, an activity concentration of $28.8 \mu \mathrm{Ci}-\mathrm{s} / \mathrm{mL}$ corresponds to a 1 rem dose.

The contribution to the dose received by the control room personnel from the release of the entire end-of-cycle LTA tritium inventory of 369,500 $\mathrm{Ci}$ has been evaluated using the methods outlined in the host plant FSAR. The integrated activity concentration of tritium in the control room thirty days after the release is $2.3 \mu \mathrm{Ci}-\mathrm{s} / \mathrm{mL}$ for the host plant. The resultant dose at the end of 30 days to a control room worker due to TPBAR tritium, using the occupancy factors given in the host plant FSAR, is $0.03 \mathrm{rem}$. Therefore, the contribution from the release of the entire LTA tritium inventory to the dose received by control room personnel is insignificant with respect to the contribution from the other radionuclides.

\subsection{Summary}

Conditions I, II, III, and IV events, with the exception of a LBLOCA do not pose a challenge to TPBAR integrity, and therefore no failures are expected. As indicated in the host plant's FSAR analyses, the postulated LBLOCA is the limiting Condition IV event for fuel damage and potential radiological consequences, and thus bounds the plant conditions for analyzing the potential degradation of the TPBARs. 
The evaluation of the TPBAR established the following:

- The design goal tritium release from the LTAs over the operating cycle will not exceed - regulatory limits for either occupational workers or the maximally exposed individual. (MEI) off-site.

- LTA storage, movement, and handling can be controlled per existing administrative policies and procedures with no adverse affects. In addition:

- $\quad$ The impacts of LTAs on the seismic analyses of the fuel storage racks are bounded by previous analyses.

- The heat contribution to the fuel pool from an irradiated LTA is negligible.

- $\quad$ No special handling tools or equipment are required.

- In the event of a TPBAR rupture during refueling, resultant doses to both occupational workers and the maximally exposed individual off-site are within regulatory limits.

- The impact of design goal TPBAR leakage on the radiological consequences of design basis steam generator tube rupture accidents or steam line break accidents do not exceed regulatory guideline values.

- Failure of all 32 TPBARs will not prevent core cooling or cause a difference in the behavior of the reactor during a LBLOCA.

- The radiological impact of failure of all 32 TPBARs during a LBLOCA will not exceed regulatory limits for off-site individuals or control room personnel.

- The contribution of failed TPBAR assemblies to combustible gas during a LOCA is negligible.

Accordingly, it can be concluded that the test irradiation of theTPBAR LTAs does not: increase the probability of occurrence or the consequences of accidents previously evaluated; increase the probability of malfunctions of equipment important to safety previously evaluated; create an accident or malfunction of equipment important to safety of a different type from those 
PNNL-11419, Rev. 1

March 12, 1997

previously evaluated; nor reduce the margin of safety as defined in the bases for any technical specification at the host reactor. 
PNNL-11419, Rev. 1

March 12, 1997

TABLE 6-1

Summary of Off-Site Radiological Consequences for the TPBARs in the Host Plant

\begin{tabular}{|c|c|c|c|c|}
\hline Condition & Receptor & $\begin{array}{l}\text { Current Total } \\
\text { Body } \\
\text { Dose }^{(A)} \text { (rem) }\end{array}$ & $\begin{array}{c}\text { Total Body } \\
\text { Dose with } \\
\text { LTA (rem) }\end{array}$ & Reference Value / Source \\
\hline Normal Operation & MEI $I^{(\mathrm{B})}$ & 0.000700 & 0.000700 & $\begin{array}{c}0.003 \text { rem / 10CFR50, } \\
\text { App. I }\end{array}$ \\
\hline Cladding Breach & MEI & 0.000700 & 0.000713 & $\begin{array}{c}0.003 \mathrm{rem} / 10 \mathrm{CFR} 50, \\
\text { App.I }\end{array}$ \\
\hline \multirow{2}{*}{ SGTR } & $\mathrm{EAB}^{(\mathrm{C})}$ & 0.863 & 0.863 & \multirow{2}{*}{$\begin{array}{c}2.5 \mathrm{rem} / \\
\mathrm{SRP} 15.6 .3\end{array}$} \\
\hline & $\operatorname{LPZ}^{(\mathrm{D})}(8 \mathrm{~h})$ & 0.200 & 0.200 & \\
\hline \multirow{2}{*}{$\begin{array}{l}\text { Fuel Handling Accident } \\
\text { (Containment) }\end{array}$} & $\mathrm{EAB}$ & 2.01 & 2.01 & \\
\hline & $\operatorname{LPZ}(2 \mathrm{~h})$ & 0.466 & 0.466 & \\
\hline \multirow{2}{*}{$\begin{array}{l}\text { Fuel Handling Accident } \\
\text { (Auxiliary Bldg) }\end{array}$} & $\mathrm{EAB}$ & 0.782 & 0.782 & \\
\hline & $\operatorname{LPZ}(2 \mathrm{~h})$ & 0.182 & 0.182 & \\
\hline \multirow{2}{*}{ LOCA } & $\mathrm{EAB}$ & 3.29 & 3.29 & \multirow{2}{*}{$\begin{array}{c}25 \mathrm{rem} / \\
10 \mathrm{CFR} 100\end{array}$} \\
\hline & LPZ (30 d) & 2.00 & 2.00 & \\
\hline
\end{tabular}

NOTES:

(A) The total body dose was calculated using the following equation: where:

Total Body Dose $=\gamma$ whole body dose $+\mathrm{w}_{\mathrm{T}} *$ Thyroid dose $+\mathrm{w}_{\beta}{ }^{*} \beta$ dose

$\begin{array}{lll}\mathrm{w}_{\mathrm{T}} & = & \text { Thyroid weighting factor from 10CFR20.1003 }(=0.03) \\ \mathrm{w}_{\beta}= & \text { Beta skin dose weighting factor }(=0.01) \text { from ICRP Publication } 60 \text { [Ref. 6-7] }\end{array}$ 
PNNL-11419, Rev. 1

March 12, 1997

TABLE 6-2

Refueling Occupational Exposures for a Constant Design Goal Tritium Release from Intact TPBARs

\begin{tabular}{|c|c|c|c|}
\hline \multicolumn{2}{|c|}{ Containment } & \multicolumn{2}{c|}{ Fuel Handling Area } \\
\hline $\begin{array}{c}\text { Expected Conditions } \\
(\% \text { of DAC) }\end{array}$ & $\begin{array}{c}\text { Worst-Case Conditions } \\
(\% \text { of DAC) }\end{array}$ & $\begin{array}{c}\text { Expected Conditions } \\
(\% \text { of DAC) }\end{array}$ & $\begin{array}{c}\text { Worst-Case Conditions } \\
\text { (\% of DAC) }\end{array}$ \\
\hline $0.05 \%$ & $0.70 \%$ & $0.01 \%$ & $0.15 \%$ \\
\hline
\end{tabular}

TABLE 6-3

Refueling Occupational Exposures

Assuming a Release of the Inventory of 1 TPBAR During the Cycle at a Constant Rate

\begin{tabular}{||c|c|c|c||}
\hline \multicolumn{2}{|c|}{ Containment } & \multicolumn{2}{c|}{ Fuel Handling Area } \\
\hline $\begin{array}{c}\text { Expected Conditions } \\
(\% \text { of DAC) }\end{array}$ & $\begin{array}{c}\text { Worst-Case Conditions } \\
\text { (\% of DAC) }\end{array}$ & $\begin{array}{c}\text { Expected Conditions } \\
(\% \text { of DAC) }\end{array}$ & $\begin{array}{c}\text { Worst-Case Conditions } \\
\text { (\% of DAC) }\end{array}$ \\
\hline $2.40 \%$ & $28.0 \%$ & $0.50 \%$ & $5.84 \%$ \\
\hline
\end{tabular}


PNNL-11419, Rev. 1

March 12, 1997

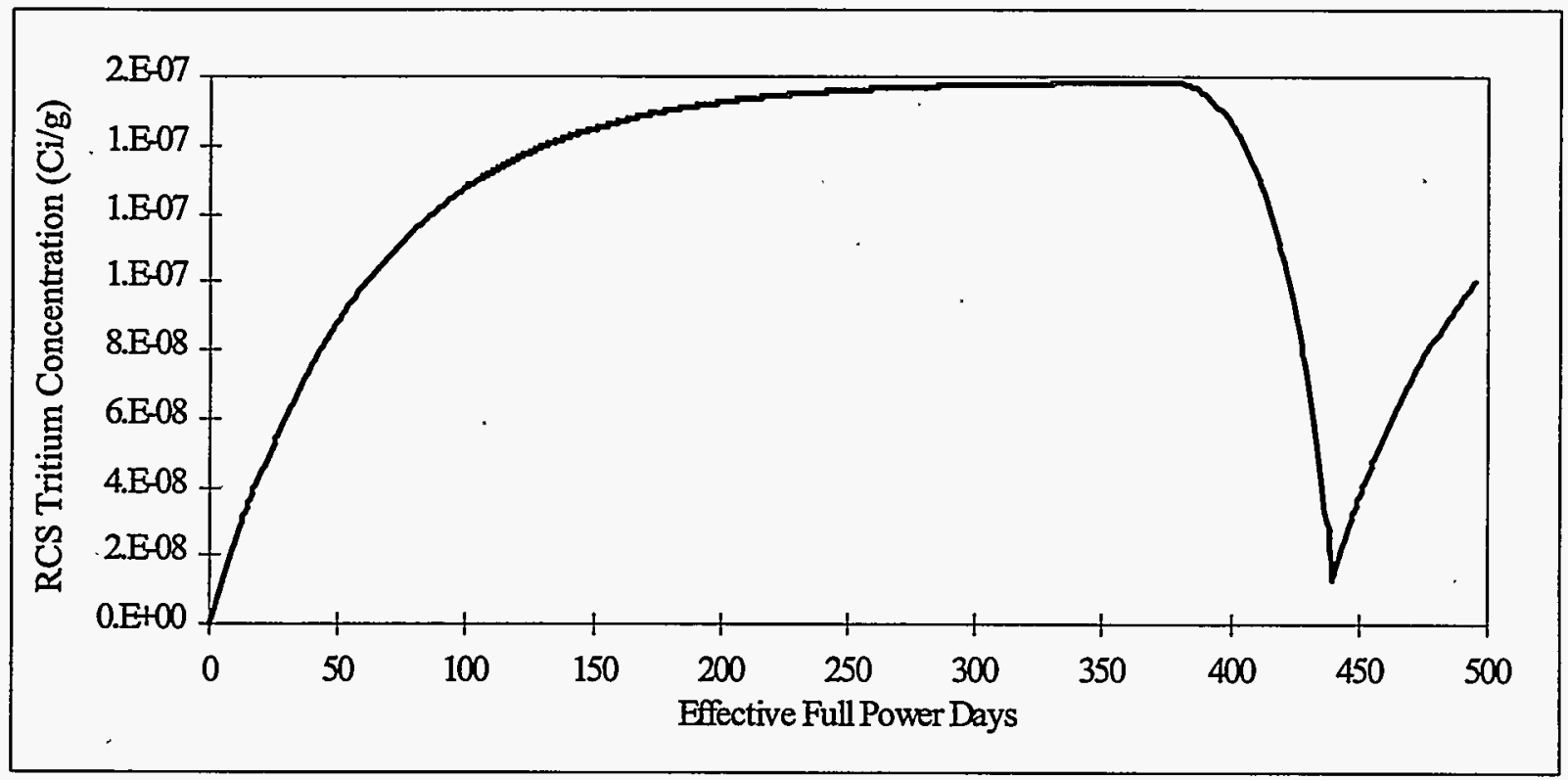

FIGURE 6-1 TPBAR Contribution to the RCS Tritium Concentration (assuming a constant tritium release rate) 


\subsection{References}

6-1. Watts Bar Nuclear Plant Plant Administrative Instruction PAI-4.01, "Offsite Dose Calculation Manual (ODCM)", Rev. 4. Tennessee Valley Authority, Chattanooga, TN.

6-2. [deleted]

6-3. Compendium of ECCS Research for Realistic LOCA Analysis, USNRC, NUREG-1230, April 1987.

6-4. PWR FLECHT SEASET 21-Rod Bundle Flow Blockage Task Data and Analysis Report, NRC/EPRI/Westinghouse Report No. 11, NUREG-CR-2444, EPRI NP-2014, WCAP9992, Volume 1.

6-5. NUREG-0800, "Standard Review Plan for the Review of Safety Analysis Reports for Nuclear Power Plants, LWR Edition," Section 6.4, "Control Room Habitability System."

6-6. 10 CFR 50 Appendix A, General Design Criteria 19, "Control Room."

6-7. ICRP Publication 60, 1990 Recommendations of the International Committee on Radiological Protection, published by Pergamon Press. 

PNNL-11419, Rev. 1

March 12, 1997

\section{QUALITY ASSURANCE}

In accordance with the host utility's NRC-accepted QA program [Ref. 7-1], the utility contractually requires PNNL and Westinghouse to establish, maintain, and implement a Quality Assurance program that meets the requirements of 10 CFR 50, Appendix B.

Due to their association with reactor fuel assemblies, the TPBARs are considered to be a part of a basic component as defined in 10 CFR Part 21. The TPBAR is important to safe and reliable operation, requiring the design and fabrication of TPBARs to be accomplished under a quality assurance program that complies with the requirements of 10 CFR 50, Appendix B. The appropriate quality assurance and $10 \mathrm{CFR}$ Part 21 requirements have been applied to the individual subcomponents of TPBARs to an extent commensurate with their importance to safety, and consistent with provisions of 10 CFR 50, Appendix B, Criterion II, Quality Assurance Program.

PNNL designs and fabricates TPBARs that meet or exceed established requirements in accordance with the PNNL Project Quality Assurance Plan. The PNNL Project Quality Assurance Plan establishes a systematic, disciplined, and uniform approach for activities affecting quality and provides a high degree of assurance against failure or malfunction, and without undue risk to the health and safety of the public.

Westinghouse is the fuel system supplier for the potential host reactors. As a service to the host utility, Westinghouse will qualify PNNL as an approved supplier for the design and fabrication of lead test assemblies in accordance with the NRC-approved Westinghouse Quality Management System (QMS) [Refs. 7-2 and 7-3]. This qualification includes evaluation of the PNNL Project Quality Assurance Plan and its implementation for compliance with 10 CFR 50, Appendix B, ASME NQA-1 Basic and Supplementary Requirements [Ref. 7-4] as delineated in the Westinghouse QMS.

Table 7-1 describes the responsibilities for quality activities and Figure 7-1 illustrates the quality assurance interfaces. 
PNNL-11419, Rev. 1

March 12, 1997

TABLE 7-1

CLWR Lead Test Assembly Program Responsibilities

\begin{tabular}{|c|c|}
\hline Party & Responsibility \\
\hline \multirow{2}{*}{$\begin{array}{l}\text { PNNL Project } \\
\text { Management }\end{array}$} & Establish and manage contract(s) for LTA irradiation. \\
\hline & $\begin{array}{l}\text { Establish and maintain a Quality Assurance Plan that meets the } \\
\text { requirements of } 10 \mathrm{CFR} 50 \text {, Appendix B. }\end{array}$ \\
\hline \multirow[t]{2}{*}{ PNNL QA } & Conduct management assessments and QA audits of PNNL activities. \\
\hline & Conduct QA audit/oversight of component and service suppliers. \\
\hline \multirow[t]{2}{*}{ PNNL Design } & Design LTA and perform design analyses. \\
\hline & Procure services as necessary to support design and analysis. \\
\hline \multirow[t]{2}{*}{ PNNL Fabrication } & Fabricate TPBARs. \\
\hline & Procure components and services to support fabrication. \\
\hline \multirow[t]{4}{*}{ Host Utility } & Identify applicable facility technical and quality requirements to PNNL. \\
\hline & $\begin{array}{l}\text { Conduct required safety reviews prior to irradiation, including Reload } \\
\text { Safety Evaluation. }\end{array}$ \\
\hline & $\begin{array}{l}\text { Conduct QA oversight of PNNL, Westinghouse, and sub-suppliers to } \\
\text { evaluate compliance with facility QA Program. }\end{array}$ \\
\hline & Conduct irradiation in accordance with facility operating license. \\
\hline
\end{tabular}


PNNL-11419, Rev. 1

March 12, 1997

TABLE 7-1

CLWR Lead Test Assembly Program Responsibilities

\begin{tabular}{|c|c|}
\hline Party & Responsibility \\
\hline \multirow[t]{6}{*}{ Westinghouse } & $\begin{array}{l}\text { Identify applicable Westinghouse technical and quality requirements to } \\
\text { PNNL. (Identify fuel assembly interface parameters and conditions.) }\end{array}$ \\
\hline & $\begin{array}{l}\text { Support PNNL by making code modifications and providing analysis } \\
\text { results (under contract directly with PNNL). }\end{array}$ \\
\hline & Assemble TPBARs with hold-down assemblies into LTAs. \\
\hline & Conduct core design and reload evaluation for the host utility. \\
\hline & $\begin{array}{l}\text { Qualify PNNL as an approved supplier for the LTA design and } \\
\text { fabrication. }\end{array}$ \\
\hline & $\begin{array}{l}\text { Conduct QA oversight of PNNL and sub-suppliers in accordance with } \\
\text { Westinghouse QA Program requirements for fuel assembly components } \\
\text { and host utility requirements. }\end{array}$ \\
\hline $\begin{array}{l}\text { Component / } \\
\text { Service Suppliers }\end{array}$ & $\begin{array}{l}\text { Meet } Q A \text { requirements for supplying components or services as } \\
\text { specified in contracts. }\end{array}$ \\
\hline
\end{tabular}


PNNL-11419, Rev. 1. March 12, 1997



CONTRACT

RELATIONSHIP

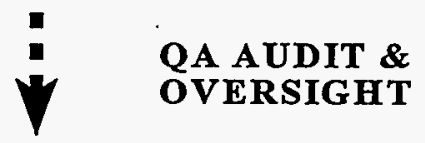

Figure 7-1 Quality Assurance Interfaces 
PNNL-11419, Rev. 1

March 12, 1997

\section{$7.1 \quad$ References}

7-1. TVA-NQA-PLN89-A, Tennessee Valley Authority's Nuclear Quality Assurance Plan accepted by NRC under Docket Nos. 390/391.

7-2. Westinghouse. 1996. "Quality Management System," Revision'1. Westinghouse Electric Corporation, Pittsburgh, PA.

7-3. NRC letter from Quality Assurance and Maintenance Branch, Division of Reactor Controls and Human factors, Office of Nuclear Reactor Regulation, to Westinghouse, dated February 23, 1996. Docket No. 99900900.

7-4. ASME. 1994. ANSI/ASME NQA-1 (1994), "Quality Assurance Program Requirements for Nuclear Facility Applications." American Society of Mechanical Engineers, New York, New York. 


\section{SAFEGUARDS AND SECURITY}

To protect DOE's investment, the host utility will account for each tritium-producing burnable absorber rod (TPBAR) and TPBAR lead test assembly (LTA) from receipt until off-site shipment. The TPBARs and some related documentation necessary to support the preparation of the host utility safety evaluation will be classified Confidential Restricted Data. As classified material and documents, they require safeguards measures to prevent diversion and/or unauthorized access to or disclosure of classified information.

\subsection{Materials Accountability}

TPBARS will be handled and protected the same as nuclear fuel. Each TPBAR will have a unique number engraved or etched on the top end plug. The TPBAR LTAs will be identified by a unique serial number on the hold-down assembly such as is currently used on fuel inserts. These serial numbers will be used in shipping documentation and irradiation records so that they can be tracked and accounted for.

A carrier who meets Department of Transportation requirements for shipment of nuclear fuel will be used for the transportation of the TPBARs to and from the site. The accountability and control of the TPBARs will be conducted consistent with the facility's administrative guidelines for handling of new and spent fuel and fuel inserts, and the special nuclear material accountability plan. Irradiation history will be provided to $\mathrm{DOE}$ to allow estimates of ${ }^{6} \mathrm{Li}$ conversion and ${ }^{3} \mathrm{H}$ production for accounting purposes, so that the utility need account for only the physical LTAs.

\subsection{Physical Security of Classified Hardware}

The TPBARs are visually unclassified; however, TPBAR internal characteristics are classified. Therefore, the TPBARs are considered classified material. No inspections other than visual will be allowed by personnel who have not been granted access to classified information.

The TPBARs will be brought to the site by a carrier approved by DOE who meets Department of Transportation requirements for shipment of nuclear fuel. Once inside the protected area, movement of the TPBAR LTAs will be monitored by personnel with DOE clearances. While the 
TPBAR LTAs are stored in the new fuel storage racks or in the fuel pool, a suitable level of physical protection will be provided by normal plant security measures meeting the requirements of 10 CFR 73, supplemented with escort by DOE-cleared personnel, when appropriate and necessary according to the plant procedures for handling of classified hardware (see discussion below). While the TPBAR LTAs are in the reactor with the reactor head bolted, they will be considered secure and no escort by $\mathrm{DOE}$-cleared personnel will be required.

\subsection{Control of Classified Documents and Hardware}

Under the requirements for a reactor operating license, the site must have a physical security plan meeting the requirements of 10 CFR Part 73 for physical protection of vital equipment and control of safeguards information. These requirements include a physical security organization, physical barriers, access controls, detection aids, communications, procedures for testing and maintenance of security equipment, and a safeguards contingency plan. Based on the facility meeting the requirements of $10 \mathrm{CFR}$ Part 73, the site will have to develop and implement procedures (under DOE assistance and guidance) only for the handling of classified hardware. Personnel will be granted access to classified information and hardware by DOE under 5 CFR 732 and 10 CFR 710 to meet Executive Orders 10450, 12958 [Ref. 8-1], and 12968 [Ref. 8-2]. These controls will meet or exceed those that would be required to meet 10 CFR Part 25 and 10 CFR Part 95 and shall be deemed to satisfy 10 CFR 50.37 requirements for licensee access to restricted data. In accordance with the memorandum of understanding between DOE and the NRC [Ref. 8-3], DOE has reached an agreement with the NRC that NRC licensees seeking access authorization from the DOE, based on their participation in the CLWR tritium program, do not require additional access authorization [Ref. 8-4]. The NRC has acknowledged this agreement and confirmed that conformance with DOE requirements relative to access authorization satisfies corresponding NRC requirements contained in 10 CFR Parts 25 and 95 as well as the facility operating license provisions contained in 10 CFR 50.37 relative to licensee access to restricted data [Ref. 8-5]. The DOE will perform the required background investigations appropriate to the level of access authorization being sought for the personnel, and -no additional NRC action is required for personnel access authorizations relative to the CLWR LTA program. Security facility approval will be coordinated between DOE and NRC to meet applicable regulatory requirements. The DOE will perform the reviews of the facility to ensure that DOE classified hardware (e.g., TPBAR LTAs; host utilities will not receive or store classified documents) to be handled or stored at the facility is appropriately safeguarded. The 
PNNL-11419, Rev̀. 1

March 12, 1997

granting of access authorization and the coordination of facility approval with NRC for a DOE program in an NRC licensed facility is consistent with the direction provided in Executive Order 12968 and the NRC "Proposed Rule on Access to and Protection of Classified Information" (61FR40555). 


\subsection{References}

8-1. Executive Order 12958, “Classified National Security Information,"dated April 17, 1995.

8-2. Executive Order 12968, “Access to Classified Information," dated August 4, 1995.

8-3. Memorandum of Understanding Between the Department of Energy and the United States Nuclear Regulatory Commission Under The Provisions of The National Industrial Security Program, dated September 19, 1996.

8-4. Letter S.M. Sohinki to J.H. Wilson, October 4, 1996 "DOE Clearances for NRC Licensees Supporting Tritium Program; Project No. 697."

8-5. Letter T.T. Martin to S.M. Sohinki, November 1, 1996 "DOE Clearances for NRC Licensees Supporting Tritium Program." 


\section{REGULATORY ANALYSIS}

The regulatory issues associated with LTA test irradiation in a commercial light water reactor within the scope of this report (from receipt of TPBARs until off-site shipment) arise from security issues unique to TPBARs and differences between operation with TPBARs and with conventional BPRA rods that may have been previously described in the host plant final safety analysis report (FSAR). The security and safeguards issues associated with TPBARs are addressed in Chapter 8. 10 CFR 50.59 allows operating license holders to conduct tests not described in the facility SAR without prior NRC approval if the test does not involve a change to Technical Specifications and does not constitute an unreviewed safety question as defined in the regulations.

The assessments described in this report indicate that irradiation of a limited number of LTAs is feasible under 10 CFR 50.59, similar to testing of new fuel designs. This chapter addresses the effects of LTA irradiation on Technical Specifications (Section 9.1) and on the final safety analysis report (Section 9.2).

\subsection{Effect on Plant Technical Specifications}

Reviews were conducted of NRC Standard Technical Specifications for Westinghouse plants, NUREG-1431 [Ref. 9-1], and the plant-specific Technical Specifications of the host plant. Technical Specifications, "Design Features - Reactor Core," allows a limited number of lead test assemblies to be placed in nonlimiting core regions. The operation of the host LTA reload core will be within the core design limits of Technical Specifications "Power Distribution Limits." Verification of LTA core operation within existing core design limits will be accomplished as part of the reload safety analysis performed by the host utility licensee and Westinghouse. As described in Chapter 6 of this report, occupational exposure and radiological effluents are within the regulatory requirements (10 CFR 20; 10 CFR 20, Appendix B, 10 CFR 50.36a; 10 CFR 50, Appendix I; and 40 CFR 190) described in Technical Specifications "Adminstrative Programs."

No changes to Technical Specifications were identified that would be necessary to accomplish irradiation of a limited number of LTAs. This conclusion will be confirmed by the host reactor licensee as part of the safety evaluation process for the reload core incorporating the LTAs. 


\subsection{Effect on Plant Final Safety Analysis Report (FSAR)}

Irradiation of the LTAs as described in this report could have an effect on the host plant's FSAR, in that TPBARs differ from the types of burnable absorbers that may have been described previously. As such, the host utility's FSAR update program must consider if information on the single operating cycle test irradiation of LTAs must be incorporated in the FSAR for compliance with 10 CFR 50.71(e). LTA test irradiation must be considered by the host utility within their process that implements the requirements of 10 CFR 50.59 and 10 CFR 50.71(e). The following conclusions, drawn from the evaluations described in this report, provide confidence that the host reactor licensee safety evaluation process will demonstrate that a reload core incorporating a limited number of LTAs does not involve an unreviewed safety question as defined in 10 CFR 50.59 .

- LTAs are compatible with existing Westinghouse $17 \times 17$ fuel assemblies and conventional BPRA handling tools, equipment, and procedures and, therefore, no new accidents or equipment malfunctions are created by the handling of LTAs.

- LTAs use materials with known and predictable performance characteristics and are compatible with PWR coolant and, therefore, no new accidents or equipment malfunctions are created by the presence of the LTAs in the reactor coolant system.

- Thermal-hydraulic criteria have been established to ensure that TPBARs will not fail during Condition I or II events. Analysis has shown that TPBARs, appropriately positioned in the core, operate within the established thermalhydraulic criteria. Therefore, no new accidents or equipment malfunctions are created by the presence of the LTAs in the reactor.

- LTAs do not adversely affect reactor neutronic or thermal-hydraulic performance; therefore, they do not create the possibility of accidents or equipment malfunctions of a different type than previously evaluated, nor do they increase the probability of accidents or equipment malfunctions while in the reactor. The reload safety analysis performed for the host reactor will confirm that any minor effects of LTAs on the reload core will be within established fuel design limits. 
- The expected occupational and off-site doses resulting from release of tritium from TPBARs over the plant operating cycle, including refueling, are within applicable regulatory limits.

- Analysis has shown that TPBARs will not fail during Condition $\mathrm{II}$ and $\mathrm{IV}$ events, with the exception of a LBLOCA. The radiological consequences of these events are essentially unchanged by the expected TPBAR tritium leakage to reactor coolant, and doses remain within a small fraction of 10 CFR 100 regulatory guidelines. Therefore, there is no increase in the consequences of these previously evaluated accidents.

- The impacts of LTAs on the radiological consequences of the design basis LOCA are negligible and they remain within $10 \mathrm{CFR} 100$ regulatory guidelines. The LTAs will not cause a difference in the analyzed behavior of the reactor during a LOCA, nor do they result in an increase in combustible gas released to the containment. Therefore, the LTAs do not result in an increase in the consequences of this previously considered accident. 
PNNL-11419, Rev. 1 March 12, 1997

\subsection{References}

9-1. NUREG-1431 Standard Technical Specifications Westinghouse Plants, Nuclear Regulatory Commission, Office of Nuclear Reactor Regulation, April 1995. 


\section{CONCLUSIONS}

The LTA design meets conservative design requirements and is expected to perform with large safety margins. In summary:

- LTAs are compatible with existing Westinghouse $17 \times 17$ fuel assemblies and conventional BPRA handling tools, equipment, and procedures.

- LTAs use materials with known and predictable performance characteristics and are compatible with PWR coolant.

- Thermal-hydraulic criteria have been established to ensure that TPBARs, appropriately positioned in the core, will not fail during Condition I or II events. Analysis has shown that TPBARs operate within the established thermalhydraulic criteria.

- LTAs do not adversely affect reactor neutronic or thermal-hydraulic performance. The reload safety analysis performed for the host reactor will confirm that any minor effects of LTAs on the reload core will be within established fuel design limits.

- The expected occupational and off-site doses resulting from release of tritium from TPBARs over the plant operating cycle, including refueling, are within applicable regulatory limits.

- Analysis for the host plant has shown that TPBARs will not fail during Condition III and IV events, with the exception of a LBLOCA. The impacts of LTAs on the radiological consequences of these events, due to expected TPBAR tritium leakage to reactor coolant, are within a small fraction of 10 CFR 100 regulatory guidelines. 
- The impacts of LTAs on the radiological.consequences and the design basis LOCA are within 10 CFR 100 regulatory guidelines. The LTAs will not cause a difference in the analyzed behavior of the reactor during a LOCA.

The analysis of the generic aspects of TPBARs as burnable poisons in lead test assemblies in the host plant described in this report supports the conclusions that LTA irradiation at the host plant requires no changes to Technical Specifications and that this activity does not involve an unreviewed safety question. Accordingly, LTA irradiation at a host commercial light water reactor is feasible under the provisions of 10 CFR 50.59. 


\section{APPENDIX \\ ACRONYMS, ABBREVIATIONS, AND SYMBOLS}

$\mathbf{A}$

ALARA

ALHGR

ALI

$\mathrm{Al}$

appm

AOO, AOOs

ASME

ASNT

ATR

ATWS

B

BOL

BPRA

BTRS

Btu

BWR

C

CFR

cc

$\mathrm{Ci}$

CLWR

$\mathrm{cm}$

CMTR

COLR

CRD

$\mathrm{CW}$ as low as reasonably achievable

average linear heat generation rate

annual limit on intake .

element: aluminum

unit of concentration: atomic parts per million

anticipated operational occurrence, anticipated operational occurrences

American Society of Mechanical Engineers

American Society for Nondestructive Testing

Advanced Test Reactor

anticipated transient without scram

beginning of (reactor core) life

Westinghouse burnable poison rod assembly

boron thermal regeneration system

unit of heat: British thermal unit

boiling water reactor

Code of Federal Regulations

unit of volume: cubic centimeter

unit of radioactivity: curie

commercial light water reactor

unit of length: centimeter

certified material test report

core operating limits report

confidential restricted data

cold work or cold worked 
PNNL-11419, Rev. 1

March 12, 1997

D

D

DAC

DBA, DBAs

DNB

DNBR

DOE

$\mathbf{E}$

E

EAB

ECCS

EFPD

EOL

ERAB

ETR

F

$F_{\mathrm{dh}}$

FSAR

$\mathrm{ft}$

FY

G

$\mathrm{g}$

g

gpm

GVR

GWD/MTU deuterium, ${ }^{2} \mathrm{H}$

derived air concentration

design basis accident, design basis accidents

departure from nucleate boiling

departure from nucleate boiling ratio (ratio of heat flux to DNB heat flux)

U.S. Department of Energy

particle energy

exclusion area boundary

emergency core cooling system

effective full power days

end of (reactor core) life

Energy Research Advisory Board

Engineering Test Reactor

enthalpy rise hot channel factor

Final Safety Analysis Report

unit of length: foot

fiscal year

unit of mass: gram

acceleration due to gravity

unit of fluid flow: gallons per minute

gas volume ratio: measure of absorber burnup - GVR is the ratio of STP

gas volume to pellet volume

units of fuel burnup: gigawatt days per metric ton of uranium 
$\mathbf{H}$

$\mathrm{H}$

$\mathrm{hr}$

$\mathrm{He}$

I

IASCC

ICRP

ID

IFBA

IGSCC

in.

INEL

$\mathbf{K}$

$\mathrm{K}$

$\mathrm{kg}$

kpsi

$\mathrm{kW}$

L

LBLOCA

LHGR

$\mathrm{Li}$

$\mathrm{lb}, \mathrm{lb}_{\mathrm{m}}$

LTA, LTAs

LOCA

LPZ

LWNPR

LWR element: hydrogen

unit of time: hour

element: helium

irradiation assisted stress corrosion cracking

International Commission on Radiological Protection

inside diameter

Westinghouse in-fuel burnable absorber

intergranular stress corrosion cracking

unit of length: inch

Idaho National Engineering Laboratory

unit of reactivity; $\mathrm{K}=1$ for a critical reactor

unit of mass: kilogram

unit of stress: thousand pounds per square inch

unit of power: kilowatt

large break loss of coolant accident

linear heat generation rate

element: lithium

unit of mass: pounds, pounds mass

lead test assembly, lead test assemblies

loss of coolant accident

low population zone

Light Water New Production Reactor

light water reactor 
unit of length: meter

MCE

MEI

NRC technical review branch: Materials and Chemical Engineering

$\mathrm{MeV}$ maximum exposed individual

mil

million electron volts

unit of length: $=0.001$ in.

$\mathrm{mK}$

$\mathrm{mL}$

$\mathrm{MPa}$

MPH

unit of reactivity: milli- $\mathrm{K}$ (see $\mathrm{K}$ above)

unit of volume: milliliter

unit of pressure or stress: mega-Pascal

Materials Properties Handbook

mrem unit of radioactive dose: millirem

MTU

$\mathrm{MW}_{\text {th }}$

MWD

metric tonnes uranium

unit of reactor output rating: Megawatts (thermal)

unit of energy produced: Megawatt days

$\mathbf{N}$

n

neutrons

NDE

non-destructive examination

NPR

New Production Reactor

NPZ

nickel-plated Zircaloy-4

NRC

U.S. Nuclear Regulatory Commission

$\mathbf{O}$

O

element: oxygen

OBE

operating basis earthquake

ÓD

outside diameter

ODCM

off-site dose calculation manual

OFA

Westinghouse optimized fuel assembly 
P

PIE

PNL

PNNL

$\mathrm{ppb}$

ppm

PRF

psi, psia, psig

PWR, PWRs

Q

QA

QMS

$\mathbf{R}$

RAI, RAIs

RCCA

RCS

$\mathrm{RCP}$

rem

RS post-irradiation examination

Pacific Northwest Laboratory

Pacific Northwest National Laboratory

unit of concentration: parts per billion (by weight)

unit of concentration: parts per million (by weight)

permeation reduction factor: the ratio of permeability of the uncoated

cladding to the permeability of the barrier-coated cladding

unit of pressure: pounds per square inch, pounds per square inch absolute, pounds per square inch gage

pressurized water reactor, pressurized water reactors

quality assurance, also NRC technical review branch: Maintenance and

Quality Assurance

Westinghouse Quality Management System

request(s) for additional information (from NRC review branches)

rod cluster control assembly

reactor coolant system

reactor coolant pump

unit of radioactive dose: roentgen equivalent man

NRC technical review branch: Reactor Systems 
S

S

SAR

SBLOCA

SCC

SDM

SGTR

SNM

SRP

SS

SSE

STP

$\mathbf{T}$

$\mathrm{T}$

TD

TGSCC

$\mathrm{T}-\mathrm{H}$

TPBAR

TTDP

TTQP

$\mathrm{U}$

UCNI

W

WABA

WAES

$\mathbf{Y}$

y unit of time: second

safety analysis report

small break loss of coolant accident

stress corrosion cracking

shutdown margin

steam generator tube rupture

special nuclear material

NUREG-0800, "Standard Review Plan for the Review of Safety Analysis

Reports for Nuclear Power Plants, LWR Edition"

stainless steel

safe shutdown earthquake

standard temperature and pressure

tritium, ${ }^{3} \mathrm{H}$

theoretical density

transgranular stress corrosion cracking

thermal-hydraulic

tritium-producing burnable absorber rod

Tritium Target Development Project

Tritium Target Qualification Project

Unclassified Controlled Nuclear Information

Westinghouse wet annular burnable absorber

Westinghouse Advanced Energy Systems, Madison, PA

unit of time: year 
PNNL-11419, Rev. 1

March 12, 1997

$\mathbf{Z}$

$\mathrm{Zr}$

element: zirconium

Symbols

$\alpha$

$\beta$

type of particle from atomic reactions: alpha

type of radioactivity: beta

unit of temperature: degrees Centigrade

unit of temperature: degrees Fahrenheit

unit of radioactivity: microcurie

unit of length: micrometer 